\title{
Me and My New World
}

Citation for published version (APA):

Araúz Ledezma, A. B. (2020). Me and My New World: Using social-emotional learning to promote responsible and healthy behaviors in adolescents' personal relationships in Panama. [Doctoral Thesis, Maastricht University]. Maastricht University. https://doi.org/10.26481/dis.20201008aal

Document status and date:

Published: 01/01/2020

DOI:

10.26481/dis.20201008aal

Document Version:

Publisher's PDF, also known as Version of record

\section{Please check the document version of this publication:}

- A submitted manuscript is the version of the article upon submission and before peer-review. There can be important differences between the submitted version and the official published version of record.

People interested in the research are advised to contact the author for the final version of the publication, or visit the DOI to the publisher's website.

- The final author version and the galley proof are versions of the publication after peer review.

- The final published version features the final layout of the paper including the volume, issue and page numbers.

Link to publication

\footnotetext{
General rights rights.

- You may freely distribute the URL identifying the publication in the public portal. please follow below link for the End User Agreement:

www.umlib.nl/taverne-license

Take down policy

If you believe that this document breaches copyright please contact us at:

repository@maastrichtuniversity.nl

providing details and we will investigate your claim.
}

Copyright and moral rights for the publications made accessible in the public portal are retained by the authors and/or other copyright owners and it is a condition of accessing publications that users recognise and abide by the legal requirements associated with these

- Users may download and print one copy of any publication from the public portal for the purpose of private study or research.

- You may not further distribute the material or use it for any profit-making activity or commercial gain

If the publication is distributed under the terms of Article $25 \mathrm{fa}$ of the Dutch Copyright Act, indicated by the "Taverne" license above, 


\section{ME AND MY NEW WORLD}

USING SOCIAL-EMOTIONAL LEARNING TO PROMOTE RESPONSIBLE AND HEALTHY BEHAVIORS IN

ADOLESCENTS' PERSONAL RELATIONSHIPS IN PANAMA

ANA BeLINDA Araúz LEDEZMA 
(C) Ana Belinda Araúz Ledezma 2020

Cover design by: Lillyan van Buuren

Print: Ridderprint | www.ridderprint.nl.

ISBN 978-94-6416-176-2

All rights reserved. No part of this publication may be reproduced, distributed, stored in a retrieval system, or transmitted in any form o by any means, electronic, mechanical, photocopying, recording or otherwise, without prior written permission of the author. 


\title{
ME AND MY NEW WORLD
}

\section{USING SOCIAL-EMOTIONAL LEARNING TO PROMOTE}

\author{
RESPONSIBLE AND HEALTHY BEHAVIORS IN
}

\section{ADOLESCENTS' PERSONAL RELATIONSHIPS IN PANAMA}

\section{DISSERTATION}

to obtain the degree of Doctor at the Maastrich University, on the authority of the Rector Magnificus Prof.dr. Rianne M. Letschert in accordance with the decision of the Board of Deans, to be defended in public on Thursday $8^{\text {th }}$ October 2020, at 16:00 hours

by Ana Belinda Araúz Ledezma 


\title{
Promotor
}

Prof.dr. Gerjo Kok

\section{Co-promotor}

dr. Karlijn Massar

\author{
Assessment Committee \\ Prof. dr. Kai Jonas, Chair \\ Prof. dr. Christine Markham, University of Texas, School of Public Health \\ Dr. Francine Schneider, Maastricht University \\ Prof. dr. John B.F. de Wit, Utrecht University, Department of \\ Interdisciplinary Social Science \\ Dr. Fraukje E.F. Mevissen, Maastricht University
}




\section{Table of Contents}

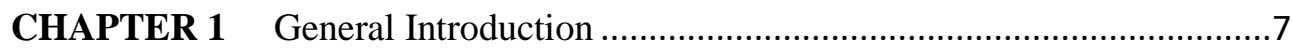

CHAPTER 2 Behavioral and environmental influences on adolescent decision making in personal relationships: A qualitative multi-stakeholder exploration in Panama ..... 33

CHAPTER 3 Social Emotional Learning and the promotion of equal personal relationships among adolescents in Panama: A study protocol .67

CHAPTER 4 Me and My New World: Effects of a school based socialemotional learning program for adolescents in Panama

CHAPTER 5 Implementation of a school-based Social Emotional Learning Program in Panama: Experiences of adolescents, teachers, and parents 149

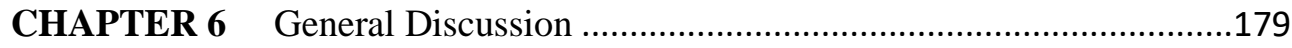

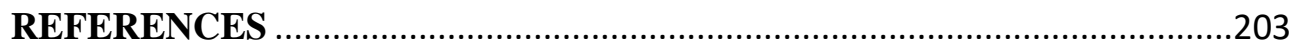

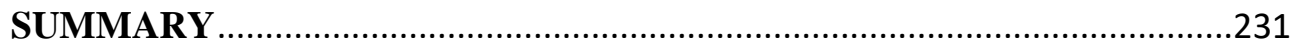

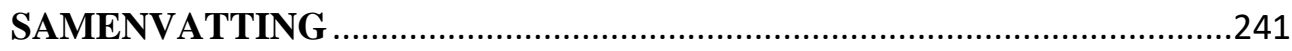

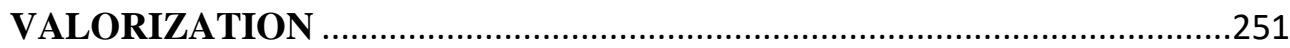

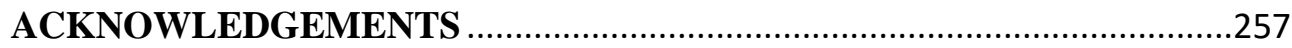

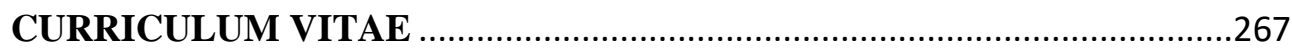

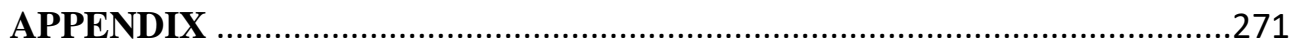





\section{CHAPTER 1}

\section{General Introduction}




\section{Chapter 1}

\section{Background and context}

Adolescents in Panama face multiple challenges to their sexual health, rights, and well-being such as high rates of teenage pregnancy, increased HIV infections, and family- and intimate partner violence. Around $30.5 \%$ of all pregnant women are girls between 10 and 19 years old (MINSA, 2018). In the absence of Comprehensive Sexuality Education (CSE) legislation, as well as an ongoing debate in Panamanian society about how to approach adolescents' health problems and the lack of sufficient scientific evidence on these topics, this dissertation had two main aims: 1) to fill this gap by gathering evidence-based data related to the multiple behavioral and environmental factors affecting the decision making capacities of adolescents, 2) The research project aimed to examine the impact of Social Emotional Learning (SEL) as a potential educational strategy, which could forge behavioral changes towards the promotion of equal personal relationships among adolescents in Panama.

The studies reported in this dissertation were conducted in the district of Boquete, Republic of Panama. Boquete is located $481 \mathrm{~km}$ west of Panama City, the capital of the Republic of Panama. Tourism and agriculture are the main economic activities of the region. The country is situated in Central America. It borders both the Caribbean Sea and the Pacific Ocean, between Colombia and Costa Rica. Its latitude lies between latitudes $7^{\circ}$ and $10^{\circ} \mathrm{N}$, and longitudes $77^{\circ}$ and $83^{\circ} \mathrm{W}$ (a piece of the country area lies west of $83^{\circ}$ ). Panama's population is around 4.1 million (MEF et al., 2018), of which 1.3 million or 33\% are children and adolescents (MEF et al., 2018). Around $32.8 \%$ of them are living in multidimensional poverty (MEF et al., 2018). In 2018, Panama became a high-income country (World Bank, 2018). 


\section{Chapter 1}

Nevertheless, the country is listed within the top five countries in Latin America with most unequal distribution of income, with a Gini coefficient of 0.51(UNECLAC, 2018).

Globally, around 16 million girls between 15 and 19 years old, and two million girls under the age of 15 become pregnant every year (UNFPA, 2015). Latin America is the only region where teenage pregnancy is not decreasing (Gianella et al., 2017), and there is a high risk that the region will not meet the Sustainable Development Goals (SDG) on adolescent pregnancy by 2030 (Fullman et al., 2017). Globally, the leading causes of death among adolescent girls between 15 to 19 years old are related to pregnancy and childbearing (WHO, 2017). Many Latin American countries are in the list of the 50 highest teenage fertility rates, and rates are especially high in Nicaragua, Panama, Honduras, Ecuador, and Guatemala (UNICEF and PLAN, 2014), where the average fertility rate is 73 per 1000 (UN, 2015). In developing countries, 12.8 million adolescent girls have an unmet need for family planning, including access to information, contraceptives, and health services (UNFPA, 2016, 2017). The consequences of becoming pregnant at an early age are mostly negative for girls in Latin America. They are more likely to drop out school, and thereby increase their risk of living in poverty as adults. Moreover, stigma and rejection are faced not only by teen mothers but also by their families and friends. In addition, the risk of (unsafe) abortion is higher among pregnant adolescents (UNFPA, 2013). Boys also face a wide range of challenges influencing their health, relationships and well-being, such as increased STIs, violence and masculinities models they are supposed to comply with. 


\section{Chapter 1}

Equality of the relationships between women and men, boys and girls are likely to increase health benefits. In many societies, gender relationships are changing, and more equality between men and women is present in virtually every sphere - at work, at home, and in public affairs. Yet the reality and hard facts show, especially in Panama, that gender gaps and inequalities persist, even in the face of recent social and economic transformations and concerted movements to challenge women's subordination to men (Ridgeway, 2011). Relationships between women and men are deeply influenced by gendered social norms and the socially developed gender identities of women and men (Unterhalter, 2007; Loots \& Walker, 2015). Gender is defined as "the array of socially constructed roles and relationships, personality traits, attitudes, behaviors, values, relative power and influence that society ascribes to the two sexes on a differential basis". Unequal gender relations are often reproduced in very subtle ways, affecting men and women's identities, leading to "behavior, choices and judgments that tend to 'normalize' gender inequalities" (Robeyns, 2006, p. 81). Equal rights, opportunities and responsibilities for boys and girls, women and men, as well as equal economic participation and decision-making, known as gender equality ${ }^{2,9}$, involve factors as power, agency and socially accepted gender cultural norms.

It is increasingly recognized that education can play a transformative and key role in furthering gender equality, both in developed and developing countries. Due to the conservative context of Panama, it is crucial to understand factors influencing and limiting the development and implementation of educational strategies focusing on personal capacities development of adolescents towards better decisions in personal relations. 


\section{Gender and the search for equality at the global and local level}

The search for gender equality has shaped the global development agenda for various decades. The international community has shown its interest to promote gender equality through the development of standard goals and strategies, such as the Millennium Development Goals (MDG), e.g. Nr.3 'to promote gender equality and empower women', and the Education for All Goals (EFA), e.g. Nr.5 'to promote gender parity and equality'. In 2015, while monitoring reports of both agendas reflected important progresses towards gender equality worldwide, particularly in relation to girls' primary education and women's political representation, deep concern was raised about the overall progress of women and girls towards reaching the MDGs, which remains low and uneven both within and between countries ${ }^{3}$. In 2015 a new sustainable development goals (SDG) agenda has been set, and the focus on gender equality is reflected in various goals (e.g. 4, 5, 16). However, especially in Panama, it is still highly necessary to address critical issues of persistent gender inequalities: violations of women's and girls' sexual and reproductive health and rights, violence against women, their unequal participation in private and public decision-making beyond national parliaments, inequalities in the division of unpaid care work, and women's limited access to assets ${ }^{4}$.

Decades of innumerable social, economic and legal global efforts to eradicate gender inequalities, by different actors in societies, raise the questions why and how the problem still persists? In the uprising of new evidence about some degree of regression in the area of domestic role distribution at the household level, even in some pioneering countries such as Sweden and Finland (Sullivan et al., 2015), it seems that efforts to eradicate 


\section{Chapter 1}

inequalities, demand a new vision and different actions. While multiple strides have been made towards the goal of gender parity in education, as a transformational capability towards gender equality and women's empowerment, critics illustrate the limitations of these interventionist approaches, that focus mainly on access of girls to school (Unterhalter, 2008). Likewise, Stambach (2000) stressed that institutions show partial progress results, transforming gender into a public discourse. In other words, institutions are not achieving the expected outcomes to transform and regulate gender policies and practices through states institutions.

Historically, theoretical debate on gender equality has tended to emphasize its legal category, rather than considering gender as a relational, social category (Unterhalter, 2014). However, as inequality remains latent, a great amount of evidence shows the importance of a more oriented focus on individual relations, meaning the relational dynamics of gender identity (DeJaeghere, 2012). In recent years several gender scholars have drawn attention to the importance of going beyond gender parity and to search for more deep and sustainable ways to transform gender inequalities, current gender roles, relations, and opportunities/capacities. One of the salient needs is to focus on individual development, through the lens of providing more capacities for women, men, boys and girls to challenge current unequal gender realities, especially the value they give to their live, relationship and the process of building their future (DeJaeghere, 2012; DeJaeghere \& Pellowski, 2013; Nussbaum, 2011; Stromquist \& Fischman, 2009; Sullivan, 2004). Since gender inequalities can be recreated by social processes that coordinate and determinate interaction among women and men, boys and girls, it appears that gender equality will need to be considered from a personal level perspective, specifically on the way an individual thinks, even 


\section{Chapter 1}

if so far legal frameworks and institutions facilitate different levels of change (Ridgway, 2011).

As recently as 2016, in Panama, non-governmental organizations with some legislative support united their efforts and presented a Comprehensive Sexuality Education (CSE) bill proposal to the National Legislative Assembly. To date this bill has not been passed, however. The attempts have been repeatedly unsuccessful and defeated by lack of knowledge, legislative delays, opposition of the catholic church and conservative groups ${ }^{5}$. The struggle to pass this bill is an example of the multiple barriers and limitations to the achievement of adolescents' rights and the achievement of increased gender equality in the country. According to the Panamanian Constitution, the Ministry of Health is the current organ with the mandate to synchronize all institutional responses to stream CSE through health and educational services (Dholakia et al., 2012). The lack of CSE in schools highlights the constraints of the educational system in its efforts to create and establish socialization programs that enforce practices towards more equal relationships among young people in the country. Likewise, “...there is an absence of structural policies in the educational curriculum that allows the eradication of prejudices, sexist stereotypes, and new definition of gender roles (femininity and masculinity)" $"$

Panama and many other countries have signed up to all existent international agreements toward gender equality, including its renewed support to the International Conference on Population and Development (ICPD) Programme of Action (2019), as a commitment to sexual and reproductive health and rights of women and adolescents ${ }^{7}$. Furthermore, multiple legal frameworks and action plans have been institutionalized towards gender equality, but implementation remains problematic. Even in 


\section{Chapter 1}

ideal conditions of equal/legal opportunities for women and men, boys and girls, the question remaining is how far individuals dare to make decisions based on the life they want to lead? In other words, making choices that benefit them and their interests in life, while considering sharing and enjoying the same rights, respect, and opportunities. Likewise, what degree of agency and freedom do they possess to achieve that? How can women and men get prepared to challenge current prescribed gender stereotypes, roles, and social processes? And most importantly, which personal and inter-personal capacities are needed to behave differently and adjust to a new model of equal gender roles and relations?

Recent scholarship on gender has been exploring further the multidimensional aspects of agency and power relations, and the intrinsic relationship with people's individual capacity to evoke changes on gender relations (e.g. DeJaeghere \& Lee, 2011; Loots \& Walker, 2015). A critical analysis of agency and power relations that examines the strength, extension, and influence of patriarchy on human behavior, thus becomes a basic step when searching for sustainable strategies toward gender equality - in Panama as well.

\section{Education as catalyst towards equal personal relationships}

Education has been found to be a crucial intervention in challenging the reproduction of socially determined gender roles (Muñoz Boudet et al., 2013; Murphy Graham, 2012; Walker, 2012). Innovative education processes remain a key factor to the promotion of societal developments, such as gender equality. An education system should develop the full capabilities of children and young people, through offering an education that is personally and 


\section{Chapter 1}

socially worthwhile. Students need the freedom to enter school, to learn and participate there, in safety and security, to develop identities that tolerate and respect themselves and others, promote equality between women and men, mental and physical health, and prepares them to enjoy economic, political and cultural opportunities (Aikman \& Unterhalter, 2005). It is not enough for education to produce individuals who can read, write and count. Education must forge a new way of relating to each other as individuals, communities and countries ${ }^{8}$.

The right to equitable access and quality education is legally accepted by the majority of countries. Over the last two decades, girls' access to education has been one of the strategies to ensure that gender appears in the international educational agendas, conventions, and national agreements. Nevertheless, important questions remain with regard to the catalyst role of education. For example, how far is education contributing to promote more equal personal relationships between women and men? How can and do educational systems enhance individual's agency? How can education provide adolescents with new knowledge, attitudes and skills, which allow them to make better decisions in their lives? How do schools prepare boys and girls to challenge the unequal social and cultural dynamics they live in, transforming it towards equality, respect, and well-being?

Education, conceived as a vector of human development, might facilitate spaces to enhance capabilities, enlarging choices and agency of people. This in return, builds a multidimensional sense of well-being, which recognizes the essential aspect of building self-image and self-worth, supporting individuals to be less vulnerable within a given context (Hoffman, 2006; Radja et al., 2003). Furthermore, educational settings, in particular, have the potential to engage a wide range of young people in opportunities to 


\section{Chapter 1}

define their identity and importance, as well as to challenge socially accepted gender norms, which could reproduce inequalities within and outside schools (Bird \& Markle, 2012; Chung \& Moore McBride, 2015; Stromquist, 2013).

\section{Theoretical framework}

\section{Social Emotional Learning}

A growing body of international empirical evidence supports the implementation of Social Emotional Learning (SEL) for positive youth development (Bierman et al., 2010; Chung \& Moore McBride, 2015; Durlak et al., 2011; Harlacher \& Merrell, 2010; Kimber et al., 2008; McKown et al., 2009; Weissberg \& O'Brien, 2004). In the last decades, the importance of addressing students social-emotional development is increasingly recognized by academics, policy makers, and teachers in several countries (Banerjee et al., 2014; Cohen, 1999; Durlak et al., 2011; Schonert Reichl \& Hymel, 2007; Weissberg et al., 2015). Empirical research has shown that SEL programs can improve academic performance, and reduce substance abuse, aggression, and other antisocial behaviors (Kimber, 2011; Weissberg \& O'Brien, 2004; Zins et al., 2007a).

Social Emotional Learning (SEL) is defined as a set of pedagogic or educational techniques, based on socio-cognitive and behavioral methods (Kimber et al., 2008). Specifically, SEL is a process that encompasses a variety of non-cognitive or socio-emotional skills and traits (Chung \& Moore McBride, 2015). SEL targets a combination of behaviors, cognition and emotions (Zins \& Elias, 2007b). Those competent in SEL are able to 


\section{Chapter 1}

recognize and manage their emotions, establish healthy relationships, set positive goals, meet personal and social needs, and make responsible decisions (Elias et al., 2015; Greenberg et al., 2003; Taylor et al., 2017). These competencies include self-awareness, self-management, social awareness, relationship skills and responsible decision making (CASEL, 2014; Zins et al., 2004). For a full overview of all SEL competencies and criteria, see Table 1. 


\section{Chapter 1}

Table 1. Framework for key social and emotional learning (SEL) competencies and criteria.

Social Emotional Learning

Social and Emotional

Criteria

Competencies

Self -awareness

*Identifying and recognizing emotions

*Accurate self-perception

*Recognizing strengths, needs and values

*Self-efficacy

Social awareness

*Perspective-taking

*Empathy

*Appreciating diversity

*Respect for others

Responsible decision making

*Problem identification and situation analysis

*Problem solving

*Evaluation and reflection

*Personal, moral and ethical responsibility

Self-management

*Impulse and stress management

*Self-motivation and discipline

*Goal-setting and organizational skills

*Coping skills

Relationship management

*Effective communication

*Working cooperatively

*Negotiation, refusal and conflict

management

*Help seeking and providing

Source: Adapted from Zins et al, 2004 


\section{Chapter 1}

Several socio-cognitive and psychological theories outline the importance of adolescence as a transition period to acquire social emotional skills that help them to cope with difficulties at different stages of their life (CASEL, 2015; Chung \& Moore McBride, 2015). As an innovative learning approach that can increase the opportunity to achieve youth behavioral changes towards gender equality, the research reported in the current dissertation proposes the use of Social and Emotional Learning (SEL) in Panamanian schools. This educational approach is proposed in this research project as a viable alternative strategy to the lacking CSE in the country, promoting and exploring changes in adolescents' capacities and behaviors toward gender equality in a conservative context.

\section{Health behavior and behavioral change theories}

Since measuring behavioral change in short terms of time is difficult, this research project particularly aims to analyze possible changes on behavioral determinants such as knowledge, attitudes, skills, perceived social norms, and intention towards gender equality, as a result of participating in a SEL/gender program intervention. Due to the nature and content of SEL, which is based on socio-cognitive theories, the focus on behavior determinants allows to complement the analysis of personal capacity development and its impact on gender behaviors. In this line, the Theory of Planned Behavior (TPB; Azjen, 2014), offers a broader view on how socio-cognitive determinants of behavior can illustrate more accurately about changes on a specific behavior. The theory outlines that the intention to perform certain behavior, is the most important immediate antecedent of behavior. However, control performance of the behavior (self-efficacy), which is intrinsically linked to relevant skills 


\section{Chapter 1}

and abilities, as well as the perceived social norms have to be taken into account. The TPB states that behavioral intention is a function of attitudes, norms and perceived behavioral control (self-efficacy) towards the behavior (Albarracin et al., 2001). In the current project, we focus on the following socio-cognitive determinants of behavior: Knowledge, which is defined as all knowledge that is necessary to take decisions. Some knowledge is not correct, there can be many misconceptions and myths. Knowledge is recognized as a "cognitive factor" according to the Social Cognitive theory (SCT) (Kelder et al., 2015). Further, attitudes refer to the perceived advantages and disadvantages, barriers and benefits of a certain behavior. It regards the latent "disposition or tendency to respond with some degree of favorableness or not favorable to a psychological object" (Fishbein \& Ajzen, 2010, p.76). Skills are very close to self-efficacy. More skills often also lead to more confidence and self-efficacy, in order to achieve goals (CASEL, 2005). Perceived social norms refer to the positive or negative influence of other, such as norms in society, peer pressure, opinion of parents, friends, religious beliefs and cultural norms. According to the Reasoned Action Approach (RAA) (Albarracin et al., 2001), "perceived social norms are considered a function of beliefs that specific, important individual or groups, e.g. friends, peers, family, approve or disapprove a certain behavior" (Rijsdijk, 2013, p.15). Moreover, the Health Belief Model (HBM) (Janz \& Becker, 1984; Skinner et al., 2015) was also part of the theoretical background of this research project. It outlines that the chances of a person taking action to involve in a healthy behavior relies on the perceived risk of a health threat, the perceived susceptibility towards the threat and the perceived benefits and limitations related to the individual engaging in the behavior (Conner \& Norman, 2005; Glanz et al., 2008). 


\section{Chapter 1}

\section{Intervention Mapping Protocol}

The Intervention Mapping Protocol (IM) was used to design, implement and evaluate the intervention development during this research project. IM plays a crucial role, as the process of intervention development in a conservative context demands extra focus on sensitive aspects, such as culture, religious beliefs, content limitations, type of applications and acceptability of programs, among a multitude of factors. IM allows a systematic theory- and evidence-based design of the health promotion program (Bartholomew Eldredge et al., 2016). Its relevance lies in the considerations of the specific context of Panama. The process of IM facilitates filtering and selection of theories, as well as the use of empirical evidence and practical experiences to inform the process of developing an intervention, especially adjusted to reality (Fernandez et al., 2019).

In this research project, it means considerations of cultural sensitivity, lack of CSE, and law limitations within educational curriculum and setting regarding sensitive issues, affecting the health and well-being of adolescents. Our intervention was aimed to stimulate adolescents to analyze the different factors (e.g. culture, social norms) influencing their identities, which in turn might impact the benefits or barriers they perceived to adopt more equal gender behaviors. Decision making processes can be triggered by a cue of action, whether internal or external (Bartholomew Eldredge et al., 2016). The IM protocol was used during this research project, as it considers a systematic process to develop, implement and evaluate a health intervention which promotes behavioral changes (Kok et al., 2017). Specifically, in the current research project we chose to focus on the following (behavioral) outcomes: 


\section{Chapter 1}

a) Equal gender roles

The World Health Organization (WHO) defines gender roles as "socially constructed roles, behaviors, activities and attributes that a given society considers appropriate for men and women". With an assumption that gender and its roles are socially constructed (i.e. non-biologically influenced), for the matters of this study, gender equal roles refer to the equal distribution of roles in personal relationships and the household's activities (e.g. evaluating their own needs and others' needs, analysis of opportunities and impact on both genders, time allocation for work and hobbies, etc.), and in the school environment (e.g. equal opportunities to discuss different subjects, attention, cleaning of classrooms, peers, friends and romantic relations).

b) Equal rights in relationships

As gender equality refers to equal rights, responsibilities and opportunities of women and men, girls and boys, equal rights in relationships are oriented towards behaving in practical ways to know and demand the same human rights in personal relationships. These include respect and legal protection in the rise of experienced abuse (e.g. bullying, violence in romantic relationships or at home), as well as recognizing the role and accountability of institutions regarding the implementation of these rights. In the case of this study, intraand interpersonal respect is encouraged, through practices at school, home, with friends.

\section{c) Nonviolent problem solving}

Due to the high level of domestic violence in Panama, it is imperative to break the "machismo culture" 10 and provide new generations with new definitions of masculinity and femininity, whereas the use of non-violence forms of conflict solution become a new social norm. The engrained patterns of 
domestic violence are socially accepted in the Panamanian culture and require deep socio-cognitive transformations.

\section{Capability Approach and the evolving Capability Concept}

The capabilities approach (CA) is a normative framework about development, well-being and justice, emphasizing that freedom (agency) to achieve wellbeing is a matter of what people are able to $d o$ and to be (functioning), and thus the kind of life they are effectively able to lead (Sen, 1999). It is considered the most influential alternative development perspective of the last decades (Biggeri et al., 2011), as it considers human development from a perspective of analyzing the real experiences of people and the influence of conversional factors (internal or external), to lead a life that has value to them (Basu \& Foster, 1998; Biggeri \& Santi, 2012; Hart \& Brando, 2018; Robeyns, 2006). Specifically, the internal factors, relating to personal characteristics (e.g physical conditions, sex, personal and professional skills, talents, intelligence) allow individuals to convert resources and commodities (or their characteristics) into functioning (Comim et al., 2011). This conversion can also be influenced by "social factors / external, e.g. gender roles, traditions, social norms, culture, public policies, institutions, legal and customary laws, societal hierarchies, power relations, public goods), and environmental factors, e.g. climate, geographical infrastructure" (Comim et al., 2011, p. 29).

In the case of children and young people, many approaches exclude the influence of conversional factors such as socio-economic realities, their relationship with their peer, parents, teachers, community (Feeny \& Boyden, 2004), especially their values and priorities (Biggeri et al., 2006). When addressing children and adolescents, the concepts of voice and power are very 


\section{Chapter 1}

contested ones, due to the age limitations and maturity. Therefore, the CA is recently further developed, through the concept of evolving capability, incorporating the opportunity concept, the capacity concept, and the agency concept that evolve over time (Ballet et al., 2011; Biggeri et al, 2011; Biggeri \& Santi, 2012; Bonvin \& Galster, 2010; Commin et al., 2011; Landsdown, 2005), as well as the concept of capable agents (Bonvin \& Galster, 2010). These new presumptions highlight children's active participation, selfexpression (Baraldi, 2008), and self-determination (Murray \& Hallett, 2000). "Promoting children's active participation means socializing children towards and understanding of their own competencies" (Mathews, 2003, p. 274).

In other words, developing capacities and competencies allow young people to plan, design, monitor and manage the intertwined connections between their environment and their decisions, to lead the life they value. The latest approach concerning children's participation purport a new dimension of children and childhood culture, where children are situated in their present - meaning in their actual existence - within the development dimensions of their environments (e.g. technology, economic, social, and cultural conditions). Particularly, in the current research project, we focus on the analysis to what extent young people explore these opportunities, within the context of gender equality behavior. It advances understanding about how they make use of expressing their opinions, autonomy and limited agency, and its implications on gender identity development and sustainability. Especially girls, who might have limited experiences, which could transform into lower aspirations and expectation in their lives. Both perspectives, the $\mathrm{CA}$ and the evolving capability concept are considered in the intervention program development of this research project. For this purpose, four 
Chapter 1

capabilities, as described below, have been chosen to support the intervention program development and to complement analysis and further insights in capacities development exploration, as well as knowledge, attitudes, and skills of adolescents towards gender equality. These capabilities are chosen corresponding with the context and gender reality of young people in Panama:

a) Practical reason: Being able to form a conception of the good and to engage in critical reflection about the planning of one's life.

b) Affiliation: Having the social bases of self-respect and nonhumiliation; being able to be treated as a dignified being whose worth is equal to that of others. This entails provisions of non-discrimination on the basis of race, sex, sexual orientation, ethnicity, caste, religion, national origin.

c) Bodily Integrity: Being able to move freely from place to place; to be secure against violent assault, including sexual assault and domestic violence; having opportunities for sexual satisfaction and for choice in matters of reproduction.

d) Voice: Related to dignity and respect, this is the capability to have a voice, as it is important for the process of having opinions heard and valued. It includes women's and men's voices in the classroom, a crucial issue for our intervention, encouraging transformation of gender inequalities. 


\section{Chapter 1}

\section{Conceptual framework}

Based on the theories mentioned above, a conceptual framework has been developed, demonstrating the relationship between social emotional skills development and the process of evolving capabilities, describing the factor that might influence changes on behavior determinants towards gender equality (see Figure 1).

This conceptual framework is adapted from Biggeri et al (2011), Ballet et al (2011) and Trani et al (2011) evolving capabilities and education framework (see fig. 1). At the center of the scheme are the main actors, i.e. the student participants, and the external conversion factors that influence their realities (peers, family, communities, state). This position is based on the new social theory and ecological theory (Bronfenbrenner \& Morris, 1998), showing the dynamics of capabilities, that change over time.

At the center left, the social emotional program with an emphasis on gender equality and teachers are established in the context of learning enhancing, a resource that students participants can use as to improve their knowledge, attitudes, and skills, and to increase their opportunities (capabilities set) and might impact their gender behavior towards equal roles, equal rights in relationships and nonviolent problem solving. At the center right, a set of capability are presented, meaning the opportunities to develop social emotional knowledge, attitudes, and skills. The evolving process of capabilities depends on the conversion of resources which is affected by conversion factors (teachers, schools, parents, peers, community family and the degree of progressive agency to decide and make choices). Next to this section, choice is presented as a middle outcome, that influences achieved 


\section{Chapter 1}

functioning (being and doings), meaning the desired changes on gender behavior (equal roles, defending rights, and nonviolence problem resolution).

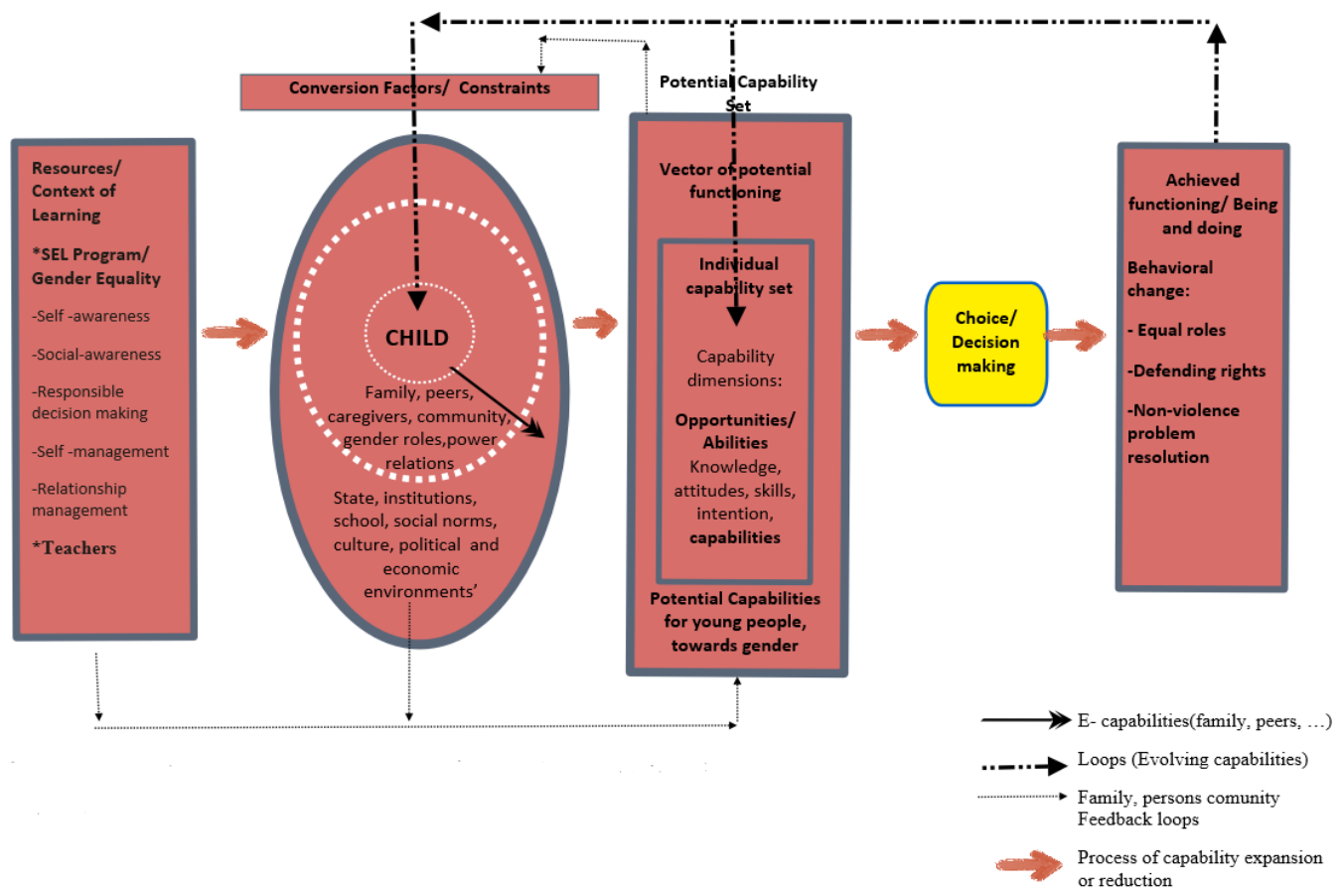

Fig 1. Evolving capabilities and social emotional learning for enhancing capacities towards gender equality behavior. Adapted from Biggeri et al (2011), Ballet et al (2011) and Trani et al (2011).

\section{Research questions}

Based on the needs of adolescents in Panama and our conceptual framework, the current project will address the following main research question:

To what extent does a Social Emotional Learning program affect adolescents' main behaviour determinants (knowledge, attitudes, skills, perceived social norms and intention) towards gender equality 


\section{Chapter 1}

behaviours: equal gender roles, equal rights in relationships and nonviolent problem solving?

In order to answer the main question, the following sub-questions are developed:

a. What are the current gender discourses in Panama and the views on gender inequality from different multi-stakeholders' perspectives?

b. How can education play a role in transforming current gender conceptions and contribute to gender equality in Panama?

c. What are the limitations, challenges and capacity development needs of educators to implement SEL programs with a focus on gender equality?

d. What were the experiences of parents during the program implementation?

This research project contributes to current academic and global debates on for whom, what and how innovative educational approaches can help to eradicate the sources of gender inequalities in the world. Furthermore, this study contributes to the analysis of context- cultural process experiences of a gender equality learning intervention, and the dialectic relationship between education and gender transformations (Unterhalter, 2008).

\section{Outline of the dissertation}

In order to answer the main research question and the sub-questions, we aimed to first, gather evidence-based data related to the multiple behavioral 


\section{Chapter 1}

and environmental factors affecting the decision-making capacities of adolescents from the perspective of various stakeholders in society. Second, the research project aimed at examining the impact of Social Emotional Learning (SEL) as a potential educational strategy, which could forge behavioral changes towards the promotion of equal personal relationships among adolescents in Panama. Here we briefly outline the content of the following chapters:

Chapter 2 presents the main discourses on gender roles and gender equality in Panama, from different actors' perspectives. It provides a wider view of the context of the study, signaling the very particular behavioral and environmental factors influencing adolescent's decision making within personal and interpersonal relationships according to key stakeholders. Adolescents in Panama face multiple challenges to their health. Perspectives on the role of education on the promotion of equal personal relationships among adolescents is explored. Capacity needs of all actors are presented, as well as recommendations as a start point to encourage constructive dialogue in society and future interventions development.

Chapter 3 describes the process of development and planning surrounding the implementation and evaluation of the SEL pilot program MANW in Panama, based on the Intervention Mapping (IM) Protocol. The findings provide a framework to analyze the multiple factors influencing the development and implementation of a SEL program to the promotion of equal relationships among adolescents in a conservative, developing country.

Chapter 4 presents the outcomes of the intervention MANW pilot program/ SEL to the promotion of gender equality behaviors - equal roles, rights and the use of nonviolent problem solving - what changes are perceived 


\section{Chapter 1}

on participants' determinants of behavior towards gender equality behaviors? It includes the dynamics perceived during the program, e.g. how students discuss the effects of the program in terms of transforming their views on equal roles, rights, and use of nonviolence.

Chapter 5 presents the intervention process -explaining the program and its implementation: How is the program developed and implemented? What challenges were encountered by teachers, students during implementation phase? How was the program experienced by teachers, students and parents? Although, barriers were observed to influence the optimal implementation of the program, the findings suggest that SEL program implementation draws a distinction as it provides a new framework to address highly contextual issues in conservative contexts, which could provide innovative strategies to promote adolescents healthier behavior and increase their well-being.

Chapter 6 offers a broad general discussion of the results of all the qualitative studies presented in this dissertation. It describes the methods used during the current research, as well as the strengths and limitations of the investigation. Further, implications of the studies and its link with theory, as well as contribution to literature are explored, leading towards recommendations for future interventions. Finally, the chapter offers recommendations for policy development and final conclusion of the dissertation. 


\section{Notes}

1. Health Canada. Ottawa: Health Canada's gender-based analysis policy; 2000. p. 14.

2. European Institute for Gender Equality. Glossary of terms. https://eige.europa.eu/thesaurus/terms/1168

3. Commission on the Status of Women, Challenges and Achievements, paragraph 9.

4. Retrieved from www.unwomen.org/en/news/in-focus/mdgmomentum\#sthash.owpyjwU1.dpuf

5. Aparicio, G. (2016, July 6) Iniciativa sobre Salud Sexual Reproductiva. La Prensa, Panama. https://www.prensa.com/locales/Proyectofundamental_0_4522047899.html

6. CLADEM (Comite de America Latina y el Caribe para la Defensa de los Derechos de la Mujer- Panama)/ Alternative Report to CEDAW. Situation of Women's Human Rights in Panama. 2010.

7. http://www.nairobisummiticpd.org/commitment/panamas-declaration-upholdcommitments-icpd-25-agenda-action-plan. Last retrieved 18 April 2020.

8. UN Education First, 2012. An initiative to ensure quality, relevant and transformative education for everyone.

9. Gender and Development: Concepts and Definitions, BRIDGE (development gender) Institute of Development Studies University of Sussex, UK. Equality does not mean that women and men will become the same but that women's and men's rights, responsibilities and opportunities will not depend on whether they are born male or female. Gender equality implies that the interests, needs and priorities of both women and men are taken into consideration, recognizing the diversity of different groups of women and men. Gender equality is not a women's issue but should concern and fully engage men as well as women.

10. Machismo: refers to the assumption that masculinity is superior to femininity. According to Cambridge Dictionary, machismo refers to "male behavior that is strong and forceful and shows very traditional ideas about how men and women should behave". https://dictionary.cambridge.org/dictionary/english/machismo 



\section{CHAPTER 2}

\section{Behavioral and environmental}

influences on adolescent decision

making in personal relationships: A

qualitative multi-stakeholder

exploration in Panama

\section{Published as:}

Araúz Ledezma, A. B., Massar, K., \& Kok, G. (2020). Behavioural and environmental influences on adolescent decision making in personal relationships: a qualitative multistakeholder exploration in Panama. Journal Health Education Research, 35(1), 1-14. https://doi.org/10.1093/her/cyz033 


\section{Chapter 2}

\section{Abstract}

Adolescents in Panama face multiple challenges to their sexual health, rights and well-being such as high rates of teenage pregnancy $(\sim 30 \%$ of all pregnancies), increased HIV infections and sexual violence. In the absence of sufficient evidence-based data and an ongoing debate in Panamanian society about how to approach adolescents' health problems, the aim of this qualitative study was to explore the perceptions and attitudes of different societal actors, namely governmental employees, NGO employees, academics, members from religious groups, teachers and parents. We conducted in-depth interviews $(\mathrm{N}=34)$ which focused on the behavioral and environmental factors considered to influence adolescents' decision making with regard to love, friendships and family relations. Furthermore, we explored how these stake- holders viewed the role of the education system, and the potential of including social-emotional learning (SEL) in the curriculum to provide skills and capacities, which could encourage adolescents to make better decisions and improve their well-being, in general but also in the context of sexual behaviors. Analysis revealed five central themes, i.e. perceptions towards gender roles and equality, adolescents' love (sexual) relationships, capacity needs regarding prevention of risk behaviors and the role of education, comprehensive sexuality education in schools and the potentiality of SEL in the education system. The findings of the study can enhance understanding on the views of stakeholders regarding the factors influencing adolescents' decision making, as well as regarding the possibilities of introducing SEL in the Panamanian educational curriculum. 


\section{Introduction}

Globally, around 16 million girls between 15 and 19 years old and 2 million girls under the age of 15 years become pregnant every year (UNFPA, 2015). Latin America and the Caribbean show the second highest teenage pregnancy rate in the world (PAHO, 2010) only exceeded by Sub-Saharan Africa. Globally, the leading causes of death among adolescent girls between 15 and 19 years old are related to pregnancy and child bearing (PAHO, 2015). The consequences of becoming pregnant at an early age are mostly negative for girls. They are more likely to drop out school, and thereby increase their risk of living in poverty as adults. Moreover, stigma and rejection are common, not only for teenage mothers but also for their families and friends.

In Panama, adolescents face a variety of challenges to their sexual health and rights, most notably high rates of unwanted teenage pregnancies, sexual violence, and STI and HIV infections. Around 30\% of all pregnant women in 2017 were adolescents between 10 and 19 years old (MINSA, 2017). A second health risk for young people in Latin America is sexual violence. Recent evidence shows that around 1.1 million adolescent girls and boys have experienced sexual violence (UNICEF, 2017). Adolescents in Panama, and especially girls, experience such violence to a high degree. There is international agreement that the development of new knowledge, attitudes, skills and socio-economic structural networks of support should be encouraged among adolescents and young adults, in order for them to achieve healthier and safer sexual behaviors (Ricco \& Trucco, 2014; UNAIDS, 2016). However, the issues of teenage pregnancy and sexual violence, as well as general sexual health, have evoked continuous political and social struggles among different stakeholders in Panama, such as the government, 


\section{Chapter 2}

conservative religious groups, parents, teachers, academics and NGOs. Moreover, the majority of these stakeholders have influenced multiple rejections by the National Assembly of legal instruments towards adolescents' empowerment that can enhance their health and well-being (e.g. a bill to allow comprehensive sexuality education (CSE) in schools, covering physical, cognitive, social and emotional aspects of sexuality (UNESCO, 2018). Therefore, in the absence of sufficient evidence- based data on the views of the aforementioned stake- holders, the current needs assessment study aims to explore beliefs and attitudes on the behavioral and environmental factors they considered to influence decision-making processes of adolescents in their personal and interpersonal relationships, specifically with regards to love, friendship and family relations. Furthermore, we explore stakeholders' views on $\mathrm{d}$ the possibility and potential of introducing social- emotional learning (SEL) in the education system to empower adolescents through social-emotional skills development. We argue that such interpersonal skills development (e.g. decision-making, communication, negotiation, self-esteem and self- efficacy), embedded in educational programs might allow youth to develop healthier (sexual) relationships, and as such could constitute a viable alternative in the absence of CSE, especially in conservative settings such as Panama. This needs assessment study is part of a larger project in Panama that explores alternative educational tools (e.g. SEL) to empower young people within their lives, and specifically within their interpersonal relationships.

Education remains an important avenue where children and adolescents can acquire and practice new knowledge, skills and attitudes. In Panama, there is a need for innovative educational alternatives which could 
Chapter 2

offer adolescents not only factual and scientific information about sexual relationships and health, but which also allow them to develop and enhance the skills they need to make better and healthier decisions at the personal and interpersonal levels (Aramburu et al., 2012; Nugent, 2006). SEL is a process intended for children and young people to develop and effectively apply social-emotional competences required to succeed in life, through its five core competencies: self- awareness, social awareness, responsible decision making, self-management and relationship management (Durlak et al., 2011; Kimber et al., 2008; Weissberg \& O'Brien, 2004 ). Recent evidence highlights multiple positive outcomes of SEL programs including the reduction of interpersonal violence, bullying, drugs use prevention and disruptive behavior (Caemmerer \& Keith, 2015; Coehlo et al., 2015; Hahn et al., 2007; Tobler et al., 2000; Wolpert et al., 2013). Several educational approaches in Panama have been attempted in these areas, but with mixed results. For example, programs such as PROBISIDA Juventud (PROBISIDA) and Youth with Options (APLAFA) have focused on HIV prevention and reproductive health (Dholakia et al., 2012). However, the implementation of these programs encountered severe limitations, such as teachers' hesitation or refusal to address sexuality issues, lack of focus on youth empowerment, lack of inclusion of scientific knowledge and lack of quality control (Dholakia $e t$ al., 2012).

Although several studies in Latin America have investigated different factors associated to adolescent's sexual risk behavior in terms of culture, social-emotional aspects, family and social norms (Rico \& Trucco, 2014; Ruiz-Canela et al., 2012), there is still a need to gain a comprehensive understanding about the individual, social and environmental determinants influencing adolescents' decision making in personal relationships in 


\section{Chapter 2}

Panama. In addition, exploring the needs and capacities of all involved stakeholders is paramount to intervention development and implementation (Bartholomew Eldredge et al., 2016), since an individual is part of a larger social environment. In particular, it is necessary to understand the perceptions and attitudes of teachers, parents, government, religious groups, ombudsman, NGOs and academics with regard to factors they consider are influencing adolescent's decision making in personal and interpersonal relationships. In Panama, as well as other (conservative) countries many important decisions regarding adolescents' health and rights (e.g. the approval of a law to include CSE in schools, the context and content of adolescents' health services) are made by these stakeholders without consultation of adolescents' opinions and needs. Moreover, evidence-based data regarding their perceptions and opinions about these issues is lacking, and we feel that gaining a full understanding of the cultural, social and religious perceptions of different adult stakeholders could ultimately contribute towards designing and implementing more structured, innovative and in- formed strategies and alternatives to CSE in conservative contexts. Especially considering the rising rates of teenage pregnancies, HIV/STIs' infections and sexual violence in Panama, all knowledge - including the facilitating and inhibiting factors identified by stakeholders - which can inform such (educational) activities is thus valuable. Given the controversial nature of topics such as gender, gender equality, and adolescents' love relationships in a conservative context like Panama, the adolescents' perceptions and beliefs about these topics could only be explored in the context of their experiences with the educational program we developed (see, e.g. Araúz Ledezma, Massar \& Kok, submitted for publication). 
The current research utilized semi-structured in- depth interviews with a range of stakeholders in Boquete, Panama. Topics and questions were partly based on the Theory of Planned Behavior (Ajzen, 2015) and the Social Cognitive Theory (Kelder et al., 2015). These theories provide insight into the determinants of behavior, such as attitudes, social norms and social learning, or one's perceived ability to perform certain behaviors. Knowledge of such determinants in turn can inform behavior change programs.

\section{Materials and methods}

\section{Study setting}

The study was conducted in Boquete, Province of Chiriquí, Panama. Boquete is located $481 \mathrm{~km}$ west of Panama City, the capital of the Republic of Panama. Tourism and agriculture are the main eco- nomic activities of the region. Boquete has a level of poverty of $30.8 \%$, and $10.4 \%$ of its population lives in extreme poverty (MEF, 2015). Teenage pregnancy (pregnant girls between 10 and 19 years old) in Boquete is high, consisting of $30 \%$ of total pregnancies (MINSA, 2017). The demographics of Boquete include indigenous groups, mestizo and foreigners (mainly Americans and Europeans).

\section{Participants and procedure}

Semi-structured in-depth interviews were conducted with a range of stakeholders who were recruited using purposive sampling. Participants for this study were recruited in three ways, as this study involves multiple stakeholders. First, participants of different institutions such as government ministries, religious organizations, NGOs, the ombudsman office and academics were contacted personally. They were informed about the study's 


\section{Chapter 2}

purpose and the voluntary and confidential nature of participation. Second, following recommendations of the Ombudsman Office, a school known for its interest to participate in new programs for adolescents' personal development was approached, and the director was provided with a brief description of the study's purpose and content. After consenting to participate, the school director subsequently approached the teacher responsible for different personal development programs in the school and authorized her to recruit other teachers who would be interested to participate in the research project. These teachers were subsequently approached by the first author to schedule an appointment for the interview. Third, parents were recruited by inviting them to attend an opening session of the research project that would be implemented at the school. All attendees received a brief overview of the study's purpose and content. Nine individuals accepted the invitation to participate in the interviews.

The final sample included 34 participants: Government Ministries employees $(\mathrm{n}=3 ; 2$ male, 1 female), teachers $(\mathrm{n}=14 ; 1$ male, 13 female), members of religious groups $(n=2$; male); academics $(n=2$; female $)$, health promotion specialists $(\mathrm{n}=2 ; 1$ male, 1 female), an NGO employee $(\mathrm{n}=1$; female), Ombudsman Office employee $(n=1$; female) and parents $(n=9 ; 3$ male, 6 female). The Ministry of Education of Panama, through the regional office in David, Chiriquí, as well as the Ethical Research Committee of Psychology and Neuroscience of Maastricht University provided ethical approval for the content and procedures used in this study, and all participants provided verbal and written informed consent before the interview started.

After consenting to participate, respondents were scheduled for an interview. Since we were investigating sensitive topics, we put extra effort into 
Chapter 2

thoroughly informing our participants about the nature, aim, and content of the interviews before commencing with the questions. We assured participants' anonymity by not documenting any identifiable details of participants, and by not making any video or audio recordings. The interviews were conducted in Spanish. The interviews were recorded in handwritten notes and were translated into English for data analysis purposes. The participants selected the locations of the interviews, except for the teachers who were interviewed at the school location. The interviews were conducted by the first author, who has the Panamanian nationality and who was conscious of the social and economic vulnerabilities of teachers and government employees voicing their opinions regarding the topics at hand. Participants were informed that they could stop the interview if they wanted, without any explanation at any given moment; moreover, at any sign of distress the interviewer terminated the interview.

\section{Research instrument and data analysis}

A semi-structured interview guide was used. The questions were based on theoretical concepts, and a literature review on the topics of equality between women and men, the topics covered in CSE and SEL. Furthermore, the interview protocol was based on the Theory of Planned Behavior (Ajzen, 2015) and the Social Cognitive Theory (Kelder et al., 2015). Specifically, knowledge, attitudes, beliefs and social norms were explored with regard to the following topics: gender, gender roles, love relationships of adolescents, teenage pregnancy, equality of opportunities and rights for women and men, the role of the educational system, providing adolescents with information and skills about these issues, CSE and SEL. Participants were asked questions such as 'How do you define gender?', 'What is gender equality?' and 'How 


\section{Chapter 2}

do you perceive the role of education in the promotion of gender equality?'. The first five questions of the protocol were similar for all stakeholders, however, depending on their roles (e.g. government, parents, teachers and religious groups), the questions differed in content and coverage. For an overview of the interview guide, with specific questions for each stakeholder, see Table 1.

All 34 transcripts of the in-depth interviews were translated from Spanish into English and saved in MS Word. The researchers read them repeatedly and thoroughly to validate transcripts. They were analyzed line by line and coded thematically. Since the interviews were semi-structured, the coding scheme was similar to the topics in the interview protocol. Data were analyzed using directed content analysis approach (Hsieh \& Shannon, 2005). This approach allowed for a categorization based on data derived from theory and relevant previous findings. An iterative coding process was used (Mayring, 2010), ensuring that preliminary and inductively arrived coding categories, were a reliable and accurate representation of the data content.

\section{Results}

After a detailed examination, the data revealed themes could be grouped under two main areas which is presented in the next sections: behavioral factors and environmental factors. Subthemes within the category of behavioral factors were: perceptions towards gender roles and equality, adolescents love (sexual relations), capacity needs regarding prevention of risk behaviors and the role of education; and within the category 
environmental determinants, the subthemes were: CSE, and the potential of SEL in the education system.

\section{Main area I: Behavioral factors}

\section{Theme 1: Perceptions towards gender roles and equality}

There was a general belief among most interviewees that the roles of women and men, boys and girls with regard to the responsibilities and tasks assigned to them $[\ldots . .$.$] , including the way they act, value themselves and behave,$ whether in personal, interpersonal relationships or other areas of life, are a logical consequence of the sex they are born with. They also stated that these roles are generally accepted in Panamanian society, as well as the fact that women do not enjoy the same opportunities as men. A clear distinction between biological sex on the one hand, and gender roles or culturally developed and assigned roles and responsibilities of women and men on the other was not present among the respondents:

"I think it [the word gender] is used to divide the sexes, women or men. I think because I am born as a man, I have a different way to be and do things than a woman, let's say our rights are different" (Father, 35-45)

Some respondents expressed that prevalent perceptions on sex, gender, gender inequalities and each sex' roles and responsibilities in society, were in most cases sustained by the patriarchal and machismo culture in Panama. They mentioned that from a very young age, boys are exposed to ideas about their tasks as protectors, providers, and to be head of the household. Some of the respondents also mentioned that these inequalities are reinforced in 


\section{Chapter 2}

Panama in a structural manner, e.g. in church and in schools, and they perceived patriarchal hierarchies in all levels of society.

"The structural patriarchal system transcends the family sphere, influencing other structures such as political, economic, cultural, social, religious, among others" (Ombudsman Office employee, woman, 30-35)

On the other hand, respondents also referred to adjustments in the perceptions about the roles and responsibility of women and men in society which seem to be emerging, in particular due to the in- crease in single mothers. In Panama $31 \%$ of all Panamanian children are living only with their mothers and most of the interviewees acknowledged that the 'traditional' hierarchical structure of a man at the head of the family is subject to change, especially when women become single parents or join extended families. However, some respondents also mentioned that often another male takes on the role of 'head of the household' in such extended families.

"When my first husband left me, I felt totally alone, but I am grateful my father could pro-vide an example to my children and in many ways be the head of the family. Eventually I married again and things changed, my new husband could protect us" (Mother, 35-45)

Most respondents indicated the importance for women to obtain an education to be able to live an independent life and make their own choices. They highlighted that avoiding early pregnancies could provide better opportunities to young women to achieve a higher level of education, and to enjoy a general better quality of life. Some respondents (e.g. a father) also pointed out that it 
should not be solely the school's responsibility to teach about equal rights and opportunities, but that family at home plays an important role as well.

"I believe that we as parents need to be also present in the life of our kids and work together with the school. The school can do one part only. Much of the practice needs to be at home as well" (Father, 3040)

There were mixed opinions among respondents whether women and men enjoy the same rights and opportunities in Panama. In terms of education, about two third of respondents considered the access of girls to school highly important, since this might increase their opportunities of finding paid jobs, and thereby breaking the cycle of poverty. However, other respondents mentioned that education alone does not ensure direct changes in unequal norms and values, and the behaviors that follow from these.

"I believe there is equality among sexes as they both have the same rights of overcoming obstacles through education for example. Opportunities are there for all, but some women do not profit from it. I see so many girls looking for a husband, who becomes responsible economically of them than to work hard to achieve economic independence" (Teacher, woman, 30-40)

Some respondents mentioned that especially conservative religious beliefs appear to have a strong influence on the way equality of rights and opportunities for women and men are approached, and laws are implemented in society. They expressed that the perpetuation of such conservative beliefs could be one factor undermining the equality of these rights and opportunities for the sexes. Within churches, 'family values' appears to be the dominant 


\section{Chapter 2}

narrative, and these values are supported not only by religious groups members but also by some teachers.

"In our culture, religion is our base to set values and norms. Family values are completely lost in our society. Young people are barely exposed to positive role models who use their religious beliefs to moderate their behavior and to be a good example for others" (Teacher, woman, 40-50)

According to most participants poverty (and lack of knowledge or education) was an additional important factor influencing the rights and opportunities of men and women. Some respondents also mentioned that teenage pregnancies may be the result from these factors, since some girls seek financial support from older men as a means to escape poverty.

Theme 2: Perceptions on adolescents' love (sexual) relationships

Love (and sexual) relationships among young people seemed to be a concern for respondents, in particular regarding the equality of rights, responsibilities and opportunities for boys and girls in such relationships. Some respondents expressed concern that in cultures like Panama, which they considered inherently patriarchal, girls are expected to remain submissive and to accept that someone else makes decisions for them. However, more than half of the respondents stressed that reality is contrasted with these perceptions, since a high percentage of girls are taking on roles as adolescent mothers, which in most cases diminished their (career) opportunities.

"In our society there is much contrast. Girls and women learn since young age about their inferiority and that they have to be submissive. But then they are sent to school and are expected to make the best 
Chapter 2

decisions. There are too many messages and less skills" (Academic, woman 55-65)

Teachers and academics also remarked that young girls receive the message sometimes at school and from modern mass media that they should make their own decisions, also in their love relationships. Nevertheless, this message is in sharp contrast to the gender roles they have been raised to follow, and may cause confusion, since they might not have the knowledge and capacities to navigate such independence.

"Young people have the rights to set out goals for life and learn about their responsibilities and opportunities. However, mass media and the internet influence in great measure the way young people see how love relationships should work, and the importance of becoming mature to make better decision concerning their sexuality" (Teacher, woman, 35-45)

Importantly, half of respondents noted that boys also receive contradictory messages about what is expected from them: on the one hand they are raised to feel superior to women, and in charge of the household; on the other hand however, these boys are also part of a culture where absence from the family scene, having multiple girlfriends, and not supporting their girlfriends when they get pregnant is not condemned.

"In our society for ages men and boys are aware that they can play in a few love relationships at the same time. It is socially accepted. The consequences of these acts are in most cases in detriment of women and girls rights and opportunities" (NGO employee, woman, 25-35) 


\section{Chapter 2}

Interestingly, according to the majority of respondents, these boys are also not stimulated - either by their family or by the adolescent mother - to assume their role as, e.g. an adolescent father, and to provide for their child.

"When my son impregnated his girlfriend, he was 16 years old and we encouraged him to keep in school, as a way to be better prepared for life. I was also very young when I got him. We did not support his girlfriend economically" (Father, 45-55)

Theme 3: Perceptions on capacity needs regarding prevention of risk behaviors and the role of education

Most participants considered formal education to play a crucial role in prevention efforts regarding adolescent risk behaviors, such as early unprotected sexual activities leading to teenage pregnancy and HIV infections; as well as the use of violence to solve problems. Nevertheless, participants showed divided opinions regarding to what extent and how education could enhance the capacities of young people to make better decisions on personal relationship issues, and to avoid these risk behaviors that could endanger their health and limit their opportunities in life. A majority of respondents mentioned that there should be more opportunities in the regular school curriculum to include lessons on the development of (inter) personal skills and relationship negotiation.

"In the past, when I was at school we had civic education that included the values a citizen should develop as to be considered a decent person and do good to society. Nowadays children are more busy to follow curriculum: mathematics, science, geography. This is not bad, but they could receive extra information about how to treat 
Chapter 2

each other, how can they solve problems without violence for example" (Mother, 35-45)

One important barrier mentioned by the teachers was the lack of time at school to include lessons on personal skills development in the regular curriculum. Furthermore, they were concerned they themselves lacked the skills and confidence to provide such lessons to adolescents.

"Honestly, I am not sure if we are completely prepared as teachers to give lessons on such specific topics as life skills. We required a lot of capacity building first, to then be able to fully transfer this kind of knowledge" (Teacher, woman, 55-65)

Moreover, although there are national laws regarding the necessity of covering the topic of the personal development of new generations as 'integral beings' in the school curriculum, there is a lack of financial resources to implement these policies.

"Financial resources are lacking to cover all young population's needs in terms of prevention against teenage pregnancies, HIV infections or other diseases. Even more, to equipping them with life skills. Also isolated efforts from different actors in society, are not being effective to reduce adolescents risk behaviors" (Health Regional Office employee, man, 35-45)

Lastly, almost half of the respondents, and members of religious groups, also identified a clear role for religion in preventing risky behaviors. They considered that schools need to be more in line with the church's guidance on how young people learn about handling feelings, emotions, and becoming a person prepared for an adult life. 


\section{Chapter 2}

\section{Main area II: Environmental and institutional factors}

Theme 4: CSE in schools

At the time of the interviews, there was a national debate on passing a bill which would allow schools to deliver CSE in Panama. As a result and mirroring this debate, there were proponents and opponents among the interviewees, and their opinions were divided in terms of their perceptions on the necessity of CSE in the national educational curriculum, the content, the capacities of teachers on the subject matter, and the level of institutional support. Some respondents - particularly the members of religious groupsshowed strong opposition to the introduction of sexuality education as part of the school curriculum, as they felt it might encourage early sexual behavior of adolescents or homosexuality. These proponents felt abstinence and family values were key to preventing disease and pregnancies, and that these issues should be the ones communicated in church, at school, and at home.

Conversely, other respondents, including some parents, stated they were very much in favor of introducing CSE in schools in Panama. They argued that the current rates of teenage pregnancies and STD's infections, as well as the use of violence among young people highlight the need to find strategies to approach and possibly solve these issues. Some however uttered concerns about the manner in which such a program should be implemented.

"If we as parents are ensured that our children, through an educational program will develop capacities to avoid bad situations, including about their own sexual behavior or against violence, I am sure that a lot of parents, even if they are opposed to sexuality education, will be open to dialogue and see possibilities. The problem 


\section{Chapter 2}

is that this issue is always approached in an imposing way, so nobody will accept it like this" (Father, 35-45)

In addition to concerns about the content of a possible CSE program, parents (but also religious groups members and academics) raised concerns about the capacities of teachers to carry out such programs at schools. A narrative of taboos, lack of knowledge, and a lack of personal capacities emerged, which influenced evaluations about the potential performance of teachers to provide CSE.

"Most teachers are not prepared to impart CSE. It is important to include them and parents in capacity development strategies, and to unite efforts increasing their social-emotional capacities as well" (Academic, woman, 55-65)

On the other hand, academics and an NGO representative expressed that given the expected strong resistance to the acceptance of CSE in the school curriculum, assessing and developing the capacities of teachers on the subject matter was crucial, and especially given the fact that some parents indicated they did not feel capable to address issues like sexuality with their children at home.

"I do not feel comfortable to talk about sexuality with my children. For me is better if they receive it at school. We grew up with so much taboos and lack of information, and I am sure must be other ways to talk about this properly with children" (Father, 30-40)

Respondents agreed that school-based interventions which combine socialemotional education and promotion of equal relations and opportunities for women and men (gender equality) were most suitable to tackle adolescents' 


\section{Chapter 2}

capacities development with the aim to enhance equal relationships and respect. Some mentioned that such interventions could even be used as nuanced ways to enhance safe and healthy sexual and reproductive behaviors of adolescents in the absence of a CSE curriculum.

"Our office has recommended the government to put more efforts on educational curriculum to elaborate programs on awareness raising, which can modify stereotyped attitudes and cultural norms about the responsibilities and roles of women and men in the family, at work, politics and society; including the adoption of measures to target boys and men" (Ombudsman Office employee, woman, 35-45)

Theme 5: The potential of SEL in the education system

Participants were asked about which specific personal capacities, behaviors, or skills they considered young people should enhance to navigate their lives, whether at school or at home. Most of the respondents mentioned they felt that adolescents needed to learn persistence to establish and achieve certain goals, as well as the skills to learn how to make better decisions which would benefit their lives.

"With all the debates going on how education could play a transformative role in the life of young people, capacities as better decision making, teamwork with respect, persistence, better communication and solving problems should be basic to ensure citizens are more aware of safe ways to achieve goals and contribute to society" (Regional Education Office employee, male, 45-55) 
Chapter 2

"I try always to encourage my children to think carefully anytime they decide to do something. Any step will have consequences. Schools are also a great place where young people could practice how to treat each other with respect" (Mother, 35-45)

Interestingly, more than the half of parents recognized that developing social emotional capacities of adolescents is a task not only of schools but that requires a continue repetitive approach at home, highlight the importance of parents involvement in sort educational path towards a more holistic development of young people.

"I am interested that my children learn about how to make better decisions, to be respectful and to persist to achieve their dreams. However, I believe that we as parents need to be also present in the life of our kids and work together with the school. The school can do one part only. Much of the practice need to be at home as well", (Father, 25-35)

On the question if stakeholders will support the inclusion of social-emotional learning programs at school level, with the aim to provide adolescents with social-emotional capacities, which not only could help adolescents to make better decisions in their personal and interpersonal relationships, but that also promotes healthier behaviors towards the increase of self-value, respect for themselves and others and promote the eradication of the use of violence of all kinds, the responses were unanimously positive, highlighting the potential benefits for young people on the long term. 


\section{Chapter 2}

\section{Discussion}

Although sexual health education is considered a basic human right, which is seen as crucial to adolescent development and the achievement of gender equality, as well as the prevention of STIs and teen- age pregnancies (UNFPA, 2015), in many countries it is a con- tested and sensitive issue, creating debate and resistance at multiple levels in societies. In Panama, governmental and societal debate concerning the sexual and reproductive health of adolescents is still ongoing, with strong opponents and proponents of the need for CSE. In the current study, different society stakeholders were therefore interviewed to investigate their perceptions regarding the psychosocial and contextual determinants influencing adolescents' decision making in personal and sexual relationships. Moreover, since the stakeholders-in particular, the parents and teachers-are crucial to successful intervention development and implementation, their needs and capacities were also explored.

One of the main findings of this study is a general assumption among the respondents that one's biological sex determines one's gender roles, rights and opportunities in life. For example, several respondents gave evidence of the perception that girls, due to the sex they are born with, are the ones who are supposed to take care of the family and be submissive to men. This is in line with findings in other Latin American countries, such as Ecuador, Costa Rica, Colombia, Brazil and Peru, where religious beliefs and social norms regarding the stereotypical roles of women and men are still prevalent, and guide individuals' behaviors (Gianella et al., 2017). The respondents indicated that these societal norms might have been caused - and sustaineddue to the fact that Panama has a patriarchal and machismo culture. However, 
respondents also indicated they felt that these societal perceptions about men, women, and their roles should change towards equality. This finding is in line with a trend during the past years showing that multiple attempts to include CSE as part of the school curriculum have failed, in part due to existing conservative beliefs regarding sexual and reproductive health education at schools and gender equality agenda (Gianella et al., 2017). Moreover, interestingly, and in line developments in other Central American countries, in Panama women more often take on the role of (financial) head of their households, especially in the absence of men in the family, or to join extended families where the male figure is represented by another man. Thus, even though women and girls are expected to conform to traditional gender roles, they are often confronted with a different reality, which reflect global influences (e.g. mass media, telenovelas, internet, advertising, social media) of modern romance discourses that are redefining gender roles perceptions, models, relations and aspirations of young people (Hirsch, 2003; Seabrook et $a l ., 2017)$. In contrast to the messages women and girls receive, the norms surrounding boys' behavior are very different. Half of the respondents mentioned that boys are raised with the beliefs that being absent from the family scene and not being responsible in case of a pregnancy are not condemned; and that there often are no consequences when a boy impregnates his girlfriend and then leaves her. This finding highlights current masculinity paradigm in society and its prevalence through boy's behavior, as well as the need to a broader focus on gender roles transformations. Recent evidence shows that a gender role perspective could add to prevention program effectiveness aimed at Latino adolescents (Lee et al., 2013). Indeed, our respondents recognize that the capacities of women to act and make their own choices in this new reality seem to be linked to getting educated and generate 


\section{Chapter 2}

income, since the majority of respondents indicated there is a need to encourage girls to finish their education, as a way to acquire economic independence. This finding is in line with different studies in Latin America that show associations between low levels of educational achievement on the one hand, and unplanned teenage pregnancies, intergenerational poverty and multiple (health) risk behaviors on the other (Binstock \& Näslund Hadley, 2010; Faisal Cury et al., 2017; Krugu et al., 2016). However, some respondents also recognized that although education has a potential to transform inequalities (Cornwall \& Rivas, 2015) more comprehensive and structural changes in the country would be needed to really change social norms about gender inequality, and with that, adolescents' health issues. These respondents also pointed out that religious beliefs and religious leaders form socio-cultural barriers to considerations of different constructions of equal gender rights and opportunities, as well as to the inclusion of CSE in the school curriculum. Indeed, most of our respondents considered 'family and moral values' as fundamental in the relationships between women and men in Panamanian society, and stated that these values are communicated by religious beliefs and in the school setting.

The respondents were aware of the current reality of many girls taken on mothers' roles, and making life changing decisions such as abandoning school. Indeed, the link between adolescents' sexual and reproductive health, rights and opportunities, and how they manage these within their love relationships seemed to be a main worry of respondents of this study. Importantly, more than half of the respondents stated that they felt adolescence must be a period to get educated and be under parental supervision, also with respect to sexual activities. Previous research in other countries in Latin America has shown that family, friends and the social 
environment during adolescence are both positively and negatively associated with adolescents' pregnancies (Campero et al., 2011; Heilborn et al., 2007; Ruiz Canela et al., 2012; Singleton et al., 2016; Vasilenko et al., 2016). Almost all respondents further indicated that poverty affects adolescents to a large extent, and especially girls. It was mentioned that young girls often start love relationships with older men as a way to gain financial stability and protection in their lives. The influence of poverty on early pregnancy, school dropouts, and risk behavior of adolescents in Latin America has been established in previous studies as well (Ibarran et al., 2012; Kruger \& Berthelon, 2014). Combined with adolescent girls' reduced chances of obtaining a higher level of education in Panama due to early pregnancies, this finding thus stresses the need for youth development programs for girls and boys, which focus on enhancing their skills and capacities to obtaining educational and economic opportunities, as well as the inclusion of comprehensive(sexual) health education (Bearinger et al., 2007). The role of education to promote the acquisition of interpersonal skills (social and emotional) as a way to prevent risky sexual behavior and improve decision making regarding relationships and sexuality, was considered essential by respondents. More than the half of participants were in favor of including such 'empowerment' skills training in the regular educational curriculum as a way to prevent risk behaviors and negotiate their personal relationships. This result is in line with studies highlighting that increasing certain socialemotional skills and capacities can improve the way they value themselves (self-esteem), increase their persistence and confidence to achieve goals, and create awareness of the need for more self-respect and respect to others (Andrade et al., 2009; De Castro et al., 2018; DePalma \& Francis, 2014; Estrada et al., 2018; Ibarran et al., 2012; Krugu et al., 2016; Wight \& 


\section{Chapter 2}

Abraham, 2000). When asked which skills they deemed most suitable for school- based programs, respondents mentioned capacities to make better decision, teamwork, better communication, respect for themselves and others, and solving problems without violence were the skills mentioned most often by the respondents as useful and necessary.

However, CSE was not seen as a part of such integral education. Most respondents, especially religious groups members, parents and some teachers, expressed an explicit concern that sexuality education would promote early sexual activity among adolescents; they would prefer the school-based health education to emphasize abstinence. Interestingly, although the respondents saw a clear role for the school as educators in the area of enhancing interpersonal skills, they also considered the school's influence to be supplementary. They indicated that the task of teaching family values and moral norms, including sexuality, should be the responsibility of parents, with the guidance of the church. One reason they felt this way was their perception of teachers' lack of time and lack of capacities to include interpersonal skills development as a subject in the regular school curriculum. This finding resonates with past research highlighting the implications of adding additional curricular activities to the already heavy workload of teachers (Collie et al., 2012; Collie et al., 2015a, 2015b; Klassen \& Chiu, 2010). Nevertheless, it is essential that educational programs oriented to adolescents health promotion including personal and interpersonal capacity development, focus on a holistic approach where teachers and parents play a central role increasing first their own personal capacities and working in unison, as to ensure rise of future interventions' effectiveness.

The findings of this study highlight some similarities and differences among stakeholders. For example, the perceptions on current gender norms, 
roles and responsibilities were not only similar but generally accepted by almost all stakeholders. Nevertheless, it seemed that for academics, NGO, Ombudsman, some teachers and parents, the constant changes on gender discourses as a result of the influences of modern media and reshaped family structures may change gender relations in the long term and influence the perpetuity of such current gender discourses. Furthermore, while the majority of stakeholders expressed negativity towards CSE, notably about the way it is presented in the national debate and consequences in terms of family values erosion and promotion of adolescents early sexual activity, interestingly, all stakeholders, especially teachers, parents, government and religious groups members expressed their support towards innovative educational alternatives (e.g. SEL/ personal-interpersonal development skills), which could reinforce modern forms of gender relations and in such way promote adolescent healthy decision and relations which in turn can improve their health and well-being. Differences arouse in terms of how such learning strategies will be implemented, emphasizing lack of time in current educational curriculum and personal/institutional capacities of stakeholders (teachers, government structures, parents) as potential limitations. Further research is necessary to enhance understanding on these issues.

\section{Limitations}

Some limitations should be acknowledged about the current research. First, since this study reports the results of qualitative interviews of multiple stakeholders in Panamanian society, the findings cannot be generalized to other Latin American countries. Likewise, because the study covers a small sample of interviews, the results may not be generalized to all stakeholders in 


\section{Chapter 2}

the country. Second, given the contested notion of the concepts discussed during this study and the ongoing debate in Panama regarding the inclusion of CSE in the school curriculum, the responses of participants may have been affected by a desire to be socially acceptable — as a way to protect their work relationships and income, and this may be especially relevant for the respondents working at the governmental level. However, we tried to prevent such influences by guaranteeing full confidentiality and anonymity during the interviews. Third, adolescents' perspectives were not addressed in this article, as the paper deepens understanding on the opinions of other important stakeholders in the Panamanian society. Furthermore, the possible influence of media on adolescents' gender perspectives, behaviors and decision-making processes constitute issues requiring further research.

This study has pointed out the complexities of discussing and increasing adolescents' health needs, including sexuality, in current Panamanian society. The historical and socio-cultural influences on perceptions about men and women, gender roles, opportunities, and responsibilities seem to aa great extent to guide stakeholders opinions. Nevertheless, the study highlights that there are avenues to explore alternative ways of increasing adolescents' knowledge, attitudes, and skills in the context of decision making in personal and sexual relationships.

\section{Conclusion}

The findings of this study suggest that interpersonal skills development (e.g. decision making, communication, negotiation, self-esteem, self-efficacy) embedded in educational programs, seem to be a viable alternative in the absence of CSE, especially in conservative settings such as Panama. This 


\section{Chapter 2}

approach seems to comply with major obstacles mentioned by stakeholders, such as local cultural norms and religious beliefs regarding interpersonal relations between women and men and their influences on behavior, rights and opportunities. By supplementing the regular educational curriculum with such 'empowerment' programs, healthier (sexual) relationships between boys and girls could be achieved, and rates of teenage pregnancies could ultimately be reduced. 


\section{Chapter 2}

Table 1. Topic list Needs Assessment/ Interview Protocol

\begin{tabular}{|c|c|c|}
\hline Topic & Stakeholders & Questions \\
\hline $\begin{array}{l}\text { Gender, gender } \\
\text { roles, gender } \\
\text { equality }\end{array}$ & $\begin{array}{l}\text { Government } \\
\text { employees, } \\
\text { teachers, parents, } \\
\text { religious groups } \\
\text { members, } \\
\text { academics, Ngo } \\
\text { and Ombudsman } \\
\text { employees, health } \\
\text { promotion } \\
\text { specialists. } \\
\text { Teachers, NGOs } \\
\text { and Ombudsman }\end{array}$ & $\begin{array}{l}\text {-How do you define gender? Gender } \\
\text { roles? Gender Equality? } \\
\text {-What is gender inequality? Are there } \\
\text { gender inequalities in Panama? If so, what } \\
\text { could be the possible causes in your } \\
\text { opinion? } \\
\text {-From your experience at schools and } \\
\text { programs with young people, what is the } \\
\text { general perception your students have } \\
\text { about gender roles, rights, relations and } \\
\text { opportunities? }\end{array}$ \\
\hline $\begin{array}{l}\text { Equality of } \\
\text { opportunities } \\
\text { and rights for } \\
\text { women and men }\end{array}$ & All stakeholders & $\begin{array}{l}\text {-What do you think about women and } \\
\text { men, boys and girls enjoying the same } \\
\text { rights and opportunities in Panama? (in } \\
\text { terms of career, income, laws, respect and } \\
\text { support in personal and interpersonal } \\
\text { relationships, e.g. with friends, } \\
\text { boyfriends). }\end{array}$ \\
\hline $\begin{array}{l}\text { Love } \\
\text { relationships of } \\
\text { adolescents }\end{array}$ & All stakeholders & $\begin{array}{l}\text {-What factors do you consider influence } \\
\text { decision making of adolescents in } \\
\text { relationships? (e.g.in love, friendship, and } \\
\text { early sexual relationships). }\end{array}$ \\
\hline $\begin{array}{l}\text { Teenage } \\
\text { pregnancy/ HIV } \\
\text { infections and } \\
\text { sexual violence }\end{array}$ & All stakeholders & $\begin{array}{l}\text {-What is your perception of teenage } \\
\text { pregnancy in Panama? } \\
\text {-What do you consider are the causes? } \\
\text {-How can teenage pregnancies be reduced } \\
\text { in the country? } \\
\text {-In your opinion, how can HIV infections } \\
\text { and sexual violence be reduced among } \\
\text { adolescents? }\end{array}$ \\
\hline $\begin{array}{l}\text { Capacity needs } \\
\text { for prevention }\end{array}$ & All stakeholders & $\begin{array}{l}\text {-What kind of capacities you consider } \\
\text { adolescents need to face multiple obstacles } \\
\text { which affect their health and well-being? } \\
\text { How can they develop it? Where? }\end{array}$ \\
\hline
\end{tabular}


Chapter 2

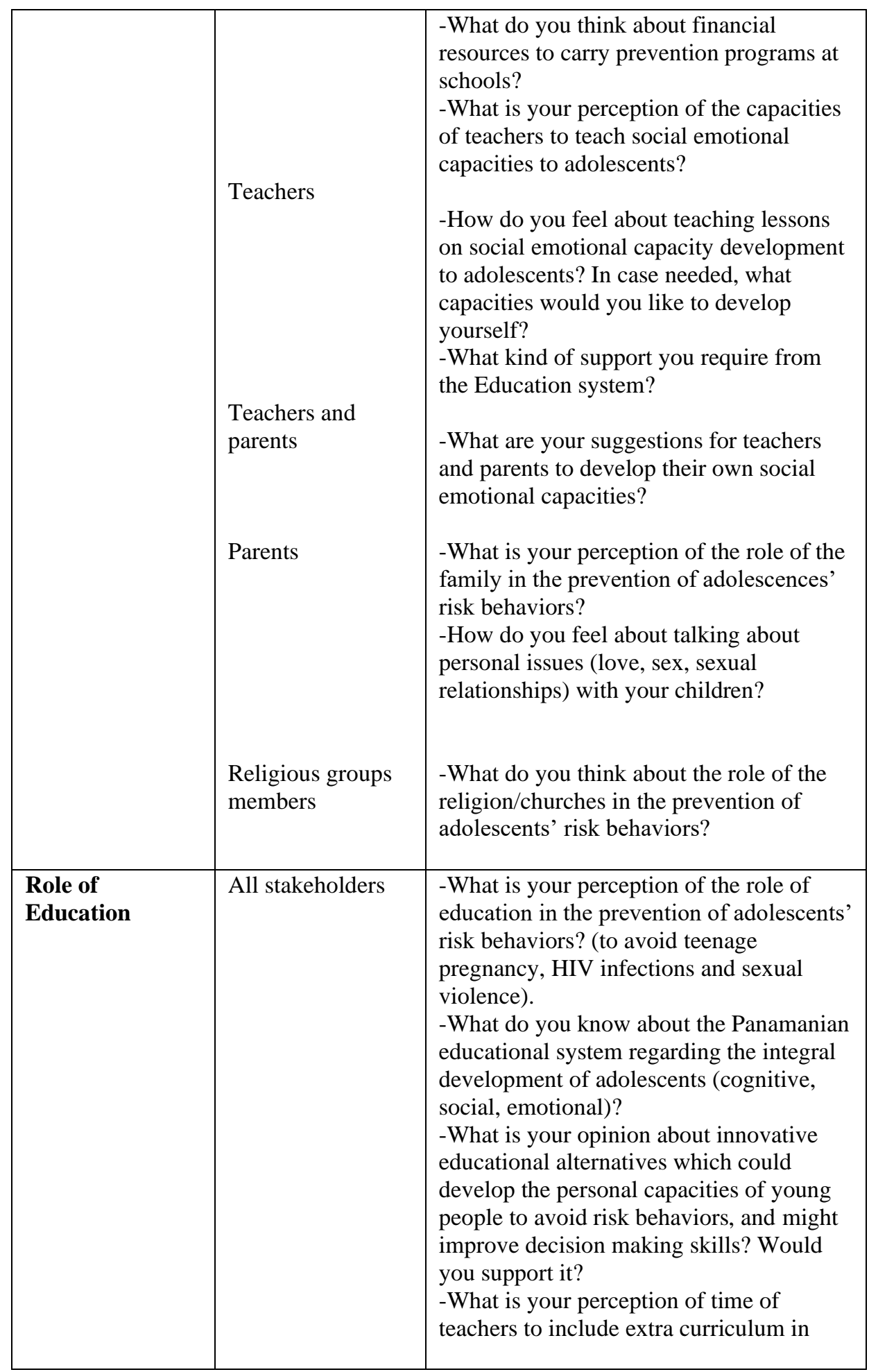




\section{Chapter 2}

\begin{tabular}{|l|l|l|}
\hline & & $\begin{array}{l}\text { their daily school plans? If not, any } \\
\text { alternatives? }\end{array}$ \\
\hline $\begin{array}{l}\text { Comprehensive } \\
\text { Education (CSE) }\end{array}$ & All stakeholders & $\begin{array}{l}\text {-What do you know about CSE? } \\
\text {-What is you perception of the reasons } \\
\text { why the bill to implement CSE has not } \\
\text { been approved in the country? } \\
\text { - What do you think about the capacities } \\
\text { of teachers to teach sexuality education at } \\
\text { schools? } \\
\text {-What kind of programs could be an } \\
\text { alternative in the absence of CSE? } \\
\text {-What do you consider would be } \\
\text { appropriate programs' content to avoid } \\
\text { risk sexual behaviors of adolescents? }\end{array}$ \\
\hline $\begin{array}{l}\text { Social Emotional } \\
\text { capacities } \\
\text { development of } \\
\text { adolescents }\end{array}$ & All stakeholders & $\begin{array}{l}\text {-How do you define social emotional } \\
\text { capacities? } \\
\text {-What social emotional capacities you } \\
\text { consider are necessary for adolescents to } \\
\text { acquire and develop? } \\
\text {-What is your perception of social } \\
\text { emotional learning programs for } \\
\text { adolescents through the Panamanian } \\
\text { regular curriculum, as an educational } \\
\text { strategy in the absence of CSE. }\end{array}$ \\
& & \\
\hline
\end{tabular}






\section{CHAPTER 3}

\section{Social Emotional Learning and the promotion of equal personal relationships among adolescents in Panama: A study protocol}

promotion of equal personal relationships among adolescents in Panama: A study protocol. Journal Health Promotion International. 


\section{Chapter 3}

\section{Abstract}

Adolescents in Panama face multiple barriers that affect their health, such as high rates of teenage pregnancy, increased HIV infections and sexual violence. Equal relationships between women and men are likely to reduce such risks. Here, we suggest that the school-based enhancement of Social and Emotional Learning core competencies - awareness of self and others, positive attitudes and values, responsible decision making, and social interaction skills - could foster positive changes in behaviors between boys and girls, specifically through a focus on equal roles, equal rights in relationships and nonviolent problem solving. This paper, using the Intervention Mapping Protocol, describes the process of development of, and planning surrounding the implementation and evaluation of the program ' $\mathrm{Me}$ and My new World', a Social Emotional Learning intervention for middle school students (12- 15 years old) in Panama. Program development was based on a needs assessment (reported in Araúz Ledezma et al, 2020a) and a literature review of theory- and evidence based SEL programs. Intervention outcomes, performance objectives, and change objectives of the intervention were identified. The practical applications of different theory-based methods allowed for contextual considerations that could potentially influence the expected behavioral outcomes of the intervention. Teachers were the implementers of the program, and during development, implementation, and evaluation, the roles, opinions, and teaching methods of all stakeholders were recognized. We conclude that Intervention Mapping allows for the analysis of multiple factors influencing the development and implementation of Social Emotional Learning programs promoting equal relationships among adolescents in a developing country, with a special consideration of culture, educational systems, and policies, from a capability development perspective. 


\section{Background}

Globally, around 16 million girls between 15 and 19 years old and two million girls under the age of 15 become pregnant every year (UNFPA, 2015). Latin America is a region where teenage pregnancy is not decreasing substantially (Caffe et al., 2017) and it is likely that the region will not meet the Sustainable Development Goals (SDG) on adolescent pregnancy by 2030 (Fullman et al., 2017). This is particularly true in Panama, as the country has been included in the 50 countries with the highest teenage fertility rates list (PAHO, UNFPA, UNICEF, 2017). In Panama, around 30\% of all pregnant women in 2017 were adolescents between 10-19 years old (MINSA, 2017). Likewise, STI, HIV infections and sexual violence remain at high rates influencing adolescents' health and well-being in the country.

Unequal relations between women and men at personal, legal, social, and cultural levels remain globally (Cornwall \& Rivas, 2015; Ridgway, 2011; Unterhalter, 2014). They often arise from differences in the socially constructed roles ascribed to women and men (Wood \& Eagly, 2015), which can (partially) generate unequal opportunities, rights, and power relations between them (Loots \& Walker, 2015). Often these roles are reflected in a society's social institutions, defined as formal and informal laws, social norms, attitudes, and practices that influence and limit individual and groups' decisions, choices, and behaviors (Jutting et al., 2008; North, 1990).

Behaviors such as violence against women/girls and violations of their sexual and reproductive health and rights constitute extreme, yet common forms of unequal treatment which affects girls' physical and emotional health (Chandra Mouli et al, 2017), and limiting agency and opportunities to advance through life (UNFPA, 2016). Evidence shows that 1 in 3 women 


\section{Chapter 3}

worldwide have experienced either physical and /or sexual intimate partner violence or non-partner sexual violence in their lifetime (WHO, 2017). Despite global efforts to promote equality of rights and opportunities for both genders (i.e. gender equality; Dejaeghere, 2012), these strategies show limited results (UN Women, 2015). Researchers suggest that the legal categorization approach to promote equality between women and men overlooks the fact that gender is also a relational and social category (Unterhalter, 2014). The revised international agreement therefore encourages development of new knowledge, attitudes, skills and socioeconomic networks among adolescents and young people, to increase healthier and safer behaviors (UNAIDS, 2017). One approach that could achieve such change is Social and Emotional Learning (SEL; Durlak et al., 2011). Programs based on this approach comprise systematic lessons which foster children's capacities development, enabling recognition and management of emotions, empathic views, establishment of personal and group goals, positive problem solving, as well as a range of inter- and intrapersonal skills, including ethical decision-making (Payton et al., 2000; Weissberg et al., 2015; Wigelsworth et al., 2016). Research has shown that SEL-programs in educational settings facilitate youths' interpersonal skills and capacities: cooperation, collaboration, critical thinking, decision-making, and social awareness (Bierman et al., 2010; Chung \& Moore McBride, 2015; Durlak et al., 2011; Durlak, 2016). SEL-programming is based on the understanding that the best learning emerges in the context of supportive relationships that make learning challenging, engaging, and meaningful (Jones \& Bouffard, 2013). The development of social and emotional skills is even more critical for students living in under-resourced areas (Yoder, 2014), including Panama. 
Chapter 3

In Panama, different strategies aimed at promoting healthier behavior - e.g. prevention of HIV and STI infection, intimate partner violence prevention and capacity development of young people, such as laws, policies, and school-based interventions, have shown limited effects, due to ineffective implementation, low sustainability, and insufficient knowledge or capacities of implementers (Dholakia et al., 2012). Likewise, the absence of a national Comprehensive Sexuality Education (CSE) law in the country has become a barrier in the public search for innovative educational alternatives promoting advancement of young people's well-being.

In the current paper, SEL is explored as a possible pedagogy to facilitate the social-emotional skills and capacities development of young people towards equal relations, roles, and rights between women and men. Empirical evidence on the implications of SEL-program implementation with a gender equality component is almost non-existent, especially in developing countries. The study aims to address this gap in the literature and describes the design and study protocol of a school-based, SEL-program. The 'Me and My New World' (MANW) is a contextualized, middle school SEL-program of 14 lessons, with a particular focus on the promotion of equal personal relationships between boys and girls. The program was implemented in a Panamanian middle school.

\section{The current research}

The development of the program followed the process of Intervention Mapping (IM), an effective protocol for theory-and evidence-based intervention development (Schutte et al., 2016; Van Der Veen et al., 2012), see Figure 1. First, a needs assessment was carried out with various 


\section{Chapter 3}

stakeholders (this is reported elsewhere; please refer to Araúz Ledezma et al, 2020a). After the objectives and limitations of the program were set, theory and empirical evidence were selected accordingly to develop the program. One part of the program focuses on social emotional competences development, the other is focused on promoting changes towards gender equality behaviors. Both parts were interwoven due to its direct implications between behavioral determinants (knowledge, awareness, attitude, perceived skills and social norms) and the desired behavioral change in the context of gender equality. The program's lessons were implemented by teachers.

A literature review of theory and evidence based SEL-programs revealed that most programs took place in Northern and developed countries (mainly USA), with the majority showing successful results (Durlak et al., 2011; Harlacher et al., 2010). However, there are mixed results for adopted or imported programs, with even some null-outcome results (Wigelsworth et al., 2016). This indicates that the transferability of SEL-learning program outcomes requires further investigation, especially regarding the context in which the SEL-intervention will be implemented, and the assumption of a universality of teachable SEL-competencies (Durlak, 2016). Barriers to success mentioned in the literature were a lack of experienced organizational support, effective preparation, and ongoing support during implementation (Durlak, 2016; Oberle et al., 2016). 
Chapter 3

Intervention Mapping Steps

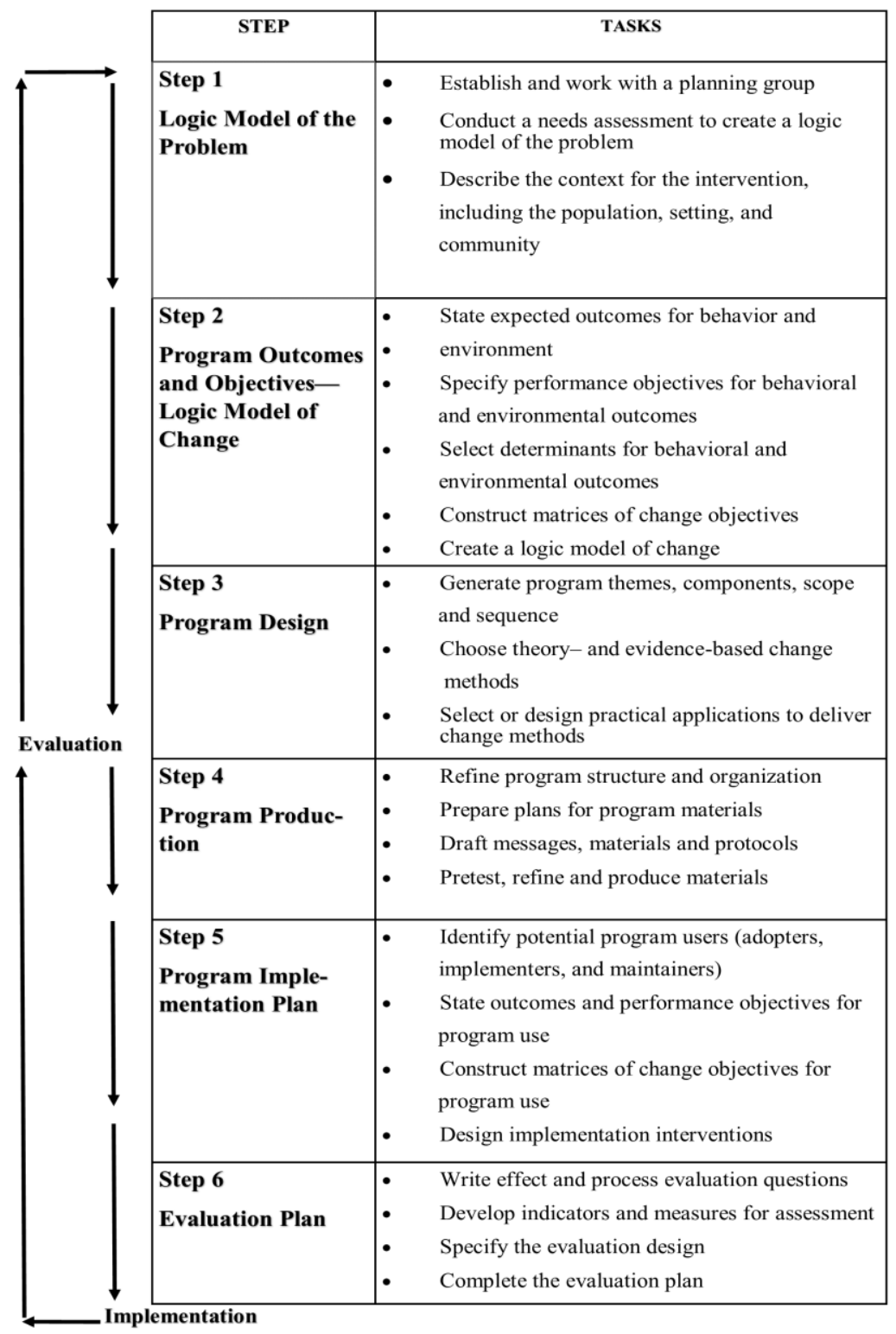

Figure 1. Intervention Mapping Steps. Source: Bartholomew Eldredge et al., 2016, p. 13 


\section{Chapter 3}

Moreover, from our literature review it became evident that SEL-programs with an emphasis on the promotion of gender equality were almost nonexistent, whether in developed or developing countries. A few studies show findings on teenage pregnancy prevention, the impact of programs by gender: the recognition of different needs of boys and girls in the designing process and the ratio of participants by gender (Coelho et al., 2015; Coelho \& Sousa, 2016; Hahn et al., 2007). However, evidence is limited regarding how social institutions (e.g. contextual formal and informal laws, social norms, attitudes, and practices) may impact on adolescents' social- emotional capacity development toward changing gender unequal behaviors. In the case of Panama, for example, a few initiatives such as PROBISIDA Juventud (PROBISIDA) and Youth with Options (APLAFA) have focused on HIV prevention and reproductive health. These programs, while useful for the objectives they aim to achieve, might not focus on youth empowerment, sexuality, and the gender issues that influence personal relationships and decisions of adolescents (see also Dholakia et al., 2012). Thus, the current program aims to foster changes on gender equality behavior, specifically through a focus on equal roles, equal rights in relationships and nonviolence problem solving, using Social Emotional Learning as educational approach.

\section{Methods \& Results}

\section{Intervention Mapping}

Intervention Mapping (IM) (Bartholomew Eldredge et al., 2016) was used to describe the development process, as well as the implementation and evaluation of the school-based Panamanian MANW program. IM supports a 
systematic theory- and evidence-based design of health promotion programs (Bartholomew Eldredge et al., 2016). It provides a framework to first identify the problem (step 1), including the perspective of all of the program's stakeholders. Then, a selection of the program's objectives and outcomes is made (step 2). Further planning and selection of theory-based methods for behavior change encourages the selection of appropriate practical applications for the program, taking into account the population and group's ecology (step 3). In step 4, the program is developed integrating themes, sequence, material and inputs from implementers and beneficiaries of the program. Step 5 includes a plan for adoption, implementation, and sustainability in a real time context, considering the users' needs and strategies to fulfill those (Fernández et al., 2019). Lastly, evaluation (step 6) involves the development of a detailed plan for measuring the effectiveness of the program, as well as the evaluation of the development and implementation process. An evaluation is crucial to unveil the underlying effect between the designed intervention in theory, and what happened during the practical implementation (Durlak, 2016). Both steps 5 and 6 are anticipated from the beginning of the planning process.

This paper presents a description of the planning process and the implementation of MANW program (Step 1-5), as well as the evaluation plan (Step 6). This paper describes the Behavioral Outcomes (BOs) of the intervention, Performance Objectives (POs), determinants, Change Objectives (COs), procedure, and measures selected. Further, it details the theory- and evidence-based methods selected for the intervention; program development, including its scope and core components, as well as the steps of adoption and implementation. The results of the program's evaluation will be presented in a separate paper. 


\section{Chapter 3}

This intervention focuses on 7th and 9th grade students enrolled in middle school (12-15 years old) as the target group. Most participants come from a low socio-economic level, including some living in extreme poverty. The intervention was developed and implemented in the Province of Chiriqui, specifically in the region of Boquete. Boquete is located $481 \mathrm{~km}$ west of Panama City, the capital of the Republic of Panama. Tourism and agriculture are the main economic activities of the region. Boquete as a level of poverty of $30.8 \%$, and $10.4 \%$ of its population lives in extreme poverty (MEF, 2015). Teenage pregnancy (pregnant girls between 10 and 19 years old) in Boquete is high. In 2017, around 30\% of total pregnancies (MINSA, 2017). The demographics of Boquete include indigenous groups, mestizo and foreigners (mainly Americans and Europeans). Teachers were the implementers of the program. Following IM, the program (the lessons) was therefore developed for the target group - teenagers - and a trainer's guide was developed for the implementers - the teachers. This paper only presents the outcomes of the student's program IM.

\section{Step 1: Needs assessment}

The needs assessment during this IM-process offered a wider view of the health problem. Likewise, it voiced the opinion of different stakeholders $(n=34)$ in the country, as well as suggesting possible alternatives for intervention development. This needs assessment is part of a larger SEL research project. First, the Ministry of Education in Chiriqui, Panama, approved the complete research project proposal. Likewise, this study was

approved by the Ethics Review Committee, Faculty of Psychology and Neuroscience, Maastricht University, the Netherlands (reference number: 
OZL 188_10_02_2018_S29). Then the selection of the school followed a suggestion from the Ombudsman Office in the province. The school was in charge of selecting teachers and students to participate in the research project. A teacher leader was selected by the school director, and this teacher subsequently recruited teachers from different subjects, e.g. Geography, English, Sports, who would be interested to participate in the research project. Parents were invited to participate through means of an invitation letter and an information session about the project. Second, participants from different institutions such as government, ombudsman office, NGOs', academics and religious groups received a short description of the research, including the purpose, as well as the voluntary and especially the confidential nature of handling the research information. For a full overview of this needs assessment, please see Araúz Ledezma et al, 2020a.

The research consisted of in-depth, semi-structured interviews conducted in Spanish (by the first author) with diverse stakeholders: government representatives (2 males, 1 female), academics ( 2 females), teachers ( 1 male, 13 females), health promotion specialists ( 1 male, 1 female), ombudsman (1 female), religious groups members (2 males), ngo representative ( 1 female), and parents ( 6 females, 3 males). The opinions of adolescents are presented in a separate article.

Interviews lasted from 30-60 minutes. Participants were informed that they could end the interview if they wanted, without any explanation and at any given moment. Furthermore, at any sign of distress the interviewer terminated the interview. At the request of the respondents, the interviews were not audio-recorded. Notes taken during the interview were verified with each respondent after each interview. The topics covered the current gender equality discourse in Panama, including knowledge, attitudes, beliefs, social 


\section{Chapter 3}

norms. Moreover, the implications of the lack of CSE at schools, the high rate of teenage pregnancy and gender-based violence were addressed. Likewise, stakeholders' opinions regarding the role of education, teachers, government, as well as the current limitations and challenges to the promotion of gender equality through innovative learning (i.e. SEL) were explored. The interview protocol was based on theoretical concepts, and a literature review on the topics of equality between women and men, CSE and SEL. Participants were asked questions such as "How do you define gender?", "What is gender equality?", and "What is the role of education in the promotion of gender equality?". The results of this needs assessment are described in detail elsewhere (Araúz Ledezma et al, 2020a).

After each interview, notes were immediately transcribed, and translated from Spanish into English. The transcripts were then anonymized and stored on a password-protected personal computer. The researchers subsequently analyzed the transcripts line by line and coded them thematically. The coding scheme was similar to the topics in the interview protocol, as the interviews were semi-structured. The data were analyzed using a directed content analysis approach (Hsieh \& Shannon, 2005). This approach facilitated a categorization based on data derived from theory and relevant previous findings. An iterative coding process was used (Mayring, 2010), which guaranteed that preliminary and inductively arrived coding categories, were a reliable and accurate representation of the data content. The needs assessment, in conclusion, offered a wide view of the behavioral and environmental factors that affect adolescents' interpersonal relationships, and shed light on the importance to search for educational strategies and methodologies addressing the realities of young people, the context where they grow-up, and the capacities they require to achieve well-being. The 
Chapter 3

complete methods and findings of this needs assessment are described in detail elsewhere (Araúz Ledezma et al, 2020a).

\section{Step 2: Identification of Intervention Outcomes/ Performance Objectives and Change objectives}

Based on the needs assessment and literature review, in this step the program goal and desired behavioral outcomes for students were stated. The program's main goal was to develop social emotional knowledge, awareness, attitudes, and perceived skills of students towards equal relationships among young people. First, based on the needs assessment, three behavioral outcomes were associated with this goal:

(1) Equal gender roles, students (a) Become aware of the difference between sex, gender and gender role allocation, (b) Become aware of the necessity to practice gender equality and recognize its importance in personal relationships and economic independence, (c) Improve their behavior regarding gender roles allocation and gender equality at home, school and with friends, boyfriends and girlfriends.

(2) Equal rights in relationships, students (a) Claim their rights to be respected, (b) Demand equal access to opportunities and resources (at home and school), (c) Communicate their needs and ask for support when needed (home, school and with friends), (d) Recognize gender based violence and report it to trusted persons or authorities.

(3) Nonviolent problem solving, students (a) Use nonviolence to deal with and solve problems, (b) Use positive strategies to manage negative emotions, (c) Respect themselves and the opinion of others, (d) Show empathy towards others who have problems. 


\section{Chapter 3}

Second, these outcomes were subdivided into performance objectives related to the behavior's determinants identified during the needs assessment (see Table 1). The performance objectives are referred to as the actions required achieving changes in the behavior and environmental outcomes (Bartholomew Eldredge, et al., 2016).

Third, determinants, i.e. the factors that rest within individuals and that affect behavior either directly or indirectly (Bartholomew Eldredge et al., 2016), were selected. These determinants were based on the preliminary findings of the needs assessment, a SEL-programs' literature review, and theories of health behavior and behavioral change such as The Theory of Planned Behavior (TPB) 1 (Ajzen, 1991), the Social Cognitive Theory (SCT) 2 (Bandura, 1997), and the Health Belief Model (HBM)3 (Janz and Becker, 1984). In accordance with these theories, the determinants of awareness, attitude, perceived skills, and perceived social norms were selected as most relevant for the intervention. Following IM, these determinants were then linked with specified change objectives, the specific and measurable changes expected at the individual level (Bartholomew Eldredge et al., 2016). A performance objective could be: 'students critically analyze how gender roles are assigned to women and men'. The accompanying change objective for the determinant attitude then could be: "students describe the benefits of acknowledging and enacting equal gender roles at school, home, and with peers (see Table 2). 


\section{Step 3: Selection of theory-based methods and practical applications}

The aim of this step is to search for the most adequate general techniques or processes, known as methods, which can influence changes in the previously identified determinants of behaviors (Bartholomew Eldredge et al., 2016). First, methods were identified in the theoretical and empirical literature. For instance, modeling is a method of behavior change: general techniques or processes that have been shown to be able to change one or more determinants of behavior of members of the at-risk group or of environmental decisionmakers (Kok et al., 2016). Through the IM-process, methods of behavior change are subsequently translated into practical applications: specific translations of theory-based methods for practical use in ways that fit the intervention population and the context in which the intervention will be conducted, (Kok et al., 2016). Moreover, the same method can be translated into various possible applications depending on the specific population and context. Similarly, one application can be a manifestation of multiple methods. An application of modeling could be: observing a role model perform the desired behavior.

Second, the methods were chosen for each change objective of the program. For awareness we chose "providing information, elaborating, and feedback", for attitudes we chose "discussions, self-reevaluation", for perceived skills "guided practices", and for perceived social norms we chose "modeling, identifying peer, teachers, and family behavior". Third, these methods were translated into practical applications: specific techniques for the practical use of theoretical methods in ways that fit with the target group and the context in which the intervention will be conducted. Importantly, here the parameters of use, which are defined as the conditions in which a program 


\section{Chapter 3}

should work (Bartholomew Eldredge et al., 2016), should be identified. For example to achieve the change objective "Demonstrate the ability to communicate better their opinions about equal gender roles at school, home and with peers", modeling was selected as an appropriate method for changing "perceived skills" and role modeling as application. In the program, the Panamanian context and the target group should be taken into consideration. Special attention was given to the conservative and 'machismo' cultural model of the country, which influences educational pedagogies and therefore influences changes in behavioral outcomes (see Table 3).

\section{Step 4: Program development}

In this step, the purpose is to design the program and develop materials combining methods and applications selected in step 3 (Bartholomew Eldredge et al., 2016). Based on the results of the needs assessment regarding the current factors affecting personals relationships and decision-making of young people in Panama, an educational program aimed at social and emotional capacities development was suggested as a feasible avenue to promote behavioral changes. From the interviews with the stakeholders it emerged that these types of programs embedded in an educational setting might play a role in the transformation of current unequal gender relations in Panama, and ultimately contribute in the long term to diminish the high level of teenage pregnancy and gender violence in the country.

Therefore, the program MANW program was then designed, to promote equality behaviors between women and men, aiming as a starting point for more equal and respectful inter- and intra-personal relationships 
Chapter 3

among adolescents. It is a pioneer program, tested for the first time in Panama. Furthermore, a focus on enhancing capacities of students, taking into account their agency, power relations and decision-making skills are also embedded in the program. The program is based on evidence-based health psychological theories (e.g. HBM, SCT and TPB). Likewise, it was designed according to the social emotional learning framework of the Collaborative for Academic, Social, and Emotional Learning (CASEL) and follows the guidelines for successful outcome achievements of SEL within educational settings, also known as SAFE (Durlak et al., 2011). The Gender Equality component of the program includes some lesson activities that were inspired by comparable life skills and gender equality programs (Butterfly Works et al., 2009; Rutgers, 2013; Ricardo et al., 2010).

During the MANW program, students learn about the impact of gender roles in their lives - in school, society, but also between peers - and how they might challenge these patterns. Using active and participatory learning methods, students are acquainted with the five areas of Social Emotional Learning (SEL) competencies. Through the SEL-competence selfawareness, students are guided to deep explorations of own aspects of identity development, especially of their genders and ways they portray their gendered social norms and values through their own thinking, feeling and acting. Then, based on this personal knowledge, students develop a broader personal and interpersonal (about others) perspectives (SEL-competence: social awareness). Furthermore, students recognize their own impact on decisionmaking and choices at intra- inter levels, whether on stress situations, emotions management or goal settings (SEL-competence: self-management). Effective communication strategies, negotiation and respectful personal relationships are elicited through the SEL-competence: relationship 


\section{Chapter 3}

management. And making informed decisions avoiding peer pressure and rejecting abuses in personal relationships are encouraged through selfreflection, evaluation and effective action (SEL-competence: responsible and ethical decisions). The activities of the program focus on providing real practical experiences to influence determinants of behaviors. Through roleplays, modeling among other activities, lessons promote fun and a positive atmosphere to reduce resistance and increase intrinsic motivation of students. A SEL-competencies framework incorporating methods and applications for the WSWM program was developed (see Table 4). The program design encompasses concepts of the evolving capability process/ capability approach (CA), namely the capacity/ability concept (individual, social-emotional skills), the opportunity concept (consideration of culture and social norms barriers) and the agency concept (self-determination and choices) (Ballet et $a l ., 2011)$. Even though agency is a contested concept when related to the age of children, it is a relevant aspect in the process of pursuing goals or changes that "one values and has reason to value" (Comim et al., 2008, p.7), fostering inner motivation of students toward the program outcomes and diminishing resistance. The $\mathrm{CA}$ and the evolving capability process recognize the different values and aspiration that different people in different cultures and societies may have (Clark, 2006). In fact, this ensures considerations of the contextual and cultural conditions in which programs are implemented (Biggeri \& Santi, 2012). 


\section{Chapter 3}

\section{Program content: Lessons}

The program consisted of 14 lessons (see Appendix 1) of 90 minutes each, delivered over the course of 4 months within the academic school year.

\section{Training the implementers}

In order to achieve the main goal of the intervention: to develop social emotional knowledge, awareness, attitudes, and skills of students towards equal relationships among young people, teachers are the implementers of the program. Teachers receive 40 hours of training (training of trainers) before the beginning of the program. The preparation of teachers includes the use of participatory and active experience methods. These methods involve processes, which directly acknowledge, welcome, value, and use the existing knowledge and competence of those being taught. It is particularly appropriate where the subject matter under consideration touches on people's deeply held beliefs and attitudes. Furthermore, teachers receive instructions about the nature of the program and participate in workshops which encourage first, exploration of own social-emotional capacities and gender equality behaviors, second to increase their teaching capacities. Teachers carry pilot sessions during the training of trainers, in which they practice the way lessons will be carried out according to the program design and manual for trainers, as well as to ensure understanding of the topics and methodologies. These sessions provide practical experience to teachers, as well as a way to improve their self-confidence and reduce resistance on the program's themes. SEL can be especially powerful when adult stakeholders in children's education are actively involved in cultivating and modeling their own social and emotional competencies (Brackett et al., 2012). 


\section{Chapter 3}

Special emphasis is given to the use of a learner centered approach. Teachers actively practice this kind of approach during the training of trainers to prepare them to integrate it during the activities of the lessons. Teachers receive a program manual as support material, which is based in literature review and successful SEL Life Skills and Gender programs. The manual covers instructions for each lesson, as well as background materials. While it offers specific description of the lessons' steps, the manual can be easily adjusted by teachers to the context and specific situations related to the topics. The content of the lessons of the program is sensitive to the contextual reality of Panama, and lessons take the legal limits of concepts regarding gender equality and equal personal relationships into account. The contributions of multiple stakeholders during the needs assessment contributed to the implementers' ownership, relevance, and understanding towards the selected focus of the program. The manual includes a wide preparation content for the teacher and the structure/content of lessons. This last section covers the outline of sessions, step-by-step process in the classroom, including objectives, expected outcomes, methodologies, time management, activities and support documents for each of the lessons.

\section{Training the target group}

Using participatory and experience based learning, the lessons start with a warm up exercise, such as "The mirror" (participants discover more positive qualities of themselves), then knowledge and information on the content of the specific lesson will be provided by an info-cartoon. Next step is usually a game, which serves as a mechanism to internalize new information and explore different opinions and scenarios. The last step is an activity, making or doing, theme based (gender equality in this case) for positively changing 
Chapter 3

attitudes and skills building: posters, storyboards, photography, artwork or a role-play. The sessions are rounded up by a short discussion, for reflection and positively changing attitudes. To increase participation and reduce resistance, the program is presented as a game, using positive language and motivational focus during lessons.

\section{Step 5: Implementation}

In this step, the objectives for program adoption and implementation are established. Theoretical methods and applications are linked to these objectives, clarifying roles and tasks of stakeholders of the program, as well as strategies facilitating implementation (Fernandez et al., 2019).

The program is implemented by teachers, during regular curriculum hours. Teachers use the teachers' manual as a guide for preparation and support during implementation. Due to the innovative nature of the program's topics, teachers carry preparation meetings before lessons, as agreed on the activities and methodologies used during implementation. If they encounter difficulties, the program leader (one of the schoolteachers) is the contact person and provides support in the school setting. This program leader is selected by the school director and is the person in charge of the school's orientation and personal development programs. Teachers use the same methods of the training of trainers: participatory and active learning. Preparation of teachers for the lessons emphasizes that teachers first review their own knowledge, views, assumptions, beliefs and prejudices about gender and social-emotional skills. The researcher (developer of the program) is available to support the whole program implementation. The school management commitment is crucial during implementation to ensure 


\section{Chapter 3}

effective communication, fair allocation of time to carry out lessons and teachers' preparation, as well as to provide all required materials and logistics. The program leader coordinates and ensures support of school management (all actors).

During implementation, every lesson of the program was assessed by teachers and students through questionnaires and evaluation forms, facilitating the improvement of methodologies and promoting fidelity and completeness of program implementation. Teachers will receive "refresher" training sessions, provided by the facilitator who was also present in the 'Training of Trainers' sessions, once per month with the goal to reinforce their motivation, clarify doubts and foster high completeness and fidelity. During each lesson throughout the program, students were highly encouraged to express their opinions regarding the content, how to improve the program, and about the teacher's delivery of the lessons.

\section{Step 6. Evaluation Plan}

During this IM-step, the evaluation plan and effectiveness measurements are set. The behavioral outcomes and change objectives (step 2) were used in the evaluation plan. As initially planned, the evaluation goal is to assess to what extent this SEL-program for adolescents can foster gender equality behaviors among young people. The intervention will be carried out in a middle high school in Panama. The evaluation process of the program will lead to improvements of future interventions. The results of this evaluation will be presented in a separate paper. 


\section{Discussion}

The aim of the current paper was to describe the process of developing and planning surrounding the implementation and evaluation of the MANW program, a SEL-intervention for middle school students in Panama for the promotion of equal personal relationships. In this study, IM proved to be a useful framework to describe the process of program planning, designing and implementation of the MANW program, exploring how SEL as an innovative learning tool, can contribute to behavioral determinants change towards gender equality in a developing country, Panama.

First, the IM-protocol provided a structural system to gather and filter theories, empirical evidence, and practical experiences relevant to the specific context of Panama and the health problems faced by young people. Second, the thorough needs analysis offered an opportunity for multi-stakeholders to voice their opinions, and influence the selection, of the desired outcome behaviors of young people. The needs assessment revealed deeper insights on the problem itself and the perceived causes, and fostered a more nuanced perspective about the personal capacities young people could develop and apply in their daily lives. These findings are in line with studies in similar context as Panama, highlighting the influence of socio-cultural and contextual factors on young people's health and sexual behaviors (Krugu et al., 2016; Leerlooijer et al., 2014). Since Panama currently does not have a program of comprehensive sexuality education in schools, the information provided by the stakeholders during the needs assessment was valuable. It allowed stakeholders to express and question their own perceptions, as well as to consider potential new strategies to encourage personal capacity development of young people, which in turn can influence gender behaviors in personal 


\section{Chapter 3}

relationships and improve their health and well-being. Given the existing differences in the country between classes, men and women's opportunities and roles, as well as the state and civil society groups' powers on educational decisions, the sense of belonging and ownership of stakeholders in the process of developing the intervention, could encourage new roles and innovation in a process of citizens' participation to solve problems.

Third, due to the complexities of the context and the topic of equality for women and men, creating matrices of change objectives was time consuming. However, it was important to specify the changes required at all individual levels to be able to achieve the outcomes of the intervention, as well as measuring these in the evaluation phase. Fourth, the IM-process allowed a more realistic selection of practical applications, taking into consideration learning pedagogies and cultural practices in the educational system of Panama. Furthermore, IM enhances understanding on the conditions and possibilities of applying SEL in contexts outside developed countries, especially on programs such as MANW, designed and implemented as alternative strategy, not only towards social and emotional development of young people, but focusing especially on promotion of equal personal relationships between women and men. These findings resonate with past research highlighting the benefits of using Intervention Mapping to assist complex interventions development focusing on young people's intrapersonal and interpersonal development within developing (conservative) contexts (Leerlooijer et al., 2014).

Nevertheless, challenges were observed during the IM-process. First, topics such as early pregnancies, adolescents' health (sexual) and well-being, gender equality are contested in Panamanian society, opening a discussion about these proved difficult at all stages. Cultural beliefs and social norms 
about the role, rights and opportunities of women and men, especially in personal relationships, as well as a machismo culture were evident at all stages of the IM-process. However, since the process of developing the intervention was presented as constructive, considering the context and involving stakeholders, the IM-protocol seemed a feasible alternative to develop a theory-evidence based program in the context of Panama. It helped to guide the directions of analysis and actions chosen throughout the entire IM-process. Emerging as an alternative path for discussion, the focus on 'personal capacities development' of young people seemed a less contested and more comfortable way to achieve participation of stakeholders. This fact reassured the intention of the research project to develop an educational intervention oriented to personal capacities development of young people. Even though the inducement of this type of intervention towards gender equality might have raised a risk, it was mitigated by the fact that stakeholders unanimously opted for education as a main avenue to offer a space to young people to develop and practice new capacities and possibly affect behaviors. The chosen methods and applications were influenced by defining in advance the type of intervention. However, a thorough analysis of theories, evidence based SEL-programs, behavioral change techniques, the context and the opinion of stakeholders, facilitated the best possible applicable methods and applications selection.

While education was perceived as an effective path for an intervention, serious concerns were raised about the capacities of teachers to teach social-emotional capacities development, especially if there would be a focus on gender equality. Coupled with a lack of room for extra activities or lessons in the school curriculum, this was considered a risk factor for the implementation, and therefore the achievement of the desired outcomes. This 


\section{Chapter 3}

result is in line with evidence showing that teachers might not deliver lessons completely and according to program goals, and therefore might decrease program effectiveness (Bessems et al., 2014). Moreover, the program was delivered by female teachers only, providing a role model for girls, and possibly facilitating discussions on sensitive issues among girls However, it is important to also provide such role models for boys, especially in a context such as Panama, where male role models are often lacking in boys' families (e.g. Wood \& Brownhill, 2018).

The IM-protocol allowed for careful deliberation on how much training teachers needed in order to carry out this type of interventions successfully, taking into consideration the less optimal conditions of education in the local context, as well as environmental factors such as culture and religious beliefs. This type of educational interventions based on SEL are necessary to provide more evidence on how a lack of experienced organizational support, effective preparation and ongoing support during implementation appears to be important barriers (Durlak, 2016; Oberle et al., 2016), including cultural transferability. Since the current empirical evidence on the implications of SEL-program implementation with a gender equality component is limited, especially in developing countries, the current research and the application of IM to the development of a SEL-based program allows for deeper understanding on capacity development of young people towards better decision-making, choices, and quality of life. 
Chapter 3

\section{Conclusion}

The program that resulted from this IM development process was carried out as a pilot project in one middle school in Panama. The overall program goal highlights a combination of psychological insights with innovative learning strategies. Schools remain a primary arena where youngsters not only share accepted social norms, beliefs and behaviors, but also have the opportunity to create, promote and exacerbate new ways of thinking and acting linked to breaking current unequal roles, relationships and quality of life of the genders. The outcomes of this intervention will indicate whether behaviors of youngsters were improved towards equal behaviors between women and men in the long term. If positive, it could be of great importance to reduce the increasing rate of early pregnancies and sexual violence in the country; and improve the decision-making capacities of young people towards more equal and meaningful personal relationships, and ultimately offering equal opportunities for men and women. 


\section{Chapter 3}

\section{Notes}

1.The Theory of Planned Behavior (TPB): "The TPB postulates that intention, the most important determinant of behavior, is in turn influenced by three constructs: attitudes, subjective norms and perceived behavioral control" (Fishbein and Ajzen, 2010, p.160)

2. The Social cognitive Theory (SCT): This theory encompasses both determinants of behavior and methods for behavior change (Bandura, 1997). SCT describes as main determinants of behavior: outcome expectations, self-efficacy, outcome expectancies, behavioral capability, perceived behaviors, and environment (Bandura, 1986).

3. Health Belief Model (HBM): According to the HBM, "behavior depends mainly upon two variables: (1) the desire to avoid illness (or if ill, to get well); and (2) the belief that a specific health action will prevent (or ameliorate) illness (i.e., the individual's estimate of the threat of illness, and of the likelihood of being able, through personal action, to reduce that threat)" (Janz and Becker, 1984, p. 2). 


\section{Chapter 3}

Table 1. Behavioral Outcomes and performance objectives of the student program: 'Me and My new World'(MANW) to the promotion of equality between women and men.

\begin{tabular}{|l|l|}
\hline Behavioral Outcomes (BO) & $\begin{array}{l}\text { Associated Performance Objectives } \\
\text { (PO) }\end{array}$ \\
\hline $\begin{array}{l}\text { BO.1 Equal Gender Roles } \\
\text { BO.1.1 Become aware of the } \\
\text { difference between sex, gender } \\
\text { and gender roles allocation. }\end{array}$ & $\begin{array}{l}\text { Students: } \\
\text { PO.1.1.1 Analyze and define sex, } \\
\text { gender, gender roles and gender } \\
\text { equality. } \\
\text { PO.1.1.2 Reflect critically on their own } \\
\text { roles as girls or boys at school, home } \\
\text { and with peers. }\end{array}$ \\
PO.1.1.3 Increase their gender equality \\
awareness.
\end{tabular}




\section{Chapter 3}

\begin{tabular}{|c|c|}
\hline & $\begin{array}{l}\text { PO.1.3.3 Discuss with peers about } \\
\text { equal roles in relationships, at home } \\
\text { and school. } \\
\text { PO.1.3.4 Practice more equal gender } \\
\text { behaviors (e.g. sharing chores at home } \\
\text { and school, having respect for } \\
\text { themselves and others). }\end{array}$ \\
\hline $\begin{array}{l}\text { BO. } 2 \text { Equal rights in } \\
\text { relationships } \\
\text { Students: } \\
\text { BO.2.1 Claim their rights to be } \\
\text { respected. }\end{array}$ & $\begin{array}{l}\text { Students: } \\
\text { PO.2.1.1 Discuss about young people' } \\
\text { rights, gender equality laws and } \\
\text { supportive institutions to report abuses. } \\
\text { PO.2.1.2 Communicate effectively } \\
\text { their personal limits regarding } \\
\text { respecting each other's rights and } \\
\text { needs. }\end{array}$ \\
\hline $\begin{array}{l}\text { BO.2.2 Demand equal access to } \\
\text { opportunities and resources (at } \\
\text { home and school). }\end{array}$ & $\begin{array}{l}\text { PO.2.2.1 Girls ask for more support } \\
\text { from teachers during regular lessons if } \\
\text { necessary or in case they feel ignored. }\end{array}$ \\
\hline $\begin{array}{l}\text { BO.2.3 Communicate their } \\
\text { needs and ask for support when } \\
\text { needed (home, school and with } \\
\text { friends). }\end{array}$ & $\begin{array}{l}\text { PO.2.3.1 Students seek help and } \\
\text { support from teachers, parents or } \\
\text { trusted persons when needed, regarding } \\
\text { abuses of their rights. }\end{array}$ \\
\hline $\begin{array}{l}\text { BO.2.4 Recognize gender- } \\
\text { based violence and report it to } \\
\text { trusted persons or authorities. }\end{array}$ & $\begin{array}{l}\text { PO.2.4.1 Students identify forms of } \\
\text { gender violence and places to report it. }\end{array}$ \\
\hline $\begin{array}{l}\text { Nonviolent problem solving } \\
\text { Students: } \\
\text { BO.3.1 Use nonviolence to deal } \\
\text { and solve problems. }\end{array}$ & $\begin{array}{l}\text { Students: } \\
\text { PO.3.1.1 Use new forms of solving } \\
\text { problem without violence at school and } \\
\text { outside. }\end{array}$ \\
\hline
\end{tabular}


Chapter 3

\begin{tabular}{|c|c|}
\hline & $\begin{array}{l}\text { PO.3.1.2 Refuse to be part of violent } \\
\text { relationships with boyfriends, } \\
\text { girlfriends or adults. } \\
\text { PO.3.1.3 Discuss with peers about } \\
\text { negatives consequences of violence. }\end{array}$ \\
\hline $\begin{array}{l}\text { BO.3.2 Use positive strategies } \\
\text { to manage negative emotions. }\end{array}$ & $\begin{array}{l}\text { PO.3.2.1 Manage their emotions in } \\
\text { positive ways (e.g. counting until } 10 \\
\text { before they react). } \\
\text { PO.3.2.2 Avoid denying emotions } \\
\text { (negative or positive). }\end{array}$ \\
\hline $\begin{array}{l}\text { BO.3.3 Respect themselves and } \\
\text { the opinion of others. }\end{array}$ & $\begin{array}{l}\text { PO.3.3.1 Reflect on the value of } \\
\text { respecting themselves, others and its } \\
\text { importance in personal relationships. } \\
\text { PO.3.3.2 Decide to use respect as basic } \\
\text { condition in personal relationships. }\end{array}$ \\
\hline $\begin{array}{l}\text { BO.3.4 Show empathy to others } \\
\text { who have problems. }\end{array}$ & $\begin{array}{l}\text { PO.3.4.1 Listen actively to others' } \\
\text { feelings and opinions calmly and } \\
\text { nonjudgmental. } \\
\text { PO.3.4.2 Offer support to others if } \\
\text { possible. }\end{array}$ \\
\hline
\end{tabular}




\section{Chapter 3}

Table 2. Sample of change objectives of the performance objective 'Students reflect critically on how gender roles are assigned to women and men, considering social norms, family values, religion, and power relations' (behavioral outcome 'Equal Gender Roles: Students improve their behaviors regarding roles distribution at home, school and with friends'.

\begin{tabular}{|c|c|c|c|}
\hline Awareness & Attitudes & $\begin{array}{l}\text { Perceived Skills } \\
\text { and Self-Efficacy }\end{array}$ & $\begin{array}{l}\text { Perceived Social } \\
\text { Norms }\end{array}$ \\
\hline Students: & Students: & Students: & Students: \\
\hline $\begin{array}{l}\text { AW 1.1 } \\
\text { Acknowledge } \\
\text { the difference } \\
\text { between sex } \\
\text { and gender, } \\
\text { and explain } \\
\text { how gender } \\
\text { roles are } \\
\text { assigned to } \\
\text { women and } \\
\text { men, } \\
\text { influencing } \\
\text { identity } \\
\text { development. }\end{array}$ & $\begin{array}{l}\text { A } 1.1 \text { Express } \\
\text { positive feelings } \\
\text { about the benefits } \\
\text { of acknowledging } \\
\text { and enacting } \\
\text { equal gender roles } \\
\text { at school, home } \\
\text { and with peers. }\end{array}$ & $\begin{array}{l}\text { S } 1.1 \text { Express } \\
\text { confidence in } \\
\text { asking for equal } \\
\text { treatment and } \\
\text { opportunities in } \\
\text { their relationship } \\
\text { with peers, } \\
\text { parents, teachers } \\
\text { and love related. }\end{array}$ & $\begin{array}{l}\text { PSN 1.1 Recognize } \\
\text { the influence of } \\
\text { gendered social } \\
\text { norms and how it } \\
\text { affects their } \\
\text { behavior and } \\
\text { attitudes. }\end{array}$ \\
\hline $\begin{array}{l}\text { AW } 1.2 \\
\text { Acknowledge } \\
\text { intersections } \\
\text { such as power, } \\
\text { agency, } \\
\text { religious } \\
\text { beliefs and the } \\
\text { different } \\
\text { implications } \\
\text { for women and } \\
\text { men. }\end{array}$ & $\begin{array}{l}\text { A } 1.2 \text { Express } \\
\text { positive feelings } \\
\text { about the } \\
\text { importance of } \\
\text { practicing equal } \\
\text { roles and } \\
\text { opportunities for } \\
\text { women and men. }\end{array}$ & $\begin{array}{l}\text { S } 1.2 \text { Demonstrate } \\
\text { the ability to } \\
\text { communicate } \\
\text { better their } \\
\text { opinions about } \\
\text { equal gender roles } \\
\text { at school, home } \\
\text { and with peers. }\end{array}$ & $\begin{array}{l}\text { PSN } 1.2 \text { State ways } \\
\text { that gender roles } \\
\text { influence their } \\
\text { capacities to } \\
\text { communicate their } \\
\text { opinions in } \\
\text { relationships. }\end{array}$ \\
\hline $\begin{array}{l}\text { AW 1.3 } \\
\text { Describes the } \\
\text { consequences } \\
\text { of unequal } \\
\text { roles and } \\
\text { responsibilities } \\
\text { between } \\
\text { women and } \\
\text { men. }\end{array}$ & $\begin{array}{l}\text { A } 1.3 \text { Express } \\
\text { positive feelings } \\
\text { toward taking } \\
\text { actions to } \\
\text { transform gender } \\
\text { unequal roles at } \\
\text { home, school and } \\
\text { with friends. }\end{array}$ & $\begin{array}{l}\text { S } 1.3 \text { Describe } \\
\text { step by step how } \\
\text { they will practice } \\
\text { equal roles in } \\
\text { their } \\
\text { relationships. }\end{array}$ & $\begin{array}{l}\text { PSN 1.3 List ways } \\
\text { how gendered } \\
\text { social norms can } \\
\text { influence gender } \\
\text { roles in } \\
\text { relationships. }\end{array}$ \\
\hline
\end{tabular}


Chapter 3

\begin{tabular}{|c|c|c|c|}
\hline $\begin{array}{l}\text { AW } 1.4 \\
\text { Acknowledge } \\
\text { how culture, } \\
\text { social norms, } \\
\text { and in-formal } \\
\text { laws determine } \\
\text { and sustain } \\
\text { unequal gender } \\
\text { roles and } \\
\text { norms (e.g. in } \\
\text { relationships, } \\
\text { income } \\
\text { generation). }\end{array}$ & $\begin{array}{l}\text { A } 1.4 \text { Express a } \\
\text { positive feeling } \\
\text { towards working } \\
\text { women/ income } \\
\text { generation. }\end{array}$ & $\begin{array}{l}\text { S } 1.4 \text { Express } \\
\text { confidence in } \\
\text { explaining to their } \\
\text { partners (friends, } \\
\text { girlfriends, } \\
\text { boyfriends) and } \\
\text { others, their needs } \\
\text { and expectations } \\
\text { regarding equal } \\
\text { personal } \\
\text { relationships. }\end{array}$ & $\begin{array}{l}\text { PSN } 1.4 \text { Explain } \\
\text { how gendered } \\
\text { social norms } \\
\text { influence their } \\
\text { ability to practice } \\
\text { equal roles at home, } \\
\text { schools and } \\
\text { personal } \\
\text { relationships. }\end{array}$ \\
\hline $\begin{array}{l}\text { AW } 1.5 \\
\text { Identify } \\
\text { barriers that } \\
\text { young people } \\
\text { face to change } \\
\text { gender } \\
\text { relations and } \\
\text { roles. }\end{array}$ & $\begin{array}{l}\text { A } 1.5 \text { Express } \\
\text { positive feelings } \\
\text { toward voicing } \\
\text { their opinions } \\
\text { about rigid gender } \\
\text { roles allocation in } \\
\text { society. }\end{array}$ & $\begin{array}{l}\text { S } 1.5 \text { Express } \\
\text { confidence in } \\
\text { listening to others } \\
\text { and being } \\
\text { empathic. }\end{array}$ & $\begin{array}{l}\text { PSN } 1.5 \text { Recognize } \\
\text { that gender roles } \\
\text { can influence the } \\
\text { ways they listen } \\
\text { and understand } \\
\text { others. }\end{array}$ \\
\hline $\begin{array}{l}\text { AW.1.6 } \\
\text { Explain how } \\
\text { they plan to } \\
\text { integrate equal } \\
\text { gender roles at } \\
\text { home, school } \\
\text { and with } \\
\text { friends. }\end{array}$ & $\begin{array}{l}\text { A } 1.6 \text { Express } \\
\text { positive feelings } \\
\text { towards acquiring } \\
\text { personal } \\
\text { capacities which } \\
\text { encourage } \\
\text { respectful and } \\
\text { equal personal } \\
\text { relationships. }\end{array}$ & $\begin{array}{l}\text { S } 1.6 \text { Express } \\
\text { confidence in the } \\
\text { ability to avoid } \\
\text { peer pressure on } \\
\text { accepting unequal } \\
\text { roles and } \\
\text { relations. }\end{array}$ & $\begin{array}{l}\text { PSN 1.6 Recognize } \\
\text { how gender roles } \\
\text { influence decisions } \\
\text { to avoid unhealthy } \\
\text { relationships. }\end{array}$ \\
\hline
\end{tabular}




\section{Chapter 3}

Table 3. Methods and Applications of the intervention.

\begin{tabular}{|c|c|c|c|}
\hline $\begin{array}{l}\text { Determinants } \\
\text { and Methods }\end{array}$ & Parameters & Applications & $\begin{array}{l}\text { How population, context } \\
\text { and parameters were } \\
\text { taken into account }\end{array}$ \\
\hline $\begin{array}{l}\text { Awareness } \\
\text { Consciousness } \\
\text { raising: } \\
\text { Providing } \\
\text { information, } \\
\text { feedback, or } \\
\text { confrontation } \\
\text { about the } \\
\text { causes, } \\
\text { consequences } \\
\text { and alternatives } \\
\text { for a problem or } \\
\text { a problem } \\
\text { behavior. }\end{array}$ & $\begin{array}{l}\text { Can use } \\
\text { feedback and } \\
\text { confrontation; } \\
\text { however, raising } \\
\text { awareness must } \\
\text { be quickly } \\
\text { followed by } \\
\text { increase in } \\
\text { problem-solving } \\
\text { ability and } \\
\text { (collective) self- } \\
\text { efficacy. }\end{array}$ & $\begin{array}{l}\text { Booklets with } \\
\text { information, and } \\
\text { visual } \\
\text { representation of } \\
\text { content and } \\
\text { expected } \\
\text { outcomes }\end{array}$ & $\begin{array}{l}\text { Population: Information, } \\
\text { discussion and feedback } \\
\text { introduce students to new } \\
\text { topics, e.g. gender, gender } \\
\text { roles, equality, identity and } \\
\text { strategies to change gender } \\
\text { unequal behaviors and } \\
\text { relations. } \\
\text { Context: Using peer to } \\
\text { peer cartoon graphics, the } \\
\text { lessons become more } \\
\text { appealing to adolescents' } \\
\text { students and initiate a } \\
\text { more active participation } \\
\text { and discussion. } \\
\text { Parameters: The texts of } \\
\text { the cartoon graphics } \\
\text { describe the connection } \\
\text { between social-emotional } \\
\text { capacity development (e.g. } \\
\text { self-worth, decision- } \\
\text { making) and gender } \\
\text { equality concepts, } \\
\text { emphasizing advantages of } \\
\text { gender equality behaviors } \\
\text { and relations. }\end{array}$ \\
\hline $\begin{array}{l}\text { Awareness } \\
\text { Self- } \\
\text { reevaluation: } \\
\text { Encouraging } \\
\text { combining both } \\
\text { cognitive and } \\
\text { affective } \\
\text { assessments of } \\
\text { one's self-image } \\
\text { with and } \\
\text { without an } \\
\text { unhealthy } \\
\text { behavior. }\end{array}$ & $\begin{array}{l}\text { Stimulation of } \\
\text { both cognitive } \\
\text { and affective } \\
\text { appraisal of } \\
\text { self-image. Can } \\
\text { use feedback } \\
\text { and } \\
\text { confrontation; } \\
\text { however, raising } \\
\text { awareness must } \\
\text { be quickly } \\
\text { followed by } \\
\text { increase in } \\
\text { problem-solving } \\
\text { ability and self- } \\
\text { efficacy. }\end{array}$ & $\begin{array}{l}\text { Self-reflection } \\
\text { exercise } \\
\text { (questionnaire/ } \\
\text { tool) }\end{array}$ & $\begin{array}{l}\text { Population: Students } \\
\text { explore unequal gender } \\
\text { beliefs and social norms } \\
\text { sustaining gender } \\
\text { inequalities. } \\
\text { Context: Students through } \\
\text { this tool reflect on their } \\
\text { gender behaviors and its } \\
\text { impact on their lives and } \\
\text { relationships. } \\
\text { Parameters: After } \\
\text { completing the assessment } \\
\text { students confront their } \\
\text { recognized unequal gender } \\
\text { norms and practices in } \\
\text { daily life. Likewise, they } \\
\text { are encouraged to search }\end{array}$ \\
\hline
\end{tabular}


Chapter 3

\begin{tabular}{|c|c|c|c|}
\hline & & & $\begin{array}{l}\text { for alternatives towards } \\
\text { more balanced, respectful } \\
\text { and equal relationships. }\end{array}$ \\
\hline $\begin{array}{l}\text { Awareness } \\
\text { Framing: } \\
\text { Using gain- } \\
\text { framed } \\
\text { messages } \\
\text { emphasizing the } \\
\text { advantages of } \\
\text { performing the } \\
\text { healthy } \\
\text { behavior; or } \\
\text { loss-framed } \\
\text { messages, } \\
\text { emphasizing the } \\
\text { disadvantages of } \\
\text { not performing } \\
\text { the healthy } \\
\text { behavior. }\end{array}$ & $\begin{array}{l}\text { Requires high } \\
\text { self-efficacy } \\
\text { expectations. } \\
\text { Gain frames are } \\
\text { more readily } \\
\text { accepted and } \\
\text { prevent } \\
\text { defensive } \\
\text { reactions. }\end{array}$ & Role- plays & $\begin{array}{l}\text { Population: Students } \\
\text { analyze gain- messages } \\
\text { and develop their own } \\
\text { role-plays, with a focus on } \\
\text { the advantage messages of } \\
\text { the expected outcome } \\
\text { behaviors (equal gender } \\
\text { roles, equal rights in } \\
\text { relationships and } \\
\text { nonviolent problem } \\
\text { solving). } \\
\text { Context: Students are } \\
\text { guided to search for stories } \\
\text { where they find reasons } \\
\text { and advantages of equal } \\
\text { behaviors, e.g. equal } \\
\text { opportunities for women } \\
\text { and men. } \\
\text { Parameters: Students are } \\
\text { exposed to gain framed } \\
\text { messages through role- } \\
\text { plays. Students analyze } \\
\text { and discuss the different } \\
\text { role plays, facilitating } \\
\text { deeper understanding of } \\
\text { the benefits of equal roles, } \\
\text { relations and opportunities } \\
\text { for women and men. }\end{array}$ \\
\hline $\begin{array}{l}\text { Awareness } \\
\text { Self- } \\
\text { affirmation: } \\
\text { Increasing } \\
\text { people's self- } \\
\text { image by having } \\
\text { them elaborate } \\
\text { on their relevant } \\
\text { values or } \\
\text { desirable } \\
\text { characteristics. }\end{array}$ & $\begin{array}{l}\text { Must be tailored } \\
\text { to individual } \\
\text { self-image. }\end{array}$ & $\begin{array}{l}\text { Writing exercise/ } \\
\text { Diary }\end{array}$ & $\begin{array}{l}\text { Population: Students are } \\
\text { encouraged to expand on } \\
\text { their own values and } \\
\text { positive characteristics, } \\
\text { which can support them in } \\
\text { the achievement of } \\
\text { personal goals. Emphasis } \\
\text { is given on personal } \\
\text { characteristics required in } \\
\text { equal and respectful } \\
\text { relationships e.g. 'respect } \\
\text { and love yourself'. } \\
\text { Context: Students carry } \\
\text { written exercises recording } \\
\text { not only their desirable } \\
\text { characteristics to increase } \\
\text { them, but also to focus on } \\
\text { how it could support them }\end{array}$ \\
\hline
\end{tabular}




\section{Chapter 3}

\begin{tabular}{|c|c|c|c|}
\hline & & & $\begin{array}{l}\text { to make better decisions in } \\
\text { personal relationships. } \\
\text { Parameters: Students } \\
\text { begin with recognizing and } \\
\text { considering their own } \\
\text { positive characteristics and } \\
\text { ways to benefit from them, } \\
\text { including their choices, } \\
\text { decisions and } \\
\text { relationships. }\end{array}$ \\
\hline $\begin{array}{l}\text { Attitudes } \\
\text { Self- } \\
\text { reevaluation: } \\
\text { Encouraging } \\
\text { combining both } \\
\text { cognitive and } \\
\text { affective } \\
\text { assessments of } \\
\text { one's self-image } \\
\text { with and } \\
\text { without an } \\
\text { unhealthy } \\
\text { behavior. }\end{array}$ & $\begin{array}{l}\text { Stimulation of } \\
\text { both cognitive } \\
\text { and affective } \\
\text { appraisal of } \\
\text { self-image. Can } \\
\text { use feedback } \\
\text { and } \\
\text { confrontation; } \\
\text { however, raising } \\
\text { awareness must } \\
\text { be quickly } \\
\text { followed by } \\
\text { increase in } \\
\text { problem-solving } \\
\text { ability and self- } \\
\text { efficacy. }\end{array}$ & $\begin{array}{l}\text { Self-reflection } \\
\text { tool }\end{array}$ & $\begin{array}{l}\text { Population: Students carry } \\
\text { individual analysis of } \\
\text { attitudes towards unequal } \\
\text { gender social norms, } \\
\text { rights, violence, and } \\
\text { develop role-plays. } \\
\text { Context: Awareness } \\
\text { raising through group } \\
\text { discussions after self- } \\
\text { reflection about different } \\
\text { situations of equal and } \\
\text { unequal gender behaviors. } \\
\text { Parameters: Role-play of } \\
\text { positive and negative } \\
\text { situations are followed by } \\
\text { discussions which focus on } \\
\text { searching for solutions to } \\
\text { the problem. }\end{array}$ \\
\hline $\begin{array}{l}\text { Attitudes } \\
\text { Cultural } \\
\text { Similarity: } \\
\text { Using } \\
\text { characteristics } \\
\text { of the target } \\
\text { group in source, } \\
\text { message and } \\
\text { channel. }\end{array}$ & $\begin{array}{l}\text { Using surface } \\
\text { characteristics } \\
\text { of the target } \\
\text { group enhances } \\
\text { receptivity. } \\
\text { Using social- } \\
\text { cultural } \\
\text { characteristics } \\
\text { leads to a more } \\
\text { positive } \\
\text { reception of the } \\
\text { message. }\end{array}$ & $\begin{array}{l}\text { Role-model } \\
\text { stories and short } \\
\text { films }\end{array}$ & $\begin{array}{l}\text { Population: Students } \\
\text { through role model stories } \\
\text { and short films connect } \\
\text { with important and } \\
\text { sensitive concepts of the } \\
\text { topic's lessons. } \\
\text { Context: Popular young } \\
\text { people (singers, actors, } \\
\text { actress, national or } \\
\text { international) as role- } \\
\text { models, who participate } \\
\text { together with different } \\
\text { organizations promoting } \\
\text { talent development, } \\
\text { achieving and respectful } \\
\text { and positive relationships } \\
\text { are included through } \\
\text { videos during lessons. } \\
\text { Parameters: Messages of } \\
\text { videos and stories covered }\end{array}$ \\
\hline
\end{tabular}


Chapter 3

\begin{tabular}{|c|c|c|c|}
\hline & & & $\begin{array}{l}\text { sensitive topics, however } \\
\text { from a general perspective } \\
\text { (early pregnancy, finishing } \\
\text { high school, positive } \\
\text { relationships among young } \\
\text { people, etc.). }\end{array}$ \\
\hline $\begin{array}{l}\text { Attitudes } \\
\text { Environmental } \\
\text { reevaluation: } \\
\text { Encouraging } \\
\text { realizing the } \\
\text { negative impact } \\
\text { of the unhealthy } \\
\text { behavior and the } \\
\text { positive impact } \\
\text { of the healthful } \\
\text { behavior. }\end{array}$ & $\begin{array}{l}\text { Stimulation of } \\
\text { both cognitive } \\
\text { and affective } \\
\text { appraisal to } \\
\text { improve } \\
\text { appraisal and } \\
\text { empathy skills. }\end{array}$ & $\begin{array}{l}\text { Role-plays/ Short } \\
\text { documentaries' } \\
\text { reviews }\end{array}$ & $\begin{array}{l}\text { Population: Students are } \\
\text { encouraged to discuss } \\
\text { situations regarding gender } \\
\text { equality (e.g. respectful } \\
\text { relations). They review of } \\
\text { short video/ documentaries } \\
\text { showing advantages and } \\
\text { disadvantages of equal } \\
\text { gender behavior. } \\
\text { Context: The videos } \\
\text { represented stories of } \\
\text { young girls (e.g. victims of } \\
\text { violence, teenage } \\
\text { pregnancy, etc.), as to } \\
\text { observe the impact of } \\
\text { those situations in their } \\
\text { lives. Afterwards, students } \\
\text { developed role-plays } \\
\text { portraying situations with } \\
\text { non-equal and equal } \\
\text { gender behaviors, trying } \\
\text { affective appraisal and } \\
\text { empathy skills. } \\
\text { Parameters: Students } \\
\text { experience through role- } \\
\text { plays situations of unequal } \\
\text { gender relations, exploring } \\
\text { the negative impact of } \\
\text { gender inequalities, as well } \\
\text { as the advantages of equal } \\
\text { gender relations. }\end{array}$ \\
\hline $\begin{array}{l}\text { Skills/ Self- } \\
\text { efficacy } \\
\text { Guided } \\
\text { practices: } \\
\text { Prompting } \\
\text { individuals to } \\
\text { rehearse and } \\
\text { repeat the } \\
\text { behavior various } \\
\text { times, discuss } \\
\text { the experience }\end{array}$ & $\begin{array}{l}\text { Subskill } \\
\text { demonstration, } \\
\text { instruction and } \\
\text { enactment with } \\
\text { individual } \\
\text { feedback, } \\
\text { requires } \\
\text { supervision by } \\
\text { an experienced } \\
\text { person; some } \\
\text { environmental }\end{array}$ & $\begin{array}{l}\text { Role-plays, role- } \\
\text { modeling }\end{array}$ & $\begin{array}{l}\text { Population: Students } \\
\text { deepen skills development } \\
\text { (communication, self- } \\
\text { efficacy, negotiation) } \\
\text { through scenarios of } \\
\text { different situations, which } \\
\text { allow enhancing self- } \\
\text { efficacy through positive } \\
\text { experiences. } \\
\text { Context: Lessons' } \\
\text { structure provides a } \\
\text { sequence of personal and }\end{array}$ \\
\hline
\end{tabular}




\section{Chapter 3}

\begin{tabular}{|c|c|c|c|}
\hline $\begin{array}{l}\text { and provide } \\
\text { feedback. }\end{array}$ & $\begin{array}{l}\text { changes cannot } \\
\text { be rehearsed. }\end{array}$ & & $\begin{array}{l}\text { interpersonal skills } \\
\text { development through } \\
\text { repetition and experiences } \\
\text { which give opportunity to } \\
\text { receive feedback during } \\
\text { group discussion and } \\
\text { individually from the } \\
\text { teacher, although only as } \\
\text { guidance. } \\
\text { Parameters: All practices } \\
\text { combine a description of } \\
\text { the problem with a search } \\
\text { for positive solutions. }\end{array}$ \\
\hline $\begin{array}{l}\text { Skills/ Self- } \\
\text { efficacy } \\
\text { Modeling: } \\
\text { Providing an } \\
\text { appropriate } \\
\text { model; being } \\
\text { reinforced for } \\
\text { the desired } \\
\text { action. }\end{array}$ & $\begin{array}{l}\text { Attention, } \\
\text { remembrance, } \\
\text { self-efficacy and } \\
\text { skills, } \\
\text { reinforcement of } \\
\text { model; } \\
\text { identification } \\
\text { with model; } \\
\text { coping model } \\
\text { instead of } \\
\text { mastery model. }\end{array}$ & Role- modeling & $\begin{array}{l}\text { Population: Students } \\
\text { organize a competition on } \\
\text { expressing gender equality } \\
\text { ideas and behavior, and } \\
\text { ways to promote it at all } \\
\text { levels, through scenario } \\
\text { writing and plays, } \\
\text { individual and group } \\
\text { (including multiple art } \\
\text { expressions, e.g. singing, } \\
\text { painting, theater, etc.). It } \\
\text { includes finding for } \\
\text { positive solutions to the } \\
\text { problematic addressed. } \\
\text { Context: Students develop } \\
\text { their scenarios as } \\
\text { challenges and show it } \\
\text { during lessons. } \\
\text { Parameters: Scenarios } \\
\text { related to the behavior to } \\
\text { be modeled emphasizing } \\
\text { coping model or strategies. }\end{array}$ \\
\hline 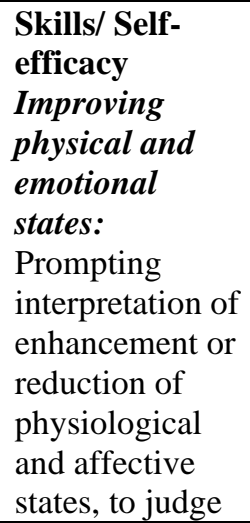 & $\begin{array}{l}\text { Must carefully } \\
\text { interpret and } \\
\text { manage } \\
\text { emotional } \\
\text { states. }\end{array}$ & $\begin{array}{l}\text { Peer video on the } \\
\text { importance to use } \\
\text { different } \\
\text { strategies to } \\
\text { manage emotional } \\
\text { states. Role-plays }\end{array}$ & $\begin{array}{l}\text { Population: Students } \\
\text { explore different emotions } \\
\text { and its influence on } \\
\text { behavior. } \\
\text { Context: Students use peer } \\
\text { video to see alternatives on } \\
\text { how to manage the } \\
\text { different types of emotions } \\
\text { and how can they use them } \\
\text { for more positive personal } \\
\text { relationships. The video } \\
\text { includes practices like } \\
\text { deep breathing, relaxation, }\end{array}$ \\
\hline
\end{tabular}


Chapter 3

\begin{tabular}{|c|c|c|c|}
\hline $\begin{array}{l}\text { own } \\
\text { capabilities. }\end{array}$ & & & $\begin{array}{l}\text { counting until } 10 \text { when } \\
\text { feeling anger, etc. } \\
\text { Additionally, role- plays } \\
\text { are used to practice deeper } \\
\text { emotions' management in } \\
\text { different situations. } \\
\text { Parameters: Students feel } \\
\text { safe to experience different } \\
\text { emotions and its } \\
\text { physiological and affective } \\
\text { and affective states, } \\
\text { acquiring and using skills } \\
\text { to cope. }\end{array}$ \\
\hline $\begin{array}{l}\text { Skills/ Self- } \\
\text { efficacy } \\
\text { Goal setting: } \\
\text { Prompting } \\
\text { planning what } \\
\text { the person will } \\
\text { do, including a } \\
\text { definition of } \\
\text { goal-directed } \\
\text { behaviors that } \\
\text { result in the } \\
\text { target behavior. }\end{array}$ & $\begin{array}{l}\text { Commitment to } \\
\text { the goals; goals } \\
\text { that are difficult } \\
\text { but available } \\
\text { within the } \\
\text { individual's } \\
\text { skills level. }\end{array}$ & Diary & $\begin{array}{l}\text { Population: Students } \\
\text { analyze and set goals they } \\
\text { would like to achieve } \\
\text { related to gender equal } \\
\text { behaviors in a short and } \\
\text { long term. They record } \\
\text { their goals using diaries } \\
\text { and progress is assessed } \\
\text { weekly by students } \\
\text { themselves following } \\
\text { given steps and strategies } \\
\text { through the program's } \\
\text { lessons. } \\
\text { Context: Students are } \\
\text { encouraged through the } \\
\text { duration of the program to } \\
\text { settle and keep a progress } \\
\text { record towards gender } \\
\text { equal behaviors. } \\
\text { Parameters: Students } \\
\text { settle goals, plan and } \\
\text { review progress through } \\
\text { strategies oriented towards } \\
\text { gender equal behaviors. }\end{array}$ \\
\hline $\begin{array}{l}\text { Skills/ Self- } \\
\text { efficacy } \\
\text { Resistance to } \\
\text { social pressure: } \\
\text { Stimulating } \\
\text { building skills } \\
\text { for resistance to } \\
\text { social pressure. }\end{array}$ & $\begin{array}{l}\text { Commitment to } \\
\text { earlier intention; } \\
\text { relating } \\
\text { intended } \\
\text { behavior to } \\
\text { values; } \\
\text { psychological } \\
\text { inoculation } \\
\text { against pressure. }\end{array}$ & $\begin{array}{l}\text { Role-plays and } \\
\text { discussions }\end{array}$ & $\begin{array}{l}\text { Population: Students } \\
\text { review peer stories and } \\
\text { discuss in which ways they } \\
\text { can say NO to abuse, } \\
\text { communicating } \\
\text { effectively. } \\
\text { Context: Student develop } \\
\text { and carry out role-plays } \\
\text { focusing on } \\
\text { communication strategies } \\
\text { to refuse abuses. }\end{array}$ \\
\hline
\end{tabular}




\begin{tabular}{|c|c|c|c|}
\hline & & & $\begin{array}{l}\text { Parameters: Students } \\
\text { practice and reinforce } \\
\text { strategies to deal with } \\
\text { social pressure. }\end{array}$ \\
\hline $\begin{array}{l}\text { Skills/ Self- } \\
\text { efficacy } \\
\text { Shifting focus: } \\
\text { Prompting } \\
\text { hiding of the } \\
\text { unpopular } \\
\text { behavior or } \\
\text { shifting } \\
\text { attention away } \\
\text { from the } \\
\text { behavior. }\end{array}$ & $\begin{array}{l}\text { Preferably shift } \\
\text { focus to a new } \\
\text { reason for } \\
\text { performing the } \\
\text { behavior. }\end{array}$ & $\begin{array}{l}\text { Discussion and } \\
\text { role-plays }\end{array}$ & $\begin{array}{l}\text { Population: Students } \\
\text { explore advantages to live } \\
\text { in gender equality (roles, } \\
\text { rights, opportunities and } \\
\text { non-violence). } \\
\text { Context: During the } \\
\text { discussions, student list } 5 \\
\text { positive outcomes of } \\
\text { gender equality. Then they } \\
\text { develop role plays about it. } \\
\text { Parameters: Students } \\
\text { practice alternative ways to } \\
\text { focus on gender equal } \\
\text { behavior (e.g. equal } \\
\text { opportunities, respectful } \\
\text { relationships). }\end{array}$ \\
\hline $\begin{array}{l}\text { Social norms } \\
\text { Behavioral } \\
\text { Journalism: } \\
\text { Using by the } \\
\text { mass and local } \\
\text { media of } \\
\text { appropriate role- } \\
\text { model stories of } \\
\text { behavior change } \\
\text { based on } \\
\text { authentic } \\
\text { interviews with } \\
\text { the target group. }\end{array}$ & $\begin{array}{l}\text { Appropriate role } \\
\text { models from the } \\
\text { context describe } \\
\text { behavior and } \\
\text { positive } \\
\text { outcomes. }\end{array}$ & $\begin{array}{l}\text { Role-model, } \\
\text { discussion and } \\
\text { critical analysis }\end{array}$ & $\begin{array}{l}\text { Population: Students } \\
\text { receive posters and analyze } \\
\text { campaigns from local } \\
\text { organizations oriented to } \\
\text { promote gender equality } \\
\text { issues. } \\
\text { Context: Posters } \\
\text { encourage students to } \\
\text { analyze how gender norms } \\
\text { are perceived at home, } \\
\text { school or by peers, } \\
\text { focusing on ways to cope } \\
\text { with refusal from others, if } \\
\text { they express opinions } \\
\text { about gender equality. } \\
\text { Parameters: Posters and } \\
\text { analysis of local gender } \\
\text { equality broaden the views } \\
\text { on the scope of gender } \\
\text { social norms, at home, } \\
\text { school and with peers. }\end{array}$ \\
\hline $\begin{array}{l}\text { Social norms } \\
\text { Mass media } \\
\text { role-modeling: } \\
\text { Providing } \\
\text { appropriate } \\
\text { models being } \\
\end{array}$ & $\begin{array}{l}\text { Conditions for } \\
\text { modeling; } \\
\text { conditions of } \\
\text { persuasive } \\
\text { communication. }\end{array}$ & $\begin{array}{l}\text { Peer video/ } \\
\text { YouTube }\end{array}$ & $\begin{array}{l}\text { Population: Students } \\
\text { watch peer video focused } \\
\text { on a positive way to } \\
\text { practice gender equal roles } \\
\text { (e.g. sharing chores at } \\
\text { home, respectful }\end{array}$ \\
\hline
\end{tabular}


Chapter 3

\begin{tabular}{|c|c|}
\hline $\begin{array}{l}\text { reinforced for } \\
\text { the desired } \\
\text { action through } \\
\text { the mass media. }\end{array}$ & $\begin{array}{l}\text { relationships, finishing } \\
\text { school). } \\
\text { Context: Students Peer } \\
\text { video explain the } \\
\text { importance of respect and } \\
\text { harmony for healthy } \\
\text { relationships, as well as } \\
\text { ways how to achieve it. } \\
\text { Parameters: Students } \\
\text { identify with mass media } \\
\text { role model and can relate } \\
\text { to their own environment. }\end{array}$ \\
\hline
\end{tabular}




\section{Chapter 3}

Table 4. Key Social and Emotional Learning Competencies Framework and sample of Methods and applications of the MANW program. Performance Objective (PO): Reflect critically on how gender roles are assigned to women and men, considering social norms, family values, religion, and power relations.

\begin{tabular}{|c|c|c|c|c|}
\hline $\begin{array}{l}\text { Social and } \\
\text { Emotional } \\
\text { Learning } \\
\text { (SEL) } \\
\text { Competencies } \\
(*)\end{array}$ & $\begin{array}{l}\text { SEL Criteria } \\
(*)\end{array}$ & $\begin{array}{l}\text { Change } \\
\text { Objectives }\end{array}$ & Methods & Application \\
\hline $\begin{array}{l}\text { Self - } \\
\text { awareness }\end{array}$ & $\begin{array}{l}\text {-Identifying } \\
\text { and } \\
\text { recognizing } \\
\text { emotions } \\
\text {-Accurate self- } \\
\text { perception } \\
\text {-Recognizing } \\
\text { strengths, } \\
\text { needs and } \\
\text { values } \\
\text {-Self-efficacy }\end{array}$ & $\begin{array}{l}\text { Awareness: } \\
\text { Acknowledge } \\
\text { the difference } \\
\text { between sex } \\
\text { and gender } \\
\text { and explain } \\
\text { how gender } \\
\text { roles are } \\
\text { assigned to } \\
\text { women and } \\
\text { men, } \\
\text { influencing } \\
\text { identity } \\
\text { development. }\end{array}$ & $\begin{array}{l}\text { Consciousness } \\
\text { raising }\end{array}$ & $\begin{array}{l}\text { A cartoon- } \\
\text { booklet bring } \\
\text { stories regarding } \\
\text { the difference } \\
\text { between gender, } \\
\text { sex and roles } \\
\text { allocation, } \\
\text { followed by } \\
\text { group } \\
\text { discussions. }\end{array}$ \\
\hline $\begin{array}{l}\text { Social- } \\
\text { awareness }\end{array}$ & $\begin{array}{l}\text {-Perspective- } \\
\text { taking } \\
\text {-Empathy } \\
\text {-Appreciating } \\
\text { diversity } \\
\text {-Respect for } \\
\text { others }\end{array}$ & $\begin{array}{l}\text { Attitudes: } \\
\text { Express } \\
\text { confidence in } \\
\text { listening to } \\
\text { others and } \\
\text { being } \\
\text { empathic. }\end{array}$ & $\begin{array}{l}\text { Self- } \\
\text { reevaluation }\end{array}$ & $\begin{array}{l}\text { Self-reflection } \\
\text { tool encourage } \\
\text { self-exploration } \\
\text { of attitudes } \\
\text { toward how } \\
\text { gender impact } \\
\text { communication } \\
\text { and to be } \\
\text { emphatic. }\end{array}$ \\
\hline $\begin{array}{l}\text { Responsible } \\
\text { decision- } \\
\text { making }\end{array}$ & $\begin{array}{l}\text {-Problem } \\
\text { identification } \\
\text { and situation } \\
\text { analysis } \\
\text {-Problem } \\
\text { solving } \\
\text {-Evaluation } \\
\text { and reflection } \\
\text {-Personal, } \\
\text { moral and } \\
\text { ethical } \\
\text { responsibility }\end{array}$ & $\begin{array}{l}\text { Perceived } \\
\text { social norms: } \\
\text { Recognize } \\
\text { how gender } \\
\text { roles influence } \\
\text { decisions to } \\
\text { avoid } \\
\text { unhealthy } \\
\text { relationships. }\end{array}$ & $\begin{array}{l}\text { Behavioral } \\
\text { Journalism }\end{array}$ & $\begin{array}{l}\text { Posters with } \\
\text { stories from } \\
\text { adequate local } \\
\text { role model } \\
\text { (young people) } \\
\text { offer examples } \\
\text { how to make } \\
\text { healthy decision } \\
\text { in relationship. }\end{array}$ \\
\hline
\end{tabular}


Chapter 3

\begin{tabular}{|c|c|c|c|c|}
\hline $\begin{array}{l}\text { Self- } \\
\text { management }\end{array}$ & $\begin{array}{l}\text {-Impulse and } \\
\text { stress } \\
\text { management } \\
\text {-Self- } \\
\text { motivation } \\
\text { and discipline } \\
\text {-Goal-setting } \\
\text { and } \\
\text { organizational } \\
\text { skills } \\
\text {-Coping skills }\end{array}$ & $\begin{array}{l}\text { Skills and self- } \\
\text { efficacy: } \\
\text { Describe steps } \\
\text { by step how } \\
\text { they will } \\
\text { practice equal } \\
\text { roles in their } \\
\text { relationships. }\end{array}$ & Goal setting & $\begin{array}{l}\text { Goal setting } \\
\text { plan and a } \\
\text { Diary, guide } \\
\text { students to } \\
\text { establish a goal } \\
\text { and monitor } \\
\text { progress. }\end{array}$ \\
\hline $\begin{array}{l}\text { Relationship } \\
\text { management }\end{array}$ & $\begin{array}{l}\text {-Effective } \\
\text { communicatio } \\
\mathrm{n} \\
\text {-Working } \\
\text { cooperatively } \\
\text {-Negotiation, } \\
\text { refusal and } \\
\text { conflict } \\
\text { management } \\
\text {-Help seeking } \\
\text { and providing }\end{array}$ & $\begin{array}{l}\text { Skills and self- } \\
\text { efficacy: } \\
\text { Demonstrate } \\
\text { the ability to } \\
\text { communicate } \\
\text { better their } \\
\text { opinions about } \\
\text { equal gender } \\
\text { roles at } \\
\text { school, home } \\
\text { and with } \\
\text { peers. }\end{array}$ & Modeling & $\begin{array}{l}\text { Role modelling } \\
\text { story of girls } \\
\text { and boys using } \\
\text { different ways } \\
\text { to express their } \\
\text { feelings and } \\
\text { decisions in } \\
\text { relationships. }\end{array}$ \\
\hline
\end{tabular}

*Adapted from Durlak et al., 2011; Payton et al., 2000. 



\section{CHAPTER 4}

\section{Me and My New World: Effects of a school based social-emotional}

learning program for adolescents in Panama

Published as:

Araúz Ledezma, A. B., Massar, K., \& Kok, G. (2020). Me and My New World: Effects of a school-based social-emotional learning program for adolescents in Panama. Education Science, 10(9), 251. https://doi.org/10.3390/educsci10090251. 


\section{Chapter 4}

\section{Abstract}

Gender inequalities still affect the health and well-being of young people worldwide. Given the apprehensions among government and educators in a conservative context like Panama to implement comprehensive sexual education, there is a need for other educational efforts to stimulate healthy and respectful intimate relationships between adolescents. This article examines to what extent a newly developed social-emotional learning (SEL) program, Me and My New World, provides a context in which students can learn to recognize and manage emotions, to care about others and themselves, make responsible decisions, develop social awareness. The program could additionally facilitate behavioral changes of young people towards more gender equality. Specifically, we focused on equal gender roles, equal rights in relationships and nonviolent problem solving, and present the qualitative effect evaluation among adolescents in Panama. The findings suggest that SEL-based lessons might broaden views on how young people experience the process of exploring identity formation, how assumptions of inequalities can be recreated through the lessons, and that SEL can emphasize the significance of choice and decision-making in interpersonal relationships. The perspectives, needs, and limitations highlighted by the adolescents living in a conservative context are highly valuable for improving future learning strategies for the development of healthier relationships. 


\section{Introduction}

Relationships between women and men are deeply influenced by gender social norms and the socially developed gender identities of women and men (Unterhalter, 2007; Loots et al., 2015). Gender is defined as "the roles, behaviors, activities, attributes and opportunities that any society considers appropriate for boys and girls, and men and women" (Manandhar et al., 2018, p. 644). Unequal gender relations are often reproduced in very subtle ways, affecting men and women's identities, leading to "behavior, choices and judgments that tend to 'normalize' gender inequalities" (Robeyns, 2006, p. 81). Equal rights, opportunities and responsibilities for women and men, boys and girls, as well as equal economic participation and decision-making, known as gender equality (EIGE, 2020), involve factors as power, agency and socially accepted gender cultural norms. Equal relationships consist of both partners considering the different needs and interests of men and women, involving equal allocation of power and resources (Malhotra et al., 2002). Unequal gender behaviors, for example violence against women, and violations of women and girls' sexual and reproductive health and rights, prevail worldwide.

Over the past 15 years, stimulated by the UN Millennium Development Goals (MDG), the Education for All (EFA) goals and the latest UN Sustainable Development Goals (SDG), governments and international NGOs have promoted a gender equality agenda based on girls' rights for and access to school. However, although more girls now access education, this approach - focusing mainly on rights to education and access to school - has been debated, as evidence shows limited and low results in the overall progress of women towards equal rights and opportunities throughout their 


\section{Chapter 4}

lives, both at national and international levels (Cornwall \& Rivas 2015). In Panama, where several legal reforms towards commitment to international agreements on protection of Women's Rights and Gender Equality have been implemented, young people are nevertheless faced with multiple challenges related to unequal gender relations and behaviors. Teenage pregnancies, HIV infections and violence against women and girls grow exponentially. In 2017, an average of $30 \%$ of pregnant women were girls between 10-19 years old (MINSA 2017). Scholars recognize multiple causes, such as the absence of comprehensive sexuality education (CSE), a culture of 'machismo', religious beliefs, and low socio-economic status for a majority of the population (Dholakia et al., 2012).

Since gender inequalities and their mental and physical consequences are recreated by social processes that coordinate interactions among women, men, boys and girls, achieving equality of women and men will require additional interventions to current laws and institutional policies (Ridgway 2011). A focus on individual relations between women and men (DeJaeghere 2012), might urge transformative strategies. Vaughn (2016, p. 4) stresses that "legal rights and access to institutions are crucial starting points for gender equality, but they are not sufficient in themselves to undo many of the facets of gender inequalities which are evident in the ways in which social interactions reproduce gender inequalities". Socio-emotional Learning (SEL), "the process through which children and adults acquire and effectively apply the knowledge, attitudes and skills necessary to understand and manage emotions, set and achieve positive goals, feel and show empathy for others, establish and maintain positive relationships and make responsible decisions" (CASEL, 2012, p. 9), might encourage changes in gender unequal behaviors of adolescents in Panama. 
Research has demonstrated multiple positive outcomes of SEL-programs related to interpersonal violence, bullying, drug use, social isolation, health, and well-being, disruptive behaviors, and educational achievement (Coehlo \& Sousa, 2016; Durlak et al., 2011). SEL offers a framework to explore gender issues, e.g. conceptions of the self (gender identities), patterns that promote stereotyping, unequal relationships (attitudes, beliefs), the extent of self-determination (choice, decision-making), enhancement of agency and active participation. Although most of SEL-programs have been implemented in the United States and Northern countries, socio-emotional skills lessons were adopted worldwide in school classrooms (Wigelsworth et al., 2016). As knowledge advances on what, how, and for whom SEL works, and under which ecological conditions (Wigelsworth et al., 2016), experiences in developing countries such as Panama are especially relevant. Knowledge about the influence of social norms, religious beliefs, race, ethnicity, as well as different educational systems and pedagogies on adolescents' interpersonal relationships in these countries is lacking. Evidence about the benefits of SEL on gender issues is still insufficient. Some findings are related to teenage pregnancy prevention, the impact of programs by gender, recognition of different needs of boys and girls, and the ratio of participants by gender (Coelho et al., 2015; Kimber et al., 2008).

Education remains a crucial arena where the reproduction of gender roles can be challenged (Walker, 2015). It plays a role in transforming norms and dominant ideas about what are appropriate roles and activities for women/girls and men/boys (Durrani, 2008; Stromquist, 2006; Vaughn, 2016). Since children and adolescents spend a great part of their time at school, educational settings can provide opportunities in the process of deconstructing unequal gender identities, either by structural changes (e.g. 


\section{Chapter 4}

mixed gender classes) or by adjusting curriculum and learning practices. Engaging teachers, and stimulating the exploration of their views on gender norms and practices might increase ownership towards gender transformations (Vaughn, 2016). SEL could facilitate the provision of gender equality lessons and healthy interpersonal relationships through schools.

The inclusion of a SEL-based lesson plan in secondary schools in Panama might provide an alternative route to achieving more gender equal relationships among adolescents, characterized by mutual respect. A needs assessment among different stakeholders in Panama (Araúz Ledezma et al., 2020a), such as parents, teachers, government and NGO representatives, revealed that these stakeholders recognized the importance of interpersonal skills development of adolescents. Moreover, they agreed that educational programs based on SEL could be a suitable option to start improving personal capacities of young people towards more equal and respectful personal relationships. These results were used to support the development and implementation of the school based SEL-program Me and My New World (MANW) in Panama (Araúz Ledezma et al., to be submitted). The lessons in this program focus on the promotion of equal gender behaviors: equal roles, equal rights in relationships and nonviolent problem solving among adolescents. We present the first effects of a pilot implementation of the MANW program among adolescents from Boquete, Panama.

The significance of the current study lies on broadening insights regarding adolescents' views and experiences in personal relationships, and the potential of social-emotional capacities development lessons that might positively influence their decisions and behaviors, and ultimately reduce health risks, especially teenage pregnancies. The adolescents in the current research were interviewed before and after their participation in the MANW 
Chapter 4

program, and they were questioned about these issues to determine the effect of the program on their attitudes and beliefs regarding gender equal and respectful interpersonal relationships.

\section{Methods}

\section{Study setting}

This evaluation examines the perceived effects of the MANW program to the promotion of gender equality among young people in Panama. Approval was given by the Ethics Committee of Psychology and Neuroscience at Maastricht University. The Ministry of Education of Panama, through the regional office in David, authorized this research study to be carried out at a public middlehigh School in Boquete, Panama. This regional school offered relevant conditions for the intervention and is representative for schools in the area: a diverse population, including students with a low socio- economic level, low participation of parents, and a very high level of teenage pregnancy in the region. Data for this study were collected through interviews. Student participants in the MANW program were interviewed at pre and post implementation of the program at the school.

\section{The School-based SEL intervention}

MANW is a contextualized, middle-school based SEL-program with a focus on the promotion of Gender Equality. The program follows a socio-emotional learning framework (CASEL, 2012), Teaching the Whole Child: Instructional Practices that Support SEL (Yoder, 2014), and the guidelines for successful outcomes achievement: SAFE (Durlak et al., 2011). It refers to the sequenced 


\section{Chapter 4}

training approach, the use of active learning methodologies to promote an experiential setting for new skills development, requiring focus on timing and attention, emphasizing the priority of skills development and an explicit conception of which specific socio-emotional skills the programs focuses on (Durlak et al., 2011). MANW is in part based on evidence-based health psychological theories that focus on the determinants of behavior and behavior change, in particular the Theory of Planned Behavior (TPB; Fishbein \& Ajzen 2010). The Gender Equality component of the program includes activities inspired by comparable life skills and gender equality programs (Butterfly Works et al., 2009; Ricardo et al., 2010; Rutgers, 2013). Some of these programs focus on life skills such as self-esteem, communication, negotiation, problem-solving and assertiveness. The Capabilities Approach, enhancement of personal and inter-personal capacities towards gender equality, was paramount in the design of the program (Table 1). For a full description of the program's objectives and development, see Araúz Ledezma et al., to be submitted.

The program consisted of 14 lessons of 90 minutes each, delivered over 4 months within the academic school year. It was implemented by class teachers who volunteered to participate in the research project. These teachers offered up the time allotted to regular curriculum hours and provided the MANW lessons instead of subject matters such as English, Geography, and Orientation. All the required materials of the program were distributed during every lesson by the teachers. Sessions were assessed by teachers and students through self-report questionnaires. The five components of SEL encouraged changes on three different gender behaviors (CASEL, 2012). Therefore, the learning activities of the program focused on these expected behavioral 
outcomes: Equal roles, which are related to "the responsibilities and tasks assigned to women, men, girls and boys. Like gender itself, gender roles can evolve over time, in particular through the empowerment of women and transformation of masculinities." (EIGE, 2020). Equal rights in relationships refers to practical ways to become aware and demand equal rights for women and men in personal relationships, recognizing and making institutions accountable for the respect and implementation of rights, as well as integrating it through school and home practices. Nonviolent problem solving refers to positive coping strategies to solve conflicts and negotiation skills.

The program includes activities to promote changes in socio-cognitive determinants of behavior derived from the Theory of Planned behavior, i.e. knowledge/awareness, attitude, skills and perceived social norms, which could elicit transformations towards gender equality. Knowledge is a cognitive factor, which allows misconceptions and myths to be disentangled from facts. Attitudes refer to the individual's positive or negative evaluation of the performance of the health behavior (Ajzen, 1988). It allows evaluation of advantages and disadvantages, as well as perceived barriers and benefits of a certain behavior. For example, the positive or negative attitude towards practicing gender equality, in the case of students, will be influenced by the barriers, advantages, and disadvantages they may encounter that are established by social and cultural norms, and lived through experiences with peers, family, friends, boyfriends and girlfriends. "Attitude toward the behavior is determined by salient beliefs about that behavior (Bartholomew Eldredge et al., 2006, p. 79). Skills (social-emotional) refer to competencies such as negotiation skills, self-esteem, self-concept, decision-making and assertiveness (Payton et al., 2000). Perceived social norms refer to parents', 


\section{Chapter 4}

peers', and friends' beliefs about a certain behavior. Appendix 1 shows an overview of the program's lessons and expected outcomes.

\section{Participants}

Participants, 55 students in total (26 girls and 29 boys) from group 7th and 9th of middle-high school, were selected by the school. The criteria for the selection of the students was based on a prior 'high need' assessment conducted by the school administration and the leader teacher of the research project at the school, considering factors such as high risk of teenage pregnancy, violence, bulling, and the need to increase academic achievement. At baseline level 55 students were interviewed and at post-intervention level, 49 students were interviewed. Six students were excluded as they were not able to complete the program. Each group of students, group 7th and 9th received the program lessons in separate classrooms and groups. All students of both groups were allowed to participate in the program. The age of students was between 12-15 years. Most participants indicated having a low socioeconomic level, some living in extreme poverty.

\section{Implementers}

Teachers were the implementers of the program and were guided by a teacher's manual, which described the lessons and the design of the program. A school leader was selected by the administration of the school and was the contact person throughout the research project for all stakeholders (e.g. teachers, students, parents). Teachers receive 40 hours of training (training of trainers/ ToT) prior to implementing the program. This training emphasized that teachers first reviewed their own knowledge, views, assumptions, beliefs, 
and prejudices about gender and social-emotional skills. Furthermore, special attention was given to the acquirement of practical experience during the Tot, for example by role-playing, to ensure that teachers gained self-confidence and reduced potential resistance on the sensitive themes of the lessons. The ToT was based on a learner centered approach and the use of participatory and active learning methods.

\section{Research instrument and Data Analysis}

Data were collected during fieldwork in Panama, July and November 2014. In depth, semi-structured interviews were conducted with the adolescents before and after the intervention. The interview protocol was based on the program's objectives, literature review, and theoretical frameworks (e.g., SEL, Theory of Planned Behavior). Interviews lasted from 20-30 minutes at pre-intervention, and about 45 minutes at post- intervention. Postintervention interviews were carried out one week after the last lesson was completed.

Confidentiality and anonymity were ensured to participants: Participants were informed that they could end the interview if they wanted, without any explanation and at any given moment. Furthermore, at any sign of distress the interviewer terminated the interview. Interviews were recorded on written notes since participants preferred this method rather than audio recordings, but extensive notes taken during the interviews were verified with each respondent after the interview was concluded. Interviews were conducted in Spanish and translated into English by the first author, a Panamanian national who was sensitive to the social and cultural norms, as well as the economic and political conditions in this conservative context. 


\section{Chapter 4}

The transcripts were anonymized and stored on a password-protected personal computer. The researchers subsequently analyzed the transcripts line by line and coded them thematically. The coding scheme was similar to the topics in the interview protocol as the interviews were semi-structured, covering self-knowledge, knowledge/awareness of gender and gender equality, attitudes, skills, social and cultural norms and practices, agency, and intentions towards gender equality behaviors. The coding scheme also included intersectionalities between topics (e.g. agency, poverty, religion, and power relations). The data were analyzed using a directed content analysis approach (Hsieh \& Shannon, 2005). This approach facilitated a categorization based on data derived from theory and relevant previous findings. An iterative coding process was used (Mayring, 2010), which guaranteed that preliminary and inductively arrived coding categories were a reliable and accurate representation of the data content, which resulted in categories, which were further synthesized into overarching themes, presented in the results section. Table 2 shows an overview of the interview questions.

\section{Results}

The findings of this study reveal both the SEL competencies and the sociocognitive determinants of behavior and behavior change in adolescents' perceptions of the program: knowledge, awareness, attitudes, skills/ selfefficacy, perceived social norms and intentions of participants as subcategories, regarding gender equal behaviors, which were grouped into three themes: Equal roles, equal rights in relationships, and nonviolent problem solving. Within these broader themes, categories can be identified 
Chapter 4

(e.g. within equal gender roles, knowledge/awareness of the concept of gender and gender equality was one of the categories).

\section{Theme 1: Equal gender roles}

Knowledge/ awareness

At baseline, most participants defined gender as a word to describe types of music. Equality between women and men was described as an abstract concept that they might have heard of, but that they did not completely understand. Awareness of girls' and boys' roles in relationships, at home or school appeared to be biased by a "macho culture", social norms, religious beliefs, media, and school practices.

"As girls we are supposed to help at home and school. My mother does that too" (girl, 13 years)

"Men are strong, and they bring the food to the family. Women take care of children and grandparents. They are sweet" (boy, 14 years)

The adolescents also mentioned that the consequences of early pregnancy were constant messages of current reproductive health educational curriculum and indicated differences between boys and girls in this respect. For example, most girls mentioned that they needed to invest more effort than boys in keeping love relationships, e.g. being more communicative and understanding of the needs of the boys.

"My boyfriend gets very upset many times, if I do not do what he wants. I always need to talk a lot with him and explain the situations" (girl, 15 years) 


\section{Chapter 4}

Frequently, girls were supposed to show "proof of love" (engaging in sexual encounters) to their boyfriends, in order not to lose them. In this sense, girls perceived pregnancy as an act of love. In contrast, more than half of the boys mentioned that they were 'supposed to' have girlfriends, and that early pregnancies were a consequence of these relationships.

Differences in roles for boys and girls also became apparent in the home setting, where most girls expressed that they were responsible to carry out household chores, while their brothers, fathers, and uncles were more allowed to enjoy other activities, e.g. play or watch television. Even though more than half of the girls expressed an interest using their time differently, accepting this as a normal fact of life was evident from their responses. At school, participants expressed that classroom chores were assigned to couples (girls and boys randomly), but the girls were mostly in charge of cleaning rooms, chalkboards, and general tasks. Boys also helped with those tasks, as well as making copies, bringing school materials, etc.

After the lessons, the majority of participants showed increased knowledge and awareness in gender, gender equality and its influence on ways to relate to each other. Participants stated that the MANW program was the first opportunity they had to explore these concepts and that they were now able to define them.

"Gender is not the way we are born, is learned and can be changed" (boy, 14 years)

\section{Attitudes}

Half of the participants described factors involved in gender role formations, mentioning religious beliefs, family values, and social norms as strong influences. 


\section{Chapter 4}

"I didn't know anything about my roles before. I just did what I was supposed to do to be a good girl, but yes, now I think more about all, we are not born with genders. Boys should listen and do more" (girl, 15 years)

However, analyzing these intersections was experienced as difficult by some participants. For example, they indicated that their religious beliefs were in conflict with the MANW program's lessons about gender, and these beliefs were difficult to overcome.

"We have learned now that women and men have the same rights and should also have the same opportunities, and it is ok, but the bible is very strict about our roles. We always talk about it at home" (boy, 12 years)

Early pregnancies were an issue mentioned by most participants, yet differently than before the intervention. At baseline, the majority of participants acknowledged that early pregnancies carry a heavy burden, especially for girls (e.g. dropping out school, shame, etc.). At post intervention, girls expressed that increasing their self-esteem and developing certain skills such as better decision-making, and negotiation helped them to be more aware of their own worth and choices, and especially how to communicate this to others.

"I can make better decisions. If I want to achieve my goals and a boy asks me for a proof of love, I will say no, I am busy" (girl, 13 years)

Notably, whereas more than half of boys expressed that both girls and boys can make better decisions that benefit their own roles in personal relationships, they also indicated that early pregnancies can have a negative 


\section{Chapter 4}

impact on boys, even though the expectation in a "machismo culture" is that boys are supposed to be strong and indifferent.

"If I make a girl pregnant, I am sure she will have a lot of problems. But I will be worried as well, even though that most people say boys are strong and it is not a big deal if that happens" (boy, 13 years)

"A man should be head of a family. But having a girl pregnant when I am young, means I will probably not be a good father. It is awful, I never had a father" (boy, 15 years)

Reflecting on their own roles in the household, and among family, friends, and school (relationships), nearly all participants expressed that the program provided a starting point for considering different views and seemed to forge new attitudes towards women and men's roles.

"I never helped at home in the past. Even though I do not like it, I try now to help my sisters more" (boy, 12 years)

"We are now trying to divide more the cleaning tasks at school, but some boys don't want to help. But the teacher is helping us and talk to the boys" (girl, 15 years)

When talking about masculinities, while still reflecting notions of patriarchy, the answers also indicated changes. More than half of boys expressed that family tasks could be more equally divided in the household, so that girls might have more time for other activities, such as playing, going out, or enjoying hobbies. Most girls expressed that skills development (referring to communication, negotiation, and assertiveness) had provided them for the first time with more self-confidence, to believe that they can share equally 


\section{Chapter 4}

different roles in the household and relationships, and to make this a topic of discussion.

"I tell my mother often that my brothers should also help with the household chores. Ifeel that I can better communicate my ideas" (girl, 14 years)

"I believe that boys and girls have the same rights and can enjoy free time for hobbies or sports activities" (boy, 15 years)

The fact that a high percentage of families in Panama are headed by one member (mostly mothers or extended family members) seemed also to influence the gender perceptions of participants.

"I have now learned that men can cook and help in the house and with the family tasks. I have never had that at home. My father left us when I was very young, and my uncles say that women are for these kinds of tasks at home" (boy, 12 years)

Skills/Self-efficacy

Developing critical thinking skills and increased empathizing with the opposite gender seemed to enhance a more positive attitude toward the importance of sharing equal roles and opportunities between women and men, and increased adolescents' introspection about their own roles and behaviors.

"I never had really to think so deep in my life. I believe that now I want to know more about who I am and what I can achieve with my life. We learned that we can achieve our dreams, through thinking carefully about our plan and actions. It was cool” (boy, 14) 


\section{Chapter 4}

Furthermore, socio-economic conditions as poverty and lack of employment were often mentioned as factors that could create and reinforce gender role allocation and unequal power relations. Income generation seemed to be a very important issue for participants in terms of education and gender roles allocation. For example, the majority of participants stated that the participation of women in income generating activities could not only increase a sense of economic safety in the household, but also allow the payment for extra activities for family members and themselves (e.g. holidays, hobbies, sports). For the respondents, finishing high school was mentioned by students as a path towards achieving life goals, including income generation.

"Being economically independent will give me the freedom to have a better life. I need to finish high school, as I want to go to university and get a good job" (girl, 12 years)

"Women's income can help to pay bills in the house and give a nice life to your children" (boy, 15 years)

\section{Perceived social norms}

The agency dimension in better decision-making was evident on roles allocation. More than half of participants perceived the current gender model they experienced at home and school, as a barrier that limited them to express new ideas about gender roles or equality. Nearly half of the girls seemed less confident to be able to bring role changes at home in the context of household chores, negotiating time for pleasure activities, and participation in the community. Boys felt less comfortable to discuss equality of roles at home and in relationships. They were more worried about their masculinity profile 
Chapter 4

and the opinion of parents and friends regarding a new way of approaching gender and equal roles. Most of them expressed that while they thought the accepted social norms on gender roles and identity were not correct, they thought it would require more time and opportunities to experience and develop personal capacities encouraging new forms of masculinity and femininity that could become socially accepted.

"I am not sure if I will be able to always express my opinion about our roles with my boyfriend, family or friends" (girl, 13 years)

"I am not sure what my uncle, father and grandfather who live with us will think if I start proposing new ways to divide our roles at home. Maybe they will think I am not really becoming a man, but I will try", (boy, 15 years)

\section{Intention}

Nevertheless, despite these hesitations, the majority of participants expressed that they would be willing to consider a more equal distribution of roles, whether in relationships, home or school, showing their positive intentions.

"I would definitely think about how to be fair to girls in a relationship. It is part of having equal roles between both of us (boy, 15 years)

I will definitely try and ask my parents to get more free-time at home to do other things than chores" (girl, 12 years) 


\section{Chapter 4}

\section{Theme 2: Equal rights in relationships}

\section{Knowledge/awareness}

At baseline level, when asked about the rights of young people, the Human Rights Declaration and Children's Rights, the adolescents indicated they were aware of these and could list some of them. However, they were not familiar with specific international women rights' declarations or gender equality laws in Panama, nor what these entailed. Likewise, they lacked knowledge about places in the community where to report child abuse, and also indicated a low intention to look for help in case their rights were violated.

After the intervention, participants seemed to have become more aware of equal rights for women and men, in terms of work, equal share of roles, responsibilities, and opportunities. Furthermore, when probed, more than half of the adolescents were able to mention that equal rights also include the elimination of interpersonal and female-directed violence and the right for women to work, and respondents indicated awareness of the multiple barriers most women face in Panama.

The data showed that more than half of participants had gained more selfknowledge and self-worth after participating in the lessons, specifically regarding being more aware of their own qualities, possibilities, and especially about their rights. Some participants (around 21\%) showed less awareness, as they seemed less interested in these topics. A small group of participants (mainly girls, around 6\%) expressed to have prior knowledge on the personal capacities promoted by the program lessons and about their rights. 


\section{Chapter 4}

"I started to see myself differently, as someone with self-worth, who has rights and if I study, I can have a better life. I need to respect myself first, ask respect from others and defend my rights" (girl, 15 years)

"It is very good that everyone knows about their rights, especially to work. I have learned that girls and boys have the same self-worth and have the same rights. I don't think all children know that" (boy 12 years)

\section{Attitudes}

Most participants showed enthusiasm about being able to voice their opinions through the active learning experiences and participatory set-up of the program, especially on the issue of how they could use their voice to claim their rights.

"I believe now that we have rights as children or young people, but I think we have less opportunities to express our opinions. Sometimes, I try at home or school to say what I think. It is not always easy. But these lessons have helped" (girl, 15 years)

"I liked that we needed to play different roles during the lessons and see how gender is created in our culture and what people need to do. Rights for us exists, we need to use them" (girl, 14 years)

Skills - self-efficacy

Nevertheless, most girls felt they require more skills and opportunities to reject inequalities and ask for accountability. Further, they expressed that 


\section{Chapter 4}

knowing their rights, and becoming skilled at claiming them, especially decision-making in their intimate relationships and in school, could create new opportunities to communicate and voice their worries and feelings.

"I need to communicate better to be able to express my opinions, especially at home and with friends/ boyfriend. Sometimes is difficult if others think they know everything better" (girl, 15 years)

\section{Perceived social norms}

Half of the boys found challenging to talk with their friends and family about being gender sensitive and to have respect for the rights of girls and women. However, these existing social norms in their environment about the entitlements for women and men were perceived by participants as something that can be changed, but were likely difficult to change.

"My father used to batter us (brothers and sisters) and my mother. Like if we did not have any rights. I do not think it is ok. It needs to change. We have to become better persons; we all have rights" (boy, 12 years)

Some of the boys (around 15\%) did not think it was possible to change current cultural and socially accepted gender norms. They expressed views on masculinity and femininity paradigms that seemed rigid and confused, especially about the fear of losing masculinity and acceptance among their peers and male family members if they would behave in a more gender-equal way. Some girls (around 10\%) also expressed their intention to behave in line with existing social norms, with regard to role sharing at home, or in 


\section{Chapter 4}

relationships. They explained that that is the way their parents and their religious beliefs had taught them.

\section{Intention}

Asked about their intention to claim respect and rights in relationships and report abuse to the authorities in the future, most participants expressed that they did intend to be more communicative, and would try to find a trustful person to help them when they found themselves in such situations. More than half of the girls reported to be more willing to look for help when they would experience gender-based violence (physical/verbal), for example from a teacher. Boys mostly mentioned their intentions to report abuse perpetrated by their peer groups, as they in many cases did not see themselves as part of abuses, but also mentioned that going against some peer groups in the school is very dangerous and difficult.

"It is very difficult to try to ask respect for rights when you are in a big group. But I will try to look for help when I feel afraid of them or they are unfair" (boy, 12 years)

Interestingly, and possible inhibiting actual outreach in times of need, respondents indicated an overwhelming distrust of the authorities to reduce or handle complaints about the abuse of their rights.

"Over here, I don't think the police, or any other authority will help on cases of violence against girls or women" (girl, 15 years)

"I know women who have reported their husband or boyfriend because of violence and the police never did anything to stop it" (boy, 15 years) 


\section{Chapter 4}

\section{Theme 3: Nonviolent problem solving}

Knowledge/ awareness

At baseline measurement, more than half of the respondents mentioned the existence of violence and bullying at school. Girls seemed more affected by conflicts with other girls, as well as feeling annoyed by 'machismo' cultural jokes of boys regarding girls' bodies and behaviors, which in some cases were very aggressive. The use of violence, whether physical or emotional, was mentioned as the most likely way their peers would solve problems. Teachers were not mentioned as users of violence at school. However, respondents often mentioned to have experienced some verbal or physical violence at home. In this line, most participants were hesitant to talk about how to handle their problems, or how to deal with obstacles or decision-making in their personal relationships. Biased conceptions of violence and general statements such as 'men are violent by nature', 'women are fragile', 'violence sometimes is necessary', as well as 'battering children teaches obedience' were often raised by the adolescents as common and accepted forms to solve problems or conflicts in school, the home, or the society at large.

During the post-intervention interviews, most participants expressed that the program allowed them for the first time to become aware about sources of violence, especially against women, the influence of cultural norms - especially machismo- and how power relations in society and in their daily lives influence the behavior of boys, girls, women and men.

"Women should not accept violence at all. There are other ways to solve problems, like talking instead of fighting" (girl, 15 years) 


\section{Chapter 4}

Attitudes

Half of the boys expressed that participating in the program allowed them to explore other views on masculinities and the use of violence than they were previously exposed to:

"I was told in my family that men have to be strong and violent, that it is our nature as men. But I know now that I do not need to be violent" (boy, 15)

Skills/ Self-efficacy

Developing capacities (skills) to manage their emotions was the most common perceived positive change by the majority of participants. Half of the girls felt more confident to solve problems positively. Managing emotions was mentioned to avoid problems, and to enable searching for alternatives to solve conflict.

"I liked when we had a role-play about a boy who was very upset and threatening his girlfriend, so we could practice calming down, express our opinions, ask for respect and solve the problem without violence (girl, 13 years)

Interestingly, boys seemed more prone to talk about strategies how to negotiate themselves and their social identities in a group of peers, and to avoid violence in such groups. They expressed having more self-confidence and feelings of worthiness can make them feel stronger to face challenges with other peers. 


\section{Chapter 4}

"If I love myself more, I will not get easy in trouble because I will think that I am very important and should not follow others who only like to make trouble" (boy, 12 years)

Other capacities like negotiation skills, assertiveness, self-respect, and effective communication (e.g. listen actively, showing empathy) were mentioned by more than half of the girls as ways to try to avoid violent practices and to achieve agency in their lives.

"I never knew how to say NO to anything. I feel now I can better say NO and manage to tell my friends or boyfriend when I do not like something. It is not easy, but I really feel I can do it" (girl, 15 years)

\section{Intention}

Most girls expressed that they intended not to accept violence from a boyfriend or others in the future. They seemed to be more aware of existing laws, where to go for help, and ways to solve problems without violence. More than half of boys expressed their intention to use positive alternatives to manage emotions and avoid violence in the arise of conflicts.

\section{Discussion}

The aim of this study was examining to what extent a school-based SocioEmotional Learning program, Me and My New World, could evoke perceived changes towards gender equality beliefs and behaviors among young people in Panama. Specifically with regard to: equal roles, equal rights in 
relationships and nonviolent problem solving. We interviewed adolescents before and after participation.

Overall, participants expressed more positive opinions on gender and gender equality, increased knowledge about equal rights and nonviolent problem solving, as well as behaviors in line with these perceptions. Specifically, the intervention positively affected their awareness about gender equality, and increased positive attitudes and socio-emotional capacities, by improving their understanding of their own identities, agency, better managing their emotions, as well as increasing their self-confidence, communication, and decision-making and negotiation skills. These findings are in line with recent evidence highlighting the importance of students' selfreflection on their own and others' behaviors, which in turn could lead to alternatives to deal with sensitive issues as gender equality and its challenges (Dür \& Keller, 2018). In line with the determinants of behavior (change) identified in the Theory of Planned Behavior (Fishbein \& Ajzen, 2010), the results indicate that the lessons of the program encouraged students' selfexplorations of positive or negative evaluations of gender and gender equality (attitudes), and their beliefs regarding gender behaviors, as well as perceptions of important others' opinions and behaviors in this respect (i.e., social norms). Moreover, the respondents gave evidence of social emotional skills development (e.g. self-efficacy, negotiations skills, etc.), which could increase their intention towards more equal personal relationships and decisions. Further, the respondents indicated that the lessons of the MANW program provided them with insight into the benefits and barriers of practicing equal gender behaviors (e.g. equal roles, equal rights in relationships and non-violent problem solving). Specifically, considerations of cultural and social norms were repeatedly mentioned as a barrier in 


\section{Chapter 4}

deconstructing gender inequalities (e.g. unequal role distribution, violence) arising in the daily lives of students. The focus of the program on inter- and intra-personal skills has enhanced participants' ways to see themselves, and the way they relate to each other. This result resonates with empirical evidence in Yemen, revealing the positive effects of a life skills program on adolescents' attitudes and beliefs towards themselves and their relationships with others (Al Iryani et al., 2011).

Furthermore, the findings show that the program offered the adolescents new and safe spaces to try out alternative forms of gender roles, exploration of their gendered identities, and discussion about and enactment of different forms of masculinity and femininity. The theoretical principles upon which the MANW program is based ensured the use of active learning and effective behavioral change applications (e.g. role plays, diaries, etc.), specifically oriented towards the analysis of gender identity construction in society and daily life, the self, gender beliefs construction, and the precepts of masculinities and femininities; as well as attitudes and perceived barriers towards the use of gender equal behaviors in society. This result reinforces the importance of focusing on innovative educational strategies where young people can explore their own behavior and non-violent norms between women and men (Santamaria et al., 2019). This is in line with recent evidence in Peru, highlighting the importance of different contexts, culture and social norms influencing adolescents' behavior, as well as the need for prevention efforts oriented to increase personal capacity development (Salazar et al., 2005).

Further, the results are in line with a growing literature showing the potential of SEL-programs in schools, for enhancing socio-cognitive determinants of behavior highlighted in the TPB, such as attitudes, perceived 


\section{Chapter 4}

social norms, perceived behavioral control, self-efficacy and perceived barriers and benefits regarding gender equal behaviors, forging motivation, action and eventual behavioral changes (Durlak et al., 2011, Fishbein \& Ajzen, 2010). The findings are also consistent with views stressing that individual behavior and choices are influenced by the socio-economic, cultural, and political context (Bartholomew et al., 2016; Kok et al., 2012; Rijsdijk, 2011). The interviews highlighted the multiple barriers and socioemotional conditions young people face in the process of deconstructing and (re)classifying gender identities and behavior in the context of Panama, where conservative gender roles and machismo social norms prevail. Our study provides initial evidence for the potential of a SEL-based program in interlinking personal capacity development with the process of improving gender unequal beliefs and behaviors in relationships, and awareness of rights and opportunities.

Respondents' reflections showed that they first explored gender conceptualizations, searched for clarification of the self, and then analyzed the impact of social norms, culture, and religious beliefs on their relationships, as well as how roles and rights are operationalized in these relationships. The findings suggest that deliberations of own behavior, effect of actions on other people, and the significance of one's personal choice to make responsible decisions, offered a view to participants on the extension of opportunities that could be created towards gender equality behaviors, which could ultimately influence their relationships, health, and well-being. The process of mapping the resources and opportunities provided by parents, teachers, community, as well as the existent limitations in terms of culture, social norms, and religious beliefs, facilitated a consideration of different power relations and its implications for agency development and self- 


\section{Chapter 4}

efficacy. As such, these findings corroborate the importance of focusing on the active role young people can play in fostering changes in their own life (Biggeri \& Santi, 2012), and confirm similar research findings on the importance of increasing young people's skills and capacities to act on their rights (Loots \& Walker 2015).

\section{Implications and limitations}

The respondents reported the struggle between identifying and considering new patterns of equal relationships between women and men, with the ingrained norms communicated in their machismo and patriarchal culture. The cultural context in which these young people's identities are forming poses limitations on young people's agency, participation, and voice, at school or at home. These findings are in line with DeJaeghere and Lee (2011) who report evidence in Bangladesh emphasizing that lack of agency, gendered norms, and structures in communities that perpetuate discrimination can be difficult to overcome for young people, especially girls.

The results highlight the importance of individual capacities development of all stakeholders in the educational system, transforming existing paradigms surrounding gender in educational institutions, curriculum, and practices. Likewise, several vital factors such as uncertainty about support at home, distrust in public institutions and authorities to help them, teachers' and peer's (negative) views towards gender equality behaviors, as well as poverty and social conditions, remain influencing the intention of young people, to try out new gender equality realities. The interconnectedness of the contexts in which adolescents live, and the social norms that permeate these contexts, emphasizes the importance of the "whole 
school approach" within the SEL perspective, which includes a work alliance between the students, school, parents and the community (Durlak et al., 2011).

Interestingly, while education does not guarantee job allocation or income generation, most students seemed more motivated to embrace gender equality behaviors if women's rights to work and gain income would mean creating better socio-economic conditions for the household. This highlights the notion that economic changes might influence faster material arrangements between women and men (Ridgeway, 2011). Further, boys often considered negative consequences of early pregnancy not only for girls, but also for themselves, even though they indicated that they felt they were expected to follow normative "macho" behavior in relationships, especially regarding early pregnancies. This finding is similar to recent evidence in Paraguay, where young boys' personal behavior often differs from current masculinity and normative in their neighborhoods (Fleming et al., 2013). Therefore, it is vital to include boys' and men's voices in developing health promotion programs.

Several limitations of the current study should be acknowledged. First, the MANW program was implemented only once in the school curriculum, without a control group. We cannot say whether the changes reported by the adolescents were due to the program, or the result of processes/factors we did not take into account. Moreover, these changes are adolescents' perceptions of the effect of the program, and our results should be verified in follow-up (quantitative) research that includes a control group. Since the postintervention interviews were conducted relatively soon after the adolescents finished the last lesson, we cannot say whether these changes are sustainable and will last for longer periods of time. However, it is important to emphasize 


\section{Chapter 4}

that this study, through qualitative methods (interviews), has allowed to gain in-depth insights into youths' lives, needs and experiences in Panama, especially voicing their opinions on gender equality sensitive issues. Furthermore, the findings of this study revealed the concerns and limitations of boys and girls with respect to which strategies could be more effective in their contexts to initiate and sustain gender equal relationships and practices, as well as, how their perceived social norms (acceptance or rejection within peer groups) regarding gender equal behaviors, could limit or enhance their future performance of behaviors. These potential issues, highlighting the differing nature of responses and views from boys and girls, could be addressed in future research of SEL and Gender Equality program's design and implementation.

\section{Conclusion}

The findings of this study suggest that a school-based program using Socioemotional Learning (SEL), which seeks to enhance cognitive and psychosocial capacities of students, could be an appealing educational strategy to introduce new strategies to change young people's perceptions of and behaviors towards gender equality. Such a program can facilitate steps to transform biased gender identities, challenge assumptions of inequalities, emphasize agency development, and increases the spectrum of action and participation of young people in important domains of their lives. In line with the UN Sustainable Development Goals (SDG), as well as international health and well-being agendas for young people, achieving enacted gender equality calls for efforts towards a new perspective on the type of life women and men value. Since gender equality is the ultimate achievement of this process, special attention must be given to potential strategies that embrace gender 
Chapter 4

equality as part of the daily educational experiences and practices of young people. 


\section{Chapter 4}

Table 1. Capabilities and Expected Behavioral Outcomes (BO) of the program $\mathrm{Me}$ and My new World

\begin{tabular}{|l|l|}
\hline $\begin{array}{l}\text { Main areas of } \\
\text { expected Behavioral } \\
\text { Outcomes (BO) }\end{array}$ & Selected Capabilities(*) \\
\hline Equal Gender Roles & $\begin{array}{l}\text { Practical reason to promote equal gender roles, relates to } \\
\text { the capability of "being able to form a conception of the } \\
\text { good and to engage in critical reflection about the planning } \\
\text { of one's life" (Nussbaum, 2011). In this line, the MANW/ } \\
\text { SEL program emphasizes critical analysis of gender roles } \\
\text { allocation and identity development, including the } \\
\text { intersections of culture, family values, social norms, and } \\
\text { media influence. }\end{array}$ \\
\hline $\begin{array}{l}\text { Equal rights in } \\
\text { relationships }\end{array}$ & $\begin{array}{l}\text { Affiliation and Voice are intrinsically related to being } \\
\text { able to claim rights. It emphasizes the social basis of self- } \\
\text { respect and non- humiliation, as well as being able to be } \\
\text { treated as a dignified being whose worth is equal to that of } \\
\text { others (Nussbaum, 2011). This entails provisions of non- } \\
\text { discrimination on the basis of race, sex, sexual } \\
\text { orientation, ethnicity, caste, religion, national origin. In } \\
\text { addition, being treated with respect and dignity is related } \\
\text { to having voice. It should also imply "having freedom to } \\
\text { participate, to be taken seriously, and have their opinion } \\
\text { valued and heard" (Loots \& Walker, 2015). }\end{array}$ \\
\hline $\begin{array}{l}\text { Nonviolent problem } \\
\text { solving }\end{array}$ & $\begin{array}{l}\text { Bodily Integrity is related to "being able to move freely } \\
\text { from place to place; being free of harassment and to be } \\
\text { secure against violent assault, including sexual assault and } \\
\text { domestic violence" (Nussbaum, 2011). The MANW } \\
\text { program highlighted the importance of self-esteem, self- } \\
\text { concept and self-confidence to avoid abuses and to acquire } \\
\text { positive, non-violence strategies to manage emotions and } \\
\text { problems. }\end{array}$ \\
\hline
\end{tabular}

* Adjusted from capability procedural system lists (Loots \& Walker, 2015; Nussbaum, 2011). 
Chapter 4

Table 2. Sample of Interview questions/ Effects program evaluation

\begin{tabular}{|c|c|c|c|c|c|}
\hline $\begin{array}{l}\text { Outcomes } \\
\text { Behavior }\end{array}$ & $\begin{array}{l}\text { Determinants } \\
\text { Knowledge/ } \\
\text { awareness }\end{array}$ & Attitudes & $\begin{array}{l}\text { Skills/ } \\
\text { Self- } \\
\text { efficacy }\end{array}$ & $\begin{array}{l}\text { Perceived } \\
\text { social } \\
\text { norms } \\
\end{array}$ & Intention \\
\hline $\begin{array}{l}\text { Equal } \\
\text { gender roles }\end{array}$ & $\begin{array}{l}\text {-In your opinion } \\
\text { what is gender } \\
\text { equality? } \\
\text {-How would you } \\
\text { define equal roles } \\
\text { between girls and } \\
\text { boys, women and } \\
\text { men in Panama? } \\
\text {-Could you } \\
\text { describe which } \\
\text { tasks, roles and } \\
\text { responsibilities } \\
\text { are assigned to } \\
\text { boys and girls, at } \\
\text { home, school and } \\
\text { personal } \\
\text { relationships? } \\
\text { (probe roles). } \\
\text {-In your opinion, } \\
\text { how can men and } \\
\text { boys contribute to } \\
\text { share tasks and } \\
\text { roles more } \\
\text { equally? (probe } \\
\text { home, } \\
\text { relationships, with } \\
\text { friends) }\end{array}$ & $\begin{array}{l}\text {-If you } \\
\text { think about } \\
\text { gender } \\
\text { equality, } \\
\text { do you } \\
\text { believe it } \\
\text { is } \\
\text { something } \\
\text { positive or } \\
\text { negative? } \\
\text { Why? } \\
\text {-Do you } \\
\text { believe } \\
\text { women } \\
\text { and men; } \\
\text { boys and } \\
\text { girls have } \\
\text { equal } \\
\text { roles? } \\
\text { (probe } \\
\text { home, } \\
\text { school, } \\
\text { daily live). } \\
\text {-Is it } \\
\text { normal for } \\
\text { women to } \\
\text { have a job } \\
\text { and } \\
\text { become } \\
\text { financially } \\
\text { in- } \\
\text { dependent? } \\
\text { that } \\
\text { positive or }\end{array}$ & $\begin{array}{l}\text {-How is } \\
\text { for you } \\
\text { to talk } \\
\text { and } \\
\text { practice } \\
\text { gender } \\
\text { equality } \\
\text { and equal } \\
\text { gender } \\
\text { roles? } \\
\text { (probe } \\
\text { with } \\
\text { parents, } \\
\text { school, } \\
\text { boy- } \\
\text { friend/ } \\
\text { girlfriend } \\
\text { or with } \\
\text { friends). }\end{array}$ & $\begin{array}{l}\text {-What do } \\
\text { your } \\
\text { friends } \\
\text { think about } \\
\text { gender } \\
\text { equality? } \\
\text {-What do } \\
\text { your } \\
\text { parents } \\
\text { think about } \\
\text { gender } \\
\text { equality? }\end{array}$ & $\begin{array}{l}\text {-Do you } \\
\text { plan in the } \\
\text { future to } \\
\text { promote } \\
\text { and } \\
\text { practice } \\
\text { gender } \\
\text { equality? } \\
\text { (probe } \\
\text { roles, } \\
\text { rights and } \\
\text { use of } \\
\text { non- } \\
\text { violence). }\end{array}$ \\
\hline
\end{tabular}




\begin{tabular}{|c|c|c|c|c|}
\hline & & $\begin{array}{l}\text { negative? } \\
\text { Why? }\end{array}$ & & \\
\hline $\begin{array}{l}\text { Equal } \\
\text { rights in } \\
\text { relation- } \\
\text { ships }\end{array}$ & $\begin{array}{l}\text {-How would you } \\
\text { define human } \\
\text { rights and } \\
\text { women's rights? } \\
\text { Do you think } \\
\text { there is any } \\
\text { difference } \\
\text { between them? } \\
\text { (probe national } \\
\text { laws, places to go } \\
\text { in case of abuses) } \\
\text {-Could you } \\
\text { describe the rights } \\
\text { of young people? } \\
\text {-How can a young } \\
\text { person defend } \\
\text { his/her rights? }\end{array}$ & $\begin{array}{l}\text {-Do you } \\
\text { think } \\
\text { women } \\
\text { and men, } \\
\text { boys and } \\
\text { girls have } \\
\text { the same } \\
\text { rights? } \\
\text {-Do you } \\
\text { think } \\
\text { young } \\
\text { people } \\
\text { should } \\
\text { defend } \\
\text { their } \\
\text { rights? } \\
\text { Why yes } \\
\text { or no? }\end{array}$ & $\begin{array}{l}\text {-Do you } \\
\text { feel you } \\
\text { can talk } \\
\text { about } \\
\text { your } \\
\text { rights } \\
\text { with your } \\
\text { parents, } \\
\text { friends } \\
\text { and } \\
\text { teachers? } \\
\text {-Do you } \\
\text { feel you } \\
\text { can } \\
\text { negotiate } \\
\text { with your } \\
\text { partner to } \\
\text { wait until } \\
\text { you are } \\
\text { prepared } \\
\text { for to } \\
\text { become a } \\
\text { parent? } \\
\text {-Do you } \\
\text { feel } \\
\text { comforta } \\
\text { ble to say } \\
\text { no and } \\
\text { report } \\
\text { any } \\
\text { abuses? }\end{array}$ & $\begin{array}{l}\text {-Do you } \\
\text { feel you } \\
\text { would be } \\
\text { supported if } \\
\text { you } \\
\text { approach } \\
\text { any } \\
\text { institution } \\
\text { for help, } \\
\text { information } \\
\text { about rights } \\
\text { or to report } \\
\text { gender } \\
\text { violence? } \\
\text { (probe } \\
\text { ombudsma } \\
\text { n, police, } \\
\text { school } \\
\text { counseling, } \\
\text { parents) }\end{array}$ \\
\hline $\begin{array}{l}\text { Non-violent } \\
\text { problem- } \\
\text { solving }\end{array}$ & $\begin{array}{l}\text {-How would you } \\
\text { define gender } \\
\text { violence? }\end{array}$ & $\begin{array}{l}\text {-What do } \\
\text { you think } \\
\text { about } \\
\text { violence } \\
\text { against } \\
\text { women } \\
\text { and girls? }\end{array}$ & $\begin{array}{l}\text {-Do you } \\
\text { feel able } \\
\text { to say } \\
\text { NO } \\
\text { against } \\
\text { any kind }\end{array}$ & $\begin{array}{l}\text {-What do } \\
\text { your } \\
\text { friends and } \\
\text { parents } \\
\text { think about }\end{array}$ \\
\hline
\end{tabular}


Chapter 4

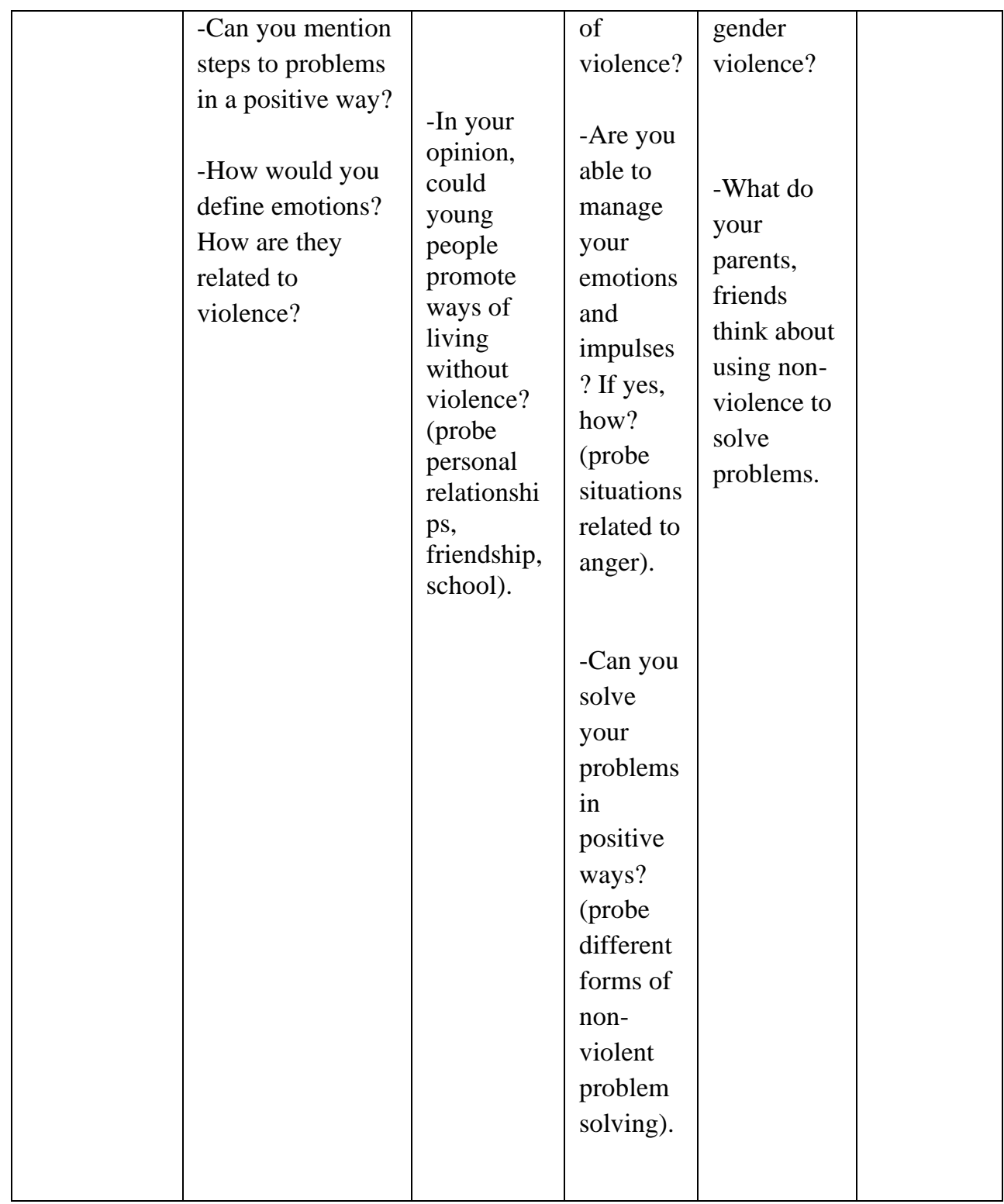





\section{CHAPTER 5}

Implementation of a school-based

Social Emotional Learning Program

in Panama: Experiences of

adolescents, teachers, and parents 


\section{Chapter 5}

\section{Abstract}

This study aims to explore the factors influencing the implementation of the pilot of a social-emotional learning program Me and My new World, which emphasizes enhancing personal capacities toward equal personal relationships and behaviors of adolescents in Panama. Since the effect assessment of the program showed improved personal capacities of adolescents that might positively influence their personal relationships and wellbeing, a deeper understanding of the conditions and factors experienced during the implementation is necessary. To this end, qualitative and quantitative methods were used for data collection: 6 in- depth interviews were carried out with teachers and parents, and 48 students participated in 12 focus group discussions. The study sought to examine completeness and fidelity, as well as exploring possible enhancing and impeding factors during a future diffusion process. The results revealed that the Me and My New World program was highly accepted by students, teachers, and parents. Enhancing factors of the implementation were the innovation aspect of the program and local needs, adaptability of lessons and acceptability of the program. Barriers influencing the implementation appeared to be the lack of time for lessons during regular curriculum, cultural transferability and organizational setting. The findings are important for improving development and implementation of social-emotional learning programs, especially oriented towards equal personal relationships and better decision making of adolescents. 


\section{Introduction}

Adolescents in Panama face multiple health challenges, such as a high rate of teenage pregnancies (adolescents between 10 and 19 years old) - making up around $30 \%$ of all pregnancies in the country (MINSA, 2017, 2018) increasing STIs and $\mathrm{HiV}$ infections, as well as gender-based violence. Worldwide, childbearing and teenage pregnancy are the main causes of death among adolescents between 15 and 19 years old (PAHO, 2015). Multiple consequences exist for teenage pregnant girls, such as dropping out of school and thereby increasing their risk of living in poverty, as well as lack of support from their partners and stigmatization of the teenage mothers and their families. In Panama, there is a clear need for educational strategies which could facilitate personal capacity development of adolescents towards healthier behaviors and better decision making in personal relationships. Panama has signed most of the international treaties and agreements aiming to increase respect and implementation of young people's sexual and reproductive rights. However, to date Comprehensive Sexuality Education (CSE) at schools is not possible, due to ongoing debate at the National Assembly level to approve legal instruments towards the empowerment of adolescents (e.g. a CSE law, covering physical, cognitive, social, and emotional aspects of sexuality; UNESCO, 2018). To reduce health risks, innovative learning strategies and methodologies offering alternative lesson plans are thus necessary. Indeed, several programs with different methodological approaches and in liaison with different stakeholders have been implemented in the country, such as government institutions (public schools), private schools, and non-governmental organizations, but these have shown mixed or very small results (Dholakia et al, 2012). Difficulties identified during the implementation process have been identified as being a 


\section{Chapter 5}

mean reason for the failure of these programs to reach their goals. These implementation issues are related to a lack of focus on youth empowerment, lack of quality control, and a hesitation or refusal of teachers to address sexuality issues in class (Dholakia et al., 2012).

The results of a needs assessment among parents, teachers, and other stakeholders in Boquete, Panama (Araúz Ledezma et al., 2020a) revealed that a more constructive and positive school-based approach to develop (inter)personal capacities of adolescents, specifically oriented towards better decision making in personal relationships, was seen as an alternative to comprehensive sexuality education programs and could offer a more holistic preparation of adolescents to face the multiple health challenges of their daily lives. Nevertheless, stakeholders also expressed their concerns regarding lack of time in current regular school curriculums, as well as personal and technical capacities of teachers to implement such programs. These insights were used to develop the Me and my New World (MANW) program based on Social Emotional Learning (SEL; Araúz Ledezma, Massar, \& Kok, under review). SEL is defined as the process of developing social emotional competencies - the knowledge, attitudes, skills, and behaviors that individuals need to make successful choices in all domains of life (CASEL, 2003). The core competencies SEL programs focus on are self-awareness, self-management, social awareness, relationships management, and responsible decision making (CASEL, 2003; Durlak et al., 2011; Elias \& Arnold, 2006; Zins et al, 2007a). 


\section{Implementation \& process evaluation}

In the last decade, research has focused not only on the content of SEL programs, but also on its implementation (Durlak et al., 2011, Durlak, 2016). Implementation relates to "what a program consists of when it is delivered in a particular setting" (Durlak \& Dupre, 2008, p. 329), and is an important element for successful, effective and high-quality interventions, and therefore should be carefully considered and planned during the development of programs (Bartholomew Eldredge et al., 2016). Thorough quality implementation based on an advanced design process might decrease the risk of program failure. A well-implemented intervention is thus fundamental for evidenced-based programs to be effective (Durlak, 2015). Main factors affecting implementation are related to fidelity, dosage, quality, responsiveness, and uniqueness of programs (Dane \& Schneider, 1998; Kelly $\&$ Perkins, 2012). These enhance understanding to which extent completeness of lessons (dosage), following program guidelines (fidelity), and receptivity of participants (engagement and the reach of content) might impact implementation and program effects. Furthermore, research evidence has added several important components which might influence the implementation process such as organizational factors, shared decisionmaking of providers, local perceived need for innovation and leadership, and internal advocates of programs (see Durlak \& Dupre, 2008; Rogers, 2003). It seems that openness for trying new approaches, advocators of programs and the acceptance of innovativeness in a specific organizational environment become of crucial importance in implementation processes. Ample research has investigated barriers and enhancing factors of program implementation. For example, lack of time, organizational constraints and lack of awareness about completeness or fidelity were identified as factors affecting negatively 


\section{Chapter 5}

the implementation of health programs (Schutte et al., 2014, Paulussen et al., 1994; van Lieshout et al., 2017). A process evaluation outlines program implementation (Patton, 2008; Rossi et al., 2004), and allows implementers to identify obstacles and select effective alternatives to correct problems, to ensure effective delivery of future interventions (Bartholomew Eldredge et al, 2016).

\section{The current research}

The MANW pilot program was implemented in one secondary school in the region of Boquete, Panama. It is a 14 lessons program carried out during a time frame of 4 months and designed for students between 12 and 15 years old, who are the target group of the intervention. Teachers are the implementers of the program. Using qualitative and quantitative tools for data collection, the aim of this study is to identify levels of fidelity and completeness, as well as to explore the enhancing and limiting factors faced during the implementation of the intervention. To this end, focus group discussions (FGD), in-depth interviews (IDI), and a self-administered questionnaire for teachers were instruments for data collection.

\section{Methods}

\section{Study setting}

The study was conducted in Boquete, Province of Chiriquí, Panama. Boquete is located $481 \mathrm{~km}$ west of Panama City, the capital of the Republic of Panama. Tourism and agriculture are the main economic activities of the region. Boquete has a level of poverty around $30.8 \%$, and $10.4 \%$ of its population 


\section{Chapter 5}

lives in extreme poverty (MEF, 2015). Teenage pregnancy (pregnant girls between 10 and 19 years old) in Boquete is high, consisting of around 30 percent of total pregnancies (MINSA, 2017, 2018). The demographics of Boquete include indigenous groups, mestizo and foreigners (mainly Americans and Europeans).

\section{Sample and Instruments}

Three teachers ( 3 females) and 48 students (25 girls and 23 boys), aged between 12 and 15 years old and belonging to middle high school. The students were part of two selected classrooms: $7^{\text {th }}$ grade (classroom 1) and $9^{\text {th }}$ grade (classroom 2). The same two classrooms' groups of students participated in the MANW pilot program implementation. Additionally, three parents ( 2 women, 1 man) agreed to participate in this study. In-depth interviews ( $\mathrm{n}=6: 3$ parents and 3 teachers), Focus Group Discussions $(\mathrm{n}=$ 48: 4 students per group) were conducted by the first author, a Panamanian national.

The research was approved by the Ministry of Education of Panama and the Ethics Review Committee Psychology and Neuroscience (ERCPN) of the Faculty of Psychology and Neuroscience, Maastricht University, The Netherlands.

\section{The program}

The program consisted of 14 lessons of 90 minutes each, delivered over the course of 4 months within the academic school year. Appendix 1 shows a brief overview of the content of lessons. 


\section{Chapter 5}

The school was selected following recommendations of the Ombudsman Office in David, Panama. A school known for its interest to participate in new programs for adolescents' personal development was approached. The school administration selected a leader teacher, who was the contact person of the intervention and in charge of recruiting the teachers and students participating in the program. Seven teachers were selected to participate in the Training of Trainers, on a voluntary basis.

\section{Training the implementers}

In order to achieve the main goal of the intervention: to develop social emotional knowledge, awareness, attitudes, and skills of students towards equal relationships among young people, teachers are the implementers of the program. Teachers receive 40 hours of training (training of trainers /ToT) before the beginning of the program. The preparation of teachers includes the use of participatory and active experience methods. These methods involve processes which directly acknowledges, welcomes, values and uses the existing knowledge and competence of those being taught. It is particularly appropriate where the subject matter under consideration touches on people's deeply held beliefs and attitudes. Furthermore, teachers receive instructions about the nature of the program and participate in workshops which encourage first, exploration of own social-emotional capacities and gender equality behaviors, second to increase their teaching capacities. Teachers carry pilot sessions during the training of trainers, in which they practice the way lessons will be carried out according to the program design and manual for trainers, as well as to ensure understanding of the topics and methodologies. These sessions provide practical experience to teachers, as well as a way to improve their self-confidence and reduce resistance on the 
program's themes. SEL can be especially powerful when adult stakeholders in children's education are actively involved in cultivating and modeling their own social and emotional competencies (Brackett et al., 2009).

In the program, special emphasis is given to the use of a learner centered approach. Teachers actively practice this kind of approach during the training of trainers to prepare them to integrate it during the activities of the lessons. Furthermore, teachers receive a program manual as support material, which is based in literature review and successful SEL Life Skills and Gender programs. The manual covers instructions for each lesson, as well as background materials. While it offers specific description of the lessons' steps, the manual can be easily adjusted by teachers to the context and specific situations related to the topics. Furthermore, the manual includes a wide preparation content for the teacher and the structure/content of lessons. This last section covers the outline of sessions, step by step process in the classroom, including objectives, expected outcomes, methodologies, time management, activities and support documents for each of the lessons.

\section{Implementation of the program/ lessons}

Using participatory and experience-based learning, the lessons start with a warm up exercise, such as "The mirror" (participants/students discover more positive qualities of themselves), then knowledge and information on the content of the specific lesson will be provided by an info-cartoon. Next step is usually a game or an interaction activity with other students, which serves as a mechanism to internalize new information and explore different opinions and scenarios. And the last step is the activity, making or doing, theme based (gender equality in this case) for positively changing attitudes and skill building. This activity is always a creative activity, for example creating 


\section{Chapter 5}

posters, a storyboard, photography, artwork, or a role-play. The sessions are rounded up by a short discussion, for reflection and positively changing attitudes. In order to increase the participation of students and reduce resistance, the program is presented as a game, using positive language and encourages intrinsic motivation of students during lessons.

\section{Data analysis}

Teachers, students and parents were informed about the research objectives and agree voluntarily to participate in the interviews and focus group discussions. A semi-structured interview protocol based on literature and the theory of Diffusion of Innovations (Rogers, 2003) guided the interviews and focus group discussions. Interviews and Focus Group Discussions lasted 30 to 90 minutes. Table 1 offers an overview of the questions asked to teachers, students, and parents during the interviews and FGD. Confidentiality and anonymity were insured to participants. They were allowed to leave the interviews of focus group discussions at any sign of distress without any further explanation. The data obtained was written recorded, as this was a preferred way of participants for reasons of anonymity.

All transcripts were translated into English by the first author, a Panamanian national; analyzed line by line, and coded thematically. Initially open coding was utilized to identify the factors influencing implementation (Thomas, 2006). Thematic content analysis resulted in several categories: Innovation and local needs, adaptability of lessons, acceptability of the program, perceptions about the manual, lack of time in regular curriculum, cultural transferability, organizational setting. After a detailed examination, three overarching themes emerged which are presented in the next sections: 


\section{Chapter 5}

Completeness \& Fidelity, Enhancing implementation factors, and Perceived barriers of implementation.

\section{Results}

\section{Theme 1: Completeness \&Fidelity}

The level of completeness was measured by the self-reported evaluation of teachers about each lesson of the program. These notes were discussed and interpreted by the teachers during the in-depth interviews. All 14 lesson of the program were implemented by teachers ensuring a high level of completeness. However, with respect to fidelity, teachers indicated that even though most of them tried to implement all lesson activities as stated in the teachers manual, around $20 \%$ of activities and exercises were adapted to fit with the regular teaching methods of teachers. For example in some lessons, rather than letting students read a short comic cartoon-characters leaflet designed for the program with a brief introduction of the topics and content of lessons, teachers utilized PowerPoint to provide structure and guide lessons, and adopted more of a lecturing style rather than increasing an open participative discussion on the topic of the lessons. Teachers expressed that they considered this way was more dynamic, and they used it to motivate students during the lessons. Likewise, role plays were the most changed activity. The reasons mentioned by teachers were that students were not used to this kind of activities, and that as a result, they perceived less participation of students. Nevertheless, teachers expressed they felt comfortable with all activities and their capacity to implement them. 


\section{Chapter 5}

"Even though that the program was very interesting and fun, due to the personal nature of lessons, students seemed very shy to use role plays and did not like much to think deep to develop their own role plays" (teacher 35-55)

"The use of role plays can be very heavy for students who are not used to it. We changed it for other activities" (teacher 35-55)

"Topics as personal capacities towards gender equality are not easy subjects for students, especially in our society. It took a lot of energy from us to motivate students on the importance of the lessons and exercises" (teacher 35-55)

"For many students is the first time they explore their own way of thinking and how to implement it in life. Perhaps they will need to research more before every lesson instead of only practicing (role plays) in the class" (teacher 35-55)

While the majority of student participants expressed during the focus group discussions that the activities of the program were interesting and that they encouraged participation, around a third of students, mostly boys, were less enthusiastic about some activities of the program, e.g. role plays.

"I liked the activities; they were fun and it made me express myself in other ways. For example, role plays are interesting, and we can play another person, who might feel different than I do" (girl, 13)

"I don't like role plays so much. It makes me feel uncomfortable and I found it difficult to do" (boy, 15) 


\section{Chapter 5}

\section{Theme 2: Enhancing implementation factors}

Innovation and local needs

All teachers expressed interest and curiosity about the nature and extent of a social-emotional learning program to promote gender equality behaviors among adolescent participants, especially due to the high rate of early pregnancies in the region, incidents of school bullying, and increasing violence in school and society:

"We need to find new ways to teach our students personal capacities to prepare them to face the different real challenges like teenage pregnancy and then drop out schools, drugs, violence in their personal relationships or at home, with friends, especially to make better decisions" (teacher, 35-55)

The program seemed to be viewed by teachers as a key component which could be combined with a parents program they were carrying at the school at the moment of the research. It was evident the motivation of the teachers to provide a more wholistic service to parents and students to avoid difficulties and promote healthier relationships.

"It is great to provide students with personal skills development, while we are carrying out seminars for parents with similar goals and objectives to improve relationships with their children and therefore improve academic achievement" (teacher 35-55)

The majority of students perceived the program as a new and positive way to learn how to relate to each other and improve personal capacity to face obstacles. They expressed that it was the first time they participated in such a program like the MANW. 


\section{Chapter 5}

"It is the first time we practice different roles and how it is to have good relationships with respect" (girl, 15)

More than the half of the students stated that the active learning and participatory nature of the program, while new, it appeared to motivate curiosity and interest on the topics of lessons.

"It was very interesting and fun. We were practicing real life cases and it gave me a sense of confidence that is possible to find positive solutions to problems" (boy, 13)

Parents expressed that once they were informed about the content of the program, their interest increased, and that they considered new learning strategies should focus more on personal capacity development of students. Interestingly, for almost all parents the first outcome expected from the program appeared to be academic achievement

"All these skills that our children are learning in the program are very necessary to get a good job and of course better relationships. But really a good job later...." (mother, 30-50)

"The reality of adolescents nowadays is so different and complex than old times, so they need a new way of thinking and personal skills to be able to face all demands in life, not only personals but professional", (father, 35-45) 


\section{Chapter 5}

Adaptability of lessons

One of the conditions during the intervention mapping process with the school and teachers was the issue of the opportunity to adapt lessons according the different situations in the class and in the context in relation to the topics ( gender equality, equal roles, rights, social emotional skills, early pregnancy, decision-making, etc.). All teachers had a positive attitude towards the program content, as they had the freedom to adjust some part if they considered appropriate.

"We tried as much as possible to follow the lesson according to the manual. The content was perfect, only some activities required changes due to class conditions (assistance, attitude of students, etc.). We felt very comfortable because we were able to modify the way of giving the lessons. Not all programs allow that" (teacher, 35-55)

"We all teachers agreed before making any changes in some activities. It was important to have consensus on such an important issue" (teacher, 35-55)

Acceptability of the program

Parents were informed by the school and researcher about the focus of the program on personal capacities development towards more respectful and equal relationships as well as to make better decisions in their lives. The high acceptability of parents was evident as all of them expressed appreciation for the program, particularly for its emphasis on exploring personal, social and emotional capacities related to academic achievement as well. They mentioned their intention to recommend the program to other parents. 


\section{Chapter 5}

"I will definitely support programs where my children can learn to be better persons, more respectful and love themselves. I will recommend it to other parents" (mother, 35-55)

"I liked the program a lot. As long as my son don't miss important regular lessons ....mathematics, science...., for me is fine this kind of programs. They can learn other important things. I will recommend it" (father 30-50)

More than half of the students perceived that the program has a logical sequence, which made it particularly easy to follow and allowed them to build knowledge and skills they could use daily in their relationships at home and school.

"It was so interesting and fun. I really felt I got to know myself better and a bit of others through the practices. It was like a game we could follow every week and use immediately after classes" (girl, 15 years)

Perceptions about the program manual

All teachers found the trainers manual very clear, easy to follow, and useful. The sequence of the manual appeared to be perceived as well easy for students.

"The manual was easy to use. The order of lessons seemed to be appealing for students. They also liked the way it was structured for every week. The topics seemed to make sense, even though that were new for them" (teacher, 35-55) 


\section{Chapter 5}

"The descriptions of lessons were clear with examples step by step. Students seemed able to connect lessons with the objectives and expected outcomes due to the easy cartoons of their manual" (teacher, $35-55)$

\section{Theme 3. Perceived implementation barriers}

Lack of time for lessons during regular curriculum

All teachers stated their constraints to find time during the regular curriculum to carry out the lessons. Flexibility of colleagues at the school to adjust their regular curriculum allowing the implementation of the MANW program lessons, appeared to be the coping mechanism used by teachers. Nevertheless, it was evident that in some cases, this situation was in detriment of carrying out other regular lessons. However, the teachers expressed that they managed through a lot of advocating and promoting a sense of ownership among colleagues in the school, as to fill up the gaps of time limitations.

"Unfortunately, we did not have extra time or a specific roster for the MANW lessons due to time limitations in regular curriculum. It took a lot of efforts to find out time with colleagues for the lessons" (teacher, 30-50)

"We are grateful that some colleagues provided us with sometime of their regular curriculum to carry out the lessons of the MANW program" (teacher, 30-50) 


\section{Chapter 5}

\section{Cultural transferability}

During the training of trainers, teachers expressed to be comfortable with the topics of the lessons on gender, identity, gender equality and social emotional capacities development among others. Likewise, the intersections of the program including gender social norms, religion, culture (machismo influence) in relation to the expected outcomes of the program seemed manageable aspects of the program. However, in the process of analyzing the implementation, teachers expressed their interest to deepen on the SEL and gender equality connections in terms of technical knowledge and skills that in turn could deepen the delivery and quality of the lessons.

"We feel fine to talk about gender equality and SEL to students and parents, but it could be helpful to become more skilled on the topics as it is not part of any teachers preparation or initial curriculum for teachers" (teacher, 35-55)

"Gender is an aspect that all of us whether as teachers, parents or persons need to get deeper knowledge and capacities, especially in the society that we live in. Being more prepare can help us to explain better also to parents the importance of equal relationships" (teacher, $35-55)$

The issue of cultural transferability appeared to be well accepted by teachers, students and parents. Teachers and parents expressed that the content and outcomes expected of the program were acceptable taking into considerations of the context conditions. Some activities adjustments of the program, as previously explained, where necessary, however, the core competences of SEL and the basic gender equality relationships focus remained on a moderate 


\section{Chapter 5}

congruent level with the local needs and promotion of new capacities and behaviors of adolescents. More than the half of students expressed that they liked the organization and content of the program. They recalled a very innovative way to approach such difficult issues of the program.

"We are very careful with programs which are designed in other societies. We are aware of our own values, and the nature and structure of this program promoted analysis and deepening on equal relationships e.g. gender roles, etc.....topics which our students really need to start becoming agents of change" (teacher, 35-55)

"Many programs made in other countries try to impose us other ways of thinking. We have to be careful at schools. However, the content of this program was delivering acceptable ideas that could help our children grow stronger and with better relationships" (father, 30-50).

"Many topics of the program were not so easy. Especially because it is not a common way of thinking over here. But it was fun and we could do and learn other things. I liked it" (boy, 14)

\section{Organizational setting}

Different factors seemed related to organizational limitations. First, assistance to the lessons was an aspect of consideration. Besides the lack of time during regular curriculum, all teachers stated that extra-curriculum activities (music band, other lessons) affected the assistance of students to the program lessons. Also, less than half of students expressed their discontent with the issue of extra activities limiting their assistance to the lessons. 


\section{Chapter 5}

"Due to the fact that students need to practice with the music band for the national celebrations in the country, a lot of time is invested on sort activities, including sports and therefore students had a lot of limitations to assist to the program lessons. More collaboration between regular curriculum, activities and schedules is necessary" (teacher 35-55)

"I decided to assist always to this program. But the school should take more consideration about when to have extracurricular activities to not affect our participation in the program" (girl, 15)

Second, organizational support from the school was to some extent limited according to teachers. The implementation of the program while supported by the school management, it seemed to face obstacles such as lack of spaces for the lessons available and extra materials support.

"During some lessons we required extra support in terms of assistance, organization of different classrooms, different schedules, also availability of projectors, copies and extra materials" (teacher, 35-55)

"Sometimes we require a bigger space for role plays or other playful activities. It would be better if we could carry out the lessons in more comfortable places". (teacher 35-55)

\section{Discussion}

The present study described the process evaluation of the MANW school pilot program implementation in Boquete, Panama. For health programs to be 
Chapter 5

effective and achieve positive outcomes, implementation involving sufficient completeness and fidelity is required (Biggs et al., 2008; Durlak \& Dupree, 2008; Kalafat et al., 2007). The aim of this study was to identify the levels of fidelity and completeness, as well as to explore enhancing and limiting factors faced during the implementation of the intervention.

First, completeness and fidelity analysis provided insight into the extent and reasoning of trainers in their decision to implement or adjust lessons of the program. While a high level of completeness was revealed, changes in activities of the manual (around 20\%) could be explained by an insufficient awareness regarding the importance of participatory methods such as role-plays, and its implications towards creating new behavioral experiences through saturation of social-emotional skills development practices through lessons. Furthermore, replacing activities in the manual with methodologies they were more familiar with, e.g., using a more lecturing style and a structured way to guide lessons might reflect some hesitation towards abandoning the regular curricular approach to learning. Several studies have shown that a lack of comprehension by teachers of the theoretical background for behavioral changes can reduce positive outcomes of health programs (Buston et al., 2002; Shepherd et al., 2014). Likewise, for some students, activities such as role plays seemed unfamiliar and difficult, which could be explained since this is a less experienced activity during their regular school curriculum.

Second, the enhancing and limiting determinants of the implementation where examined. The purpose of this study was to deepen the understanding of the contextual factors and conditions experienced during the implementation, since the effect assessment of the pilot MANW program 


\section{Chapter 5}

(Araúz Ledezma et al., 2020b), revealed improved personal capacities of adolescents, which might influence their personal relationships and wellbeing. The innovative nature of the program seems to be a basic factor positively influencing the implementation, according to all participants. One of the reasons appears to be the context, as the need for strategies to address multiple health risk factors affecting adolescents in Panama requires new learning strategies, which consider the possibilities and limitations of the context. This finding is in line with research evidence highlighting the highly likely interactions in the ecological framework between intervention's expected outcomes and the influence of local needs (Durlak \& Dupre, 2008). The effects assessment of the MANW program (Araúz Ledezma et al., 2020b) showed the potentialities of SEL in the absence of CSE in Panama, using a culturally sensitive approach.

Further, the results of the current research indicated a high level of acceptability of the program by parents, teachers and students. In the case of parents, it seems that the content and the outcomes of the program appealed to a sense of providing capacities (social-emotional) that students are not exposed to in the regular curriculum. Parents indicated they thought the capacities-based focus of the lessons would add to a more holistic preparation of students to make better decisions in their personal relationships and academic performance. Thus, the dual emphasis on academic achievement and better capacities to improve relationships and avoid health risks seems to be a viable way to approach parents in future interventions. This finding is also in line with recent evidence in Panama and other low and middle income countries that showed high acceptability by parents of programs reducing health risk behaviors of their children (Baumann et al., 2019; Mejia et al, 2015). 
While previous researchers (e.g., Yankah \& Aggleton, 2018) might argue that SEL programs (life skills development) might not have a large impact on reducing risk behaviors of young people, several factors related to careful implementation - such as frequency of lessons, fidelity, dosage of lessons several other studies have shown that effective personal capacity development programs towards healthy behavior can be a sound investment for schools (Durlak et al, 2011; James et al., 2006; Knapp et al., 2011). Indeed, the opportunity to adapt program lessons to the context appeared to be a motivating factor for teachers to positively receive the program and develop ownership during the implementation. Teachers' decisions to adjust lessons were related mainly to motivation activities and active learning applications (e.g. role plays). They perceived this kind of activities as sometimes difficult for children, a common finding in previous research (Vanwesenbeeck et al., 2016). This finding is congruent with research evidence signaling that program methodologies might not be consistent with (traditional) pedagogical approaches or styles (Wigelsworth et al., 2016), highlighting the need for adaptation. Nevertheless, overall the content and materials of the lessons were found useful and clear, by students and teachers.

Challenges experienced during the implementation were generally indicative of a variety of organizational and individual factors. First, a prominent finding is the issue of cultural transferability. SEL has been mainly developed and implemented in developed countries, through programs emphasizing discussions among students of relationships, emotions, and behaviors (Graetz et al., 2008; Holsen et al., 2008; Lendrum et al., 2013; Jones et al, 2010). In the MANW program, these competences appeared to be well accepted by teachers, parents and students participants of this study. This finding is in line with evidence regarding providers' and parents' acceptance 


\section{Chapter 5}

of program promoting healthy behavior of children and adolescents in Panama (Mejia et al., 2015). Interestingly, the gender equality component of the program, developed with high cultural sensitivity, seemed to be highly accepted not only by teachers and parents, but especially by students. The connection between personal development and relationships with friends, classmates, and family appeared to forge a positive climate to consider new ways of thinking and acting.

Further, gender beliefs of teachers seemed to converge with the objectives and content of the MANW program. Teachers showed comfort during the training of the trainer (initial preparation of teachers), when exploring current gender norms, machismo culture, and beliefs in Panama. However, for some teachers, more skills are needed in terms of transferring new knowledge, attitudes, and skills on gender equality not only during the program lessons, but also through the regular curriculum. This finding highlights the need for deeper gender equality knowledge on how to deal with the potential resistance to the concepts central to the program, and its connections with personal capacities development. This issue has been acknowledged in previous studies (Oberle et al., 2016) which stress the diffusion of the SEL competencies throughout policies, structures, leadership and curriculums at school, to promote all-round healthy behavior (Weissberg et al., 2015; Durlak et al., 2011). Further, existing research shows how teachers' beliefs play an important role during this diffusion process, and that these are intertwined with delivery, class management, and experiences in the classroom (Holzberger et al, 2014). Notwithstanding, to the best of our knowledge, evidence regarding the relation between SEL beliefs of teachers and diffusion of SEL gender equality promotion programs is almost nonexistent. 
Chapter 5

Lack of time in regular curriculum to allocate the program lessons seems to be a great barrier faced by teachers. It appeared that the effective management of the leader teacher facilitated time acquisition through multiple other teachers to include the program during their regular curriculum time. This is in line with previous research showing the importance of support (e.g. colleagues, school management, technical) at schools during implementation (Schutte et al., 2014; Paulussen et al., 1994). Nevertheless, it also derived often classroom switching, which generated less organizational management of the program and some confusion among teachers and students. This finding is in line with the common assumption that these types of programs oriented to social-emotional capacity development are not integral part of current educational systems.

Time constraints and organizational support seem almost universal barriers during program implementations, as several research evidence show (Al Iryani et al., 2013; Bessems et al., 2014; van Lieshout et al., 2017). Extracurricular activities (e.g. music band practices) also generated difficulties to comply with assistance of all participants during the lessons. Further, some studies have found that social-emotional program implementation while on its own purpose should create more harmonious classroom environment, it could backlash if providers (e.g. teachers) experience more stressful situations, due to the lack of favorable conditions ( organizational or skills related) for the implementation (Banerjee et al., 2014; Collie et al., 2012). In terms of future interventions, the lack of time to implement lessons seems a high risk to continuity of such programs. First due to the low importance still faced for personal capacities development programs and second due to an absence of structural space during regular curriculum. A deeper view and research are required on these issues to avoid 


\section{Chapter 5}

suboptimal implementation and increase the potentialities to achieve positive outcomes through effective implementation.

\section{Conclusion}

The present study has shown the multiple enhancing factors and limiting barriers experienced during the implementation of the MANW program in Panama. The results suggests that SEL program implementation draws a distinction as it provides a new framework to address highly contextual issues, such as reducing health risk of early pregnancies and STI infection, through a systemic structure of social-emotional capacities development, encouraging better decision making and personal relationship among adolescents. While the innovative character of the intervention offers opportunities to infuse a transported learning approach, the findings show a high level of acceptability among providers and beneficiaries, which might increase the potentialities of future intervention at national level. Nevertheless, multiple aspects such as school-wide SEL approach, including organizational support, and especially higher technical preparations on gender equality and SEL beliefs of providers seem to constitute the main focus of attention during the diffusion process of SEL and gender equality programs. 


\section{Chapter 5}

\section{Limitations}

This study presents a few limitations. First, the small sample of the research prevent us to generalize the results to a wider population within the country. Second, the enhancing factors and barriers identified represent the conditions experienced at the school where this program was implemented. Different context conditions, not only of the country of implementation but the school climate, motivation of children and implementers, as well as the acceptability of parents must be taken in consideration in future programing of interventions, especially on the innovator factor of this program: gender equality issues to the promotion of healthier behaviors among adolescents. This study findings help to lay the foundation for further research on the impact of SEL implementation on Gender equality and SEL beliefs of teachers, as to increase understanding of its impact on effective implementations and results of interventions. 


\section{Chapter 5}

Table 1. Process Evaluation Interview Protocol/ MANW program/ Questions Interviews and FGD.

\begin{tabular}{|c|c|c|}
\hline Participants & Questions & Instrument \\
\hline Teachers & $\begin{array}{l}\text { 1. What is your opinion about the } \\
\text { MANW program? (probe } \\
\text { innovation, needs, acceptability, } \\
\text { cultural transferability). } \\
\text { 2. What are the major obstacles and } \\
\text { limitations you have faced during } \\
\text { the implementation of this } \\
\text { program? (probe knowledge, } \\
\text { resources, time, self-efficacy, } \\
\text { support from the administration and } \\
\text { other colleagues, own values and } \\
\text { beliefs, gender social norms and } \\
\text { cultural context). } \\
\text { What do you think about the } \\
\text { manual? (probe positive and } \\
\text { negative aspects methodologies, } \\
\text { activities) } \\
\text { Did you follow the manual in all } \\
\text { lessons? If yes, how was your } \\
\text { experience with it? If not, why not? } \\
\text { (probe adaptability). } \\
\text { Did you implement all lessons of } \\
\text { the program? If not, why? } \\
\text { What do you think about teaching } \\
\text { social emotional skills? } \\
\text { What can you suggest to improve } \\
\text { the implementation of the program? } \\
\text { (probe content of program, } \\
\text { resources, personal and technical } \\
\text { capacities, time available). }\end{array}$ & $\begin{array}{l}\text { In depth- } \\
\text { interviews (3) } \\
\text { all females. }\end{array}$ \\
\hline Students & $\begin{array}{l}\text { 1. What do you think about the } \\
\text { program? (probe acceptability, } \\
\text { participatory methodology). } \\
\text { 2. Did you attend all lessons of the } \\
\text { program? } \\
\text { 3. How was your experience } \\
\text { participating in this program? } \\
\text { (probe easy or difficult to follow, } \\
\text { easy or difficult to apply in daily } \\
\text { lives) }\end{array}$ & $\begin{array}{l}12 \text { Focus } \\
\text { group } \\
\text { discussions (4 } \\
\text { students per } \\
\text { group/ mixed } \\
\text { boys and } \\
\text { girls). }\end{array}$ \\
\hline
\end{tabular}


Chapter 5

\begin{tabular}{|c|c|c|c|}
\hline & $\begin{array}{l}4 . \\
5 . \\
6 . \\
7 . \\
7 . \\
9 .\end{array}$ & $\begin{array}{l}\text { What do you consider positive and } \\
\text { negative aspects of the program? } \\
\text { (probe time, content, participatory } \\
\text { methodology) } \\
\text { What do you think about the way } \\
\text { teachers carried out the lessons } \\
\text { (probe differences with other } \\
\text { lessons, participatory } \\
\text { methodology)? } \\
\text { Do you consider that this kind of } \\
\text { programs are necessary at schools? } \\
\text { Why yes or not } \\
\text { Do you think some of your friends, } \\
\text { brothers or sisters need this type of } \\
\text { program? If yes, why? } \\
\text { Would you recommend this } \\
\text { program to other students, friends, } \\
\text { brothers or sisters? If yes, why? } \\
\text { What are your recommendations to } \\
\text { improve the program? }\end{array}$ & \\
\hline Parents & $\begin{array}{l}1 . \\
2 . \\
3 . \\
4 . \\
5 . \\
5 .\end{array}$ & $\begin{array}{l}\text { What do you think about the } \\
\text { program your son or daughter } \\
\text { participated? Was it positive or } \\
\text { negative in your opinion? } \\
\text { Can you explain in a few words } \\
\text { what this program was about? } \\
\text { Do you think this kind of programs } \\
\text { are necessary for young people? } \\
\text { Why? } \\
\text { Would you allow her/ him to } \\
\text { participate again in a similar } \\
\text { program? } \\
\text { Do you believe the educational } \\
\text { system could contribute to change } \\
\text { gender norms and relations in } \\
\text { Panama through this type of } \\
\text { programs? } \\
\text { What are your recommendations to } \\
\text { improve the program for future } \\
\text { interventions? }\end{array}$ & $\begin{array}{l}\text { In depth- } \\
\text { interviews ( } 3) \\
(2 \text { women and } \\
1 \text { man). }\end{array}$ \\
\hline
\end{tabular}





\section{CHAPTER 6}

\section{General Discussion}




\section{Chapter 6}

\section{Overview}

In Panama, there currently is an absence of Comprehensive Sexuality Education (CSE) due to an ongoing debate regarding how to approach adolescent's health problems, such as high rate of teenage pregnancies, STI \& HIV infections, and violence. Furthermore, there is insufficient scientific evidence in the country on effective educational alternatives which could holistically empower adolescents towards better decision making within personal and interpersonal relationships and equality behaviors. Likewise, there is a dearth of research in Panama about the views, perceptions, attitudes and beliefs of crucial stakeholders in society - particularly government, teachers, parents, health promotion officers, academics and religious groupson the factors they consider to influence adolescents' behaviors.

Therefore, the aim of this project is twofold. First, it intended to fill this gap by gathering evidence- based data related to the multiple behavioral and environmental factors affecting the decision-making capacities of adolescents from the perspective of various stakeholders in society. Second, the research project aimed at examining the impact of Social Emotional Learning (SEL) as a potential educational strategy, which could forge behavioral changes towards the promotion of equal personal relationships among adolescents in Panama. In the previous chapters, qualitative studies were conducted to explore the perspectives of main decision-makers in adolescents' health related issues in the country, as well as the impact of the Me and My New World (MANW) SEL pilot program on adolescents' behaviors. Lastly, an evaluation of the implementation process, which focused on the enhancing and limiting factors influencing the health 
intervention was carried out. Before elaborating on the implications, limitations and suggestions for future research, I will briefly summarize the findings.

\section{Summary of findings}

\section{Chapter 2}

The study presented in this chapter aimed to explore the perceptions and attitudes of different societal actors, including parents, teachers, government, religious group members, health promotion specialists, academics, and NGO representatives. In in-depth interviews, they were questioned about behavioral and environmental factors influencing adolescents' decisionmaking within personal and interpersonal relationships. Adolescents in Panama face multiple challenges to their health. In the absence of Comprehensive Sexuality Education (CSE) by law in the country, and since there is a dearth of research in Panama about the views, perceptions, attitudes and beliefs of other crucial stakeholders- particularly teachers, parents and health promotion officers, this study present the opinions of these implementers (of both the law and any CSE efforts). The results of the study offered a view on five central topics: perceptions towards gender roles and equality, adolescents' love (sexual) relationships, capacity needs regarding prevention of risk behaviors and the role of education, comprehensive sexuality education in schools and the potentiality of SEL in the education system. The findings strengthen scientific evidence on perceptions and views of stakeholders about these topics in a conservative context (cultural and legally) such as in Panama. Moreover, the findings of this study suggest SEL was seen as an educational strategy which could potentially enhance 


\section{Chapter 6}

capacities of adolescents towards more healthier behaviors in personal relationships.

\section{Chapter 3}

This chapter describes the process of development and planning surrounding the implementation and evaluation of the SEL pilot program MANW in Panama, based on the Intervention Mapping (IM) protocol. The six steps process of the IM (Bartholomew Eldredge et al., 2016), which include a logic model of the problem (step 1), program outcomes and objectives (step 2), program design (step 3), program production (step 4), program implementation plan (step 5) and evaluation plan (step 6), provide a framework to analyze the multiple factors influencing the development and implementation of a SEL program to the promotion of equal relationships among adolescents. Based on the problem definition and needs assessment (chapter 2) and following the Intervention Mapping (IM) protocol steps, the objectives and outcomes of the program where established (IM step 2). Equal roles, equal rights in relationships and nonviolent problem solving were selected as behavioral outcomes of the intervention. Further, a detailed literature review of theory-based methods for behavioral change encouraged the selection of appropriate practical applications for the program (IM step 3) within an ecological approach. Moreover, the chapter shows the program content development (IM step 4), highlighting the integration of themes, sequence, material inputs from implementers and beneficiaries of the program. Then the program implementation plan was developed (IM step 5), taking into considerations the needs of beneficiaries, implementers and different strategies required to fulfill those, including sustainability in a real 
time context (Fernandez et al., 2019). Finally, the evaluation planning (IM step 6) describes a framework to assess the effectiveness of the program on the target group, as well as a process implementation evaluation, assessing the fidelity and completeness level, as well as examining the enhancing and limiting factors experienced by implementers of the intervention.

\section{Chapter 4}

The effectiveness evaluation presented in this chapter, examines to what the Me and My New World (MANW) provides a context in which students can learn to recognize and manage emotions, to care about others and themselves, make responsible decisions, develop social awareness, and could facilitate behavioral changes of young people towards more gender equality behaviors. We conducted in depth, semi-structured interviews with adolescents' participants of the SEL pilot program MANW, before and after the intervention. The interview protocol was based on the program's objectives. Interviews lasted from 20-30 minutes at pre-intervention, and about 45 minutes at post- intervention. Post-intervention interviews were carried out one week after the last lesson was completed. Confidentiality and anonymity were ensured to participants. The findings suggest that SEL-based lessons might broaden views on how young people experience the process of exploring identity formation, how assumptions of inequalities can be recreated through the lessons, and that SEL can emphasize the significance of choice and decision making in interpersonal relationships. Furthermore, the findings show the perspectives, needs and limitations highlighted by the adolescents living in a conservative context, which are highly valuable for 


\section{Chapter 6}

improving future learning strategies towards healthier relationships, especially to increase their well-being and quality of life.

\section{Chapter 5}

The findings of the qualitative study presented in this chapter explore the implementation process of the MANW pilot program in Panama, to identify the levels of fidelity and completeness during the implementation. Likewise, the study assesses the conditions, enhancing and limiting factors experienced by teachers, students and parents during the implementation. The findings reveal that the Me and My New World program was highly accepted by students, teachers, and parents. Among the factors that could positively enhance future implementation were the innovation aspect of the program and local needs, adaptability of lessons and acceptability of the program. Barriers influencing the implementation appeared to be the lack of time for lessons during regular curriculum, cultural transferability and organizational setting. The findings are important for improving development and implementation of social-emotional learning programs, especially oriented towards equal personal relationships and better decision making of adolescents.

\section{Implications}

\section{Facilitating and inhibiting factors}

The research project started with a problem and needs assessment process (Chapter 2), based on the Intervention Mapping (IM) protocol (Bartholomew Eldredge et al, 2016), which was used throughout the whole research project 


\section{Chapter 6}

to develop, implement and evaluate the MANW pilot program. The needs assessment allowed to pose the main question about the specific health and social problem affecting the well-being of adolescents in Panama (Ruiter et $a l, 2013)$. By engaging in a systematic IM process, the characteristics of the context, population, and setting were identified, and allowed us to arrive at a clear description and logic model of the problem. The needs assessment revealed the importance of understanding beliefs and attitudes of multiple stakeholders in Panama as a part of an ecological system influencing behaviors of adolescents. Previous research has shown the relevance of identifying the actors and settings which could be impacted by, or have an impact on, a specific problem (Foster Fishman et al, 2007).

For the current research, this means that we should take an ecological perspective if we talk about relationships: Relationships among women and men, boys and girls are guided by the socially constructed roles and responsibilities ascribed to women and men in a given society. These roles, responsibilities, and relations between women and men are defined and constantly influenced by social institutions, which are defined as formal and informal laws, social norms, attitudes, and practices that shape and limit the decisions, choices and behaviors of groups, communities and individuals (Cerise \& Francavilla, 2012; Jütting et al., 2008; North, 1990). The findings of this research (chapter 2) show an evident lack of awareness of multistakeholders regarding how women, men, boys and girls are influenced by the roles and responsibilities ascribed to them in Panamanian society. The findings contribute to literature as highlighting the need for interventions with a basic focus on the identity formation of individuals from both genders, which on the long term could transform the unequal social norms which keep being passed on from one generation to the other. 


\section{Chapter 6}

Specifically, we found that stakeholders such as parents, teachers, religious group members, and governmental representatives voiced insufficient knowledge and understanding of basic conceptual assumptions of what gender equality entails. Likewise, at baseline level of the intervention, the findings show that adolescent participants in this research (see chapter 3 ), conceptualize the self and the influence of a socially developed identity as an abstract concept, and believed this conceptualization would have no influence on their decisions, choices, and behaviors. Interestingly however, in contrast to the observations by adolescents, the structural patriarchal system of Panamanian society was observed by many stakeholders as a crucial factor persuading the lives and well-being of adolescents in the country. They also noted that this system has a strong impact on the ongoing national debate regarding the acceptance of Comprehensive Sexuality Education (CSE) by law in the Panamanian school curriculum. This finding is in line with recent research showing similar results in different Latin American countries (Fajardo Heyward, 2016; Giannela et al, 2017). Furthermore, our findings reveal that support for family values and religious beliefs as guiding principles are strongly rooted in the beliefs and attitudes of the majority of stakeholders (chapter 2), which corroborates the importance of gathering the opinions and experiences of all involved contextual actors when one is in the process of health promotion program planning (Bartholomew Eldredge et al., 2016).

One noteworthy finding in the current project concerns sensitive issues such as the perceived dual roles attached to teenage mothers within patriarchal societies. On one side these girls are expected to show submissive behaviors, on the other side, the high levels of teenage pregnancies in the country highlight the increasing conditions of girls assuming roles as adult 
Chapter 6

mothers - mostly without a partner - 'forcing' them to show assertive and self-reliant behaviors. This duality may cause these girls to feel confused by the dichotomy between following gendered social norms for girls and assuming adult women's roles as mothers. Likewise, our findings reveal a certain duality for boys in Panama as well: the hitherto masculinity construct that portrays boys and men as strong ('macho') and indifferent to women's needs, might be contrasted with adolescent boys experiencing discomfort and sadness about the absence of a father in their lives, and consequently not wishing the same future for their own children through early pregnancies and all its consequences(see chapter 3).

In the absence of CSE in the country, the findings of this dissertation provide insights on the beliefs and expectations of different multistakeholders, as well as potential strategies which explore new perspectives to address teenage pregnancies and other health problems (chapter 2). It seems that opposition to this type of education (CSE) remains grounded in the assumption of a risk to decrease or eradicate 'family values'. Nevertheless, while rejection of a CSE law in the country by some stakeholders was evident in the study results, the majority of them considered that a more constructive approach to build up trust and acceptance of CSE is needed, because they also acknowledge the needs of adolescents in society. More cooperation, and especially a positive attitude across sectors (e.g. parents, teachers, government, religious institutions, and academics) was deemed crucial to increase the possibilities of adoption of a CSE in the country.

Furthermore, the content of CSE programs, and the capacities of teachers to carry out such a curriculum, seemed a concern for all stakeholders. 


\section{Chapter 6}

Our findings suggest that knowledge and awareness of what CSE entails and a broader spectrum of its content than is currently offered in could be a start point to a more proactive dialogue and consensus among stakeholders. That is, the content should shift from a focus solely on the biology of reproduction and prevention methods, to also include social emotional aspects of sexuality and capacities of adolescents to face such life-changing decisions regarding their health and well-being. In addition to collaboration with actors such as the catholic church and conservative groups, promoting cultural sensitivity and enhancing ownership of the lesson program seems as a viable way to direct the process towards a more progressive and contextually accepted CSE in the country. Although religious teaching might remain a prominent feature of the school system in Panama, participatory processes within the community and with relevant actors could benefit progress towards strategies aimed at increasing adolescents' (sexual) health. Similar approaches have been proven successful in countries with similar conservative conditions ( $\mathrm{Al}$ Irani et al., 2011).

The findings in this dissertation highlight education as a common ground for the stakeholders, which they see as a platform towards implementing strategies enhancing the personal capacities of adolescents, to prevent sexual risky behavior and improve their choices and decision making in personal relationships. The results of this project suggest that interpersonal skills development seems to be a viable alternative in the absence of CSE, especially in a conservative setting as Panama. The findings suggest personal capacities such as better communication skills, respect for themselves and others, teamwork, and problem solving without violence as increasingly necessary to prepare adolescents towards better decision making in personal relationships and academic achievement. Nevertheless, the findings also 
Chapter 6

revealed that the capacity needs of teachers, lack of time during regular curriculum, and lack of financial resources were identified as potential barriers for the adoption and implementation of this kind of educational strategies. The findings also show that while the role of education was perceived as important, school influence on adolescents' personal capacity development was also seen as supplementary: Stakeholders agreed that family remains the main actor towards the development of moral values of adolescents in Panama. This thus suggests the necessity of a holistic approach for such programs, highlighting the personal capacity development of parents and teachers to work in unison towards increased effectiveness level of future interventions.

\section{Intervention development and implementation}

This project, and especially the development and implementation (and evaluation) of MANW described in Chapters 3-5, highlights the importance of the use of Intervention Mapping (IM) to design, implement and evaluate interventions. In the case of this research project, IM played a crucial role, as the process of intervention development in a conservative context demands extra focus on sensitive aspects, such as culture, religious beliefs, content limitations, type of applications, and acceptability of programs. IM allows for a systematic theory- and evidence-based design of health promotion programs (Bartholomew Eldredge et al., 2016), and here, its relevance lies in the considerations of the specific context of Panama.

First, relevant theories were filtered, and empirical evidence and practical experiences were gathered to inform the process of developing an intervention adjusted to reality (Fernandez et al., 2019) - meaning considerations of cultural sensitivity, lack of CSE and law limitations to 


\section{Chapter 6}

discuss adolescents love relationships, gender, identity, gender equality, gender roles, and the use of nonviolence. The findings demonstrate the valuable contribution of a careful design during planning and development of the intervention following the steps of IM protocol. However, it is noteworthy that IM is time-consuming due to its process of systematically executing every step of the intervention development process. Moreover, the difficulties to handle such contested sensitive topics complicated matters in the current project, for example in the process of describing matrices of changes objectives. A consideration of the required time needed and potential sensitive topics conflicts that may arise during the IM process, must be acknowledged by planners prior any new intervention development such as the MANW program.

The findings of chapter 3 also show the importance of considering the current learning pedagogies in the local context. This recognition facilitates the selection of more accurate practical applications considering the current methodologies used in classrooms, although there is no guarantee that all selected applications will work as expected during the IM planning process. Importantly, the findings of the study (chapter 3) demonstrate that a constructive and positive approach involving all actors of interventions might open a space to discuss sensitive issues and reach an understanding of the priorities in terms of the content and the learning methodologies that could be explored towards more effective health promotion intervention development. Likewise, the systematic process of IM allowed for a reflection on the cultural transferability of a SEL program in a developing and conservative country, especially the equal relationships promotion component. The findings also contribute to literature on SEL and gender equality program development and implementation. Furthermore, the inclusion of the evolving capabilities 
concept in program development (chapter 3 and 4), provided a wider multidisciplinary view of potential personal capacities required by adolescents towards better decision-making in personal relationships, considering their agency and power relations limitations from a capability perspective.

The findings of chapter 4 show the moderate results of the MANW pilot program in a middle high school in Boquete, Panama. The results suggest that a focus on 'personal capacity development' of adolescents, as the objective of this program, could be an alternative path for the discussion of sensitive issues with young people regarding their health, risk factors and decision making in personal relationships. The findings also demonstrate that education seems to remain a relevant avenue to offer spaces for new experiences of adolescents. Their process of discovering their own identities, self-knowledge, self-management and self-esteem could encourage new beliefs, attitudes and skills in relation to equal and healthier personal relationships. The effectiveness evaluation of the program (chapter 4) revealed an increased awareness of the participants on identity formation, gender, gender roles and equality, including the link to potential improvement of the quality of life in economic terms and well-being. Furthermore, the findings show that a high percentage of girls had increased capacities such as self-esteem, better decision-making and negotiation, as well as their awareness of teenage pregnancies' burden. Likewise, the findings evidence a more open and changed perspective of adolescents to consider new ways to relate to each other after the intervention, which can be a start point to consider in future interventions, not only at schools but also within the family sphere. 


\section{Chapter 6}

The fact that adolescent participants of the MANW program showed progress toward more social-emotional skills and their intention to use it in personal relationships, as well as increased awareness regarding gender equality concepts and its implications, many researchers could argue its translation to behavioral changes. However, the findings suggest that these type of programs could allow explorations of masculinity and femininity constructs and the possibility of developing new knowledge, awareness, attitudes and skills based on social emotional development, which in turn could increase self-management (emotions), negotiation, and better communication. The findings (chapter 4) also suggest that education strategies as MANW - which include a consideration of the self, personal and social identities, attitudes and beliefs about the self and others - might be a first step towards deconstruction of current social norms in favor of gender inequalities, which have an impact on decision making and choices of adolescents in personal relationships (love, friendship and at home/family). Interestingly, boys seemed more selfconfident (e.g. to be able to negotiate and avoid violence) than girls after the intervention, highlighting perhaps the persistence of unequal gender norms in their environments, which often encourage boys to be more strong and effective, which in turn guides their behaviors and beliefs in the context of interpersonal relationships. This is an important aspect for intervention planning consideration, as to increase methods and applications promoting higher self-confident and negotiation skills levels of girls.

The findings of the process evaluation of the MANW program (Chapter 5) reveal a relatively high level of completeness which can be associated with the motivation of school program leader to promote this kind of programs at the school. Fidelity measurement reflected some changes of activities prescribed in the manual (around 20\%), which can perhaps be 
Chapter 6

explained by insufficient awareness among teachers regarding the importance of using participatory methods (e.g. role plays) to increase the chances of behavioral changes. The findings are in line with evidence highlighting that increasing effectiveness of health promotion programs requires sufficient levels of fidelity and completeness. Moreover, innovation seemed to be one of the most impactful factors associated with acceptance of the MANW program. One of the reasons seemed to be the current conditions of the educational system in Panama requiring new learning strategies to address adolescents' risks behaviors.

Further, the perceived local need and the consideration of the context were found to be enhancing factors during implementation and are in line with research showing its importance to increase intervention outcomes (Durlak \& Dupre, 2008). The nature of the program was highly accepted by parents, teachers and students. The findings show that the content was not considered highly conflicting with current conservative religious beliefs about CSE and family values. Implementation relates to "what a program consists of when it is delivered in a particular setting" (Durlak \& Dupre, 2008, p. 329), and is an important element for successful, effective and high-quality interventions. Therefore, it should be carefully considered and planned during the development of programs (Bartholomew Eldredge et al., 2016). Although, barriers were observed to influence the optimal implementation of the program, the findings suggest that SEL program implementation draws a distinction as it provides a new framework to address highly contextual issues in conservative contexts, which could provide innovative strategies to promote adolescents healthier behavior and increase their well-being. 


\section{Chapter 6}

Recent research has shown that personal capacity development programs such as 'life skills' might be a useful strategy to introduce highly sensitive topics in conservative contexts (Al Iryani et al., 2011). Likewise, the dual emphasis of the MANW program on academic achievement and improvement of personal capacities of adolescents seemed a viable strategy to approach parents in future intervention. Further, the findings show that adaptability of lessons, if considered necessary by implementers, enhanced their ownership, as it ensured contextual compatibility. This finding is in line with current literature highlighting the importance of program adjustment as an essential part towards effective implementation (Durlak \& Dupre, 2008).

Since the MANW program is an innovative SEL-based program with an emphasis on the promotion of gender equal behaviors, the beliefs of teachers on gender issues are of paramount importance, as it could influence knowledge transfer and learning processes during the implementation. The findings reveal that even if implementers consider that their knowledge and capacity to discuss gender are sufficient at the preparation level (Training of Trainers), it also become obvious that during the implementation process, comprehensive capacities are needed regarding concepts such as gender, identity, equal roles, and opportunities. These apply specifically to the link between social emotional capacity development and its potential to promote more equal behaviors and better decision making in personal relationships (chapter 5). This finding is noteworthy, as it contributes to literature showing that the beliefs of teachers regarding SEL core competences development appear to have great impact on implementation, as well as the perceived effectiveness and development of supplementary exercises (Brackett et al., 2012; Collie et al., 2015a, 2015b; Ransford et al., 2009; Zinsser et al., 2014). The findings also suggest that sufficient gender equality knowledge and 
capacities of teachers could improve delivery and quality of lessons in future interventions.

Lack of time was considered one of the main limitations encountered by teachers during the implementation process. Effective management by the implementation leader (a teacher) facilitated that teachers could free up time for the intervention in the regular curriculum. Research has shown the importance of support of other actors during implementation (Schutte et al., 2014; Paulussen et al., 1994). However, the use of other curriculums' hours, in the absence of time for the program implementation, could decline academic achievement and learning processes of students and teachers. It could also decrease acceptability of future program implementation by parents. Therefore, time limitations become a potential barrier for implementation that should be prioritized and addressed by intervention planners. Furthermore, organizational support, including availability of comfortable places (classrooms) and required materials, were found to be highly important for effective implementation. The absence of these conditions could backlash if implementers experience more stressful situations during implementation. Recent findings offer evidence on these issues (Collie et al., 2012; Banerjee et al., 2014; Lendrum et al., 2013; Meyers et al., 2012). In this line, the findings highlight the need to elevate the importance of personal capacity development of adolescents through socialemotional school programs /curriculum, which could increase of time allocation and resources, reducing the risk of sub-optimal implementation. The MANW program pilot implementation showed that this type of educational strategies might be a potential path to promote health behaviors among adolescents through future similar interventions in Panama. 


\section{Chapter 6}

\section{Strengths and limitations}

The studies presented in this dissertation have several strengths. First, since the majority of studies on the effectiveness of Social Emotional Learning show scientific evidence of programs carried out in developing countries (Durlak et al., 2011), a sample of Panamanian adolescents and teachers (chapter 4 and 5), allows to extend literature. Specifically, in this project we focused on SEL programs towards the promotion of gender equal behaviors among adolescents in a developing country. Second, in the absence of CSE in a conservative country like Panama, the findings of this research help towards filling a gap between research, policy, and practice. The results of these studies can enhance future dialogue among stakeholders oriented to health promotion intervention development for adolescents relying on theory and evidence, which could increase the effectiveness level and impact of future interventions in the country and settings with similar conditions. Third, the use of directed content analysis approach (Hsieh \& Shannon, 2005) for data analysis, allowed for a categorization based on data derived from theory and relevant previous findings. Furthermore, the use of an iterative coding process (Mayring, 2010), ensured that preliminary and inductively arrived coding categories of the studies, were a reliable and accurate representation of the data content. Fourth, the use of Intervention Mapping as a guiding tool directing every step of the research process, assured a systematic and structural planning and intervention development \& evaluation process taking into considerations the ecological setting to address the health problem (Bartholomew Eldredge et al., 2016). Fifth, the use of ample multidisciplinary literature including The Theory of Planned Behavior (Ajzen, 2015), the Social 


\section{Chapter 6}

Cognitive Theory (Kelder et al., 2015), Health Belief Model (Skinner et al., 2015) and the Capabilities Approach and evolving capabilities concept (Ballet et al., 2011) to provide structure, and support planning and program development, yielded a relevant combination of research body broadening the spectrum of covering multiple factors influencing the proximal antecedents of behavior (e.g. attitudes, social norms, intention) and promoting ultimately behavioral changes.

As with any study, potential limitations should be acknowledged. First, the findings of qualitative studies many not be generalizable. In this case, our studies are based on a small sample of stakeholders and adolescents that participated in a pilot program in a specific region of the country, and without a control group. Therefore, for these reasons, the findings cannot be generalized to a wider population within the country. Research on a bigger scale is recommended, and the use of a randomized controlled trial, which could identify structural and systematic ways to improve intervention implementations. Further, the fact that the adolescent participants in the research (chapter 4 and 5) were selected by school teachers and not randomly selected and assigned to the intervention, might have introduced selection bias. Second, while qualitative studies have several advantages, such as being flexible and focusing on people's real lived experiences, allowing for deductive examination of a phenomenon under research (King \& Horrocks, 2010), quantitative studies are recommended to validate and generalize the results of the studies. Third, teachers' self-reported data during the implementation process of the intervention (chapter 5) on the fidelity and completeness elements, might have presented bias. However, during the indepth interviews and focus group discussions findings were exhaustively 


\section{Chapter 6}

discussed and verified with teachers and students, to verify the validity of results obtained from self-reported information of teachers.

\section{Future directions}

\section{Research}

The findings of the studies offer three main areas for future research that were beyond the scope of this dissertation. These areas are: (1) Teachers' social emotional capacities development; (2) SEL's whole school approach with a gender equality perspective; (3) The impact of SEL capacities development on Sexual Behavior Outcomes.

An extensive body of research has shown the importance of considering teachers own social-emotional capacities on the effectiveness of SEL programs (Collie et al., 2015a, 2015b; Zinsser et al., 2014). Especially, when programs address sensitive issues such as identity formation, equal roles, and rights for women and men, the impact of cultural sensitivity and social norms should be explored. Further, the factors influencing implementation (completeness and fidelity), here mainly related to teaching methodologies and the self-beliefs of teachers, have been shown in the literature to influence outcomes of implemented programs.

A whole school approach, defined as an integration of skills development through daily practices, which involves the collaboration and efforts of all actors of the process: school staff, parents, teachers, families and children (CASEL, 2015; Jones \& Bouffard, 2012) is recommended to potentiate the impact of SEL programs (Durlak et al., 2011). The findings of this dissertation (chapter 5) enhance the understanding regarding the 
challenges of limited organizational support at school during implementation, but at the same time highlight the needs to explore strategic ways to increase school management support for these kinds of programs. Thus, a wholeschool gender equality approach, through policy and practices, as well as facilitation of time and infrastructure during the diffusion process, is necessary to reap the full benefits of the SEL programs.

The link between the gained social-emotional capacities of adolescents and the impact on actual behavior in personal (sexual) relationships requires further research. Here, the effects of the pilot intervention were limited to adolescents' self-reported experiences and 'lessons learned'. We do not yet know how these experiences and changed beliefs and attitudes translate to their actual behaviors. Anthropological methodologies are recommended for future investigations, especially case studies providing a wider view of adolescents' behavior in different settings such as at with friends (girlfriend/ boyfriend) relationships, at home, in the community, which may vary from a strict and conservative school context.

\section{Recommendations for policy development}

The high rate of teenage pregnancy in Panama, as well as the absence of CSE, calls for the government and national legislative assembly to embrace alternative and innovate learning strategies to develop adolescents' capacities to make better decisions in their personal (sexual) relationships. The MANW pilot program, emphasizing SEL and gender equality, showed the potentialities of intra and inter-personal capacities development towards equality behaviors which can in the long term reduce teenage pregnancies, STI infections, and violence among adolescents in Panama. This type of 


\section{Chapter 6}

systematically developed, theory- and evidence-based health promotion intervention is key to changing these young people's daily lives for the better. It offers a starting point to empower adolescents and provide them tools to face the multiple challenges to their sexual health, rights and well-being. We therefore strongly recommend that SEL programs with a component on equality of roles, rights and opportunities among women and men will be included in regular educational curriculum.

Since lack of time, capacity needs of teachers and organizational setting have been proven in this research to be major limitations for intervention implementation, the inclusion of SEL in the regular curriculum will require exhaustive collaboration between National Legislative Assembly Ministries (e.g. Education, Health, and Family Affairs Ministry), as well as a systematic approach involving all stakeholders in a constructive and participatory process enhancing ownership, acceptability and participation ensures in all steps of the process. Intervention Mapping is a tool highly recommended to guide such valuable process towards the quality of life and risk behaviors reduction of adolescents in Panama.

\section{Conclusion}

To conclude, the studies in this dissertation revealed that interpersonal capacity development of adolescents through Social Emotional Learning could be an effective strategy to prepare adolescents to gain self-worth, selfefficacy, and make better decisions in personal relationships, which in the long term could improve their (sexual) health and well -being. In a conservative setting such as Panama, a program like MANW that is enjoyable for teachers and pupils, and which provides both with the intra- and 


\section{Chapter 6}

interpersonal capacities that social emotional learning encompasses, encourage a holistic human development of adolescents. Further, in this dissertation Intervention Mapping was an essential tool to facilitate the process of investigating the root of the problem, developing the intervention, and analyzing the effectiveness and evaluation of an innovative intervention. Especially in the absence of CSE, the findings of this dissertation 1) offer scientific evidence on an innovative way to approach adolescents' health problems, especially to reduce teenage pregnancy; 2) identified factors enhancing and impeding this type of health promotion interventions. Specifically, we have highlighted the importance of a constructive participatory approach among main stakeholders, the capacity needs of all actors, including adolescents, parents, teachers, and government; and the potential of education as a remaining vehicle to allow adolescents to explore new ways of thinking, awareness, new attitudes and skills for adolescents, the new generation, the future! 



\section{REFERENCES}




\section{References}

Aikman, S., \& Unterhalter, E. (2005). Beyond Access: Transforming Policy and Practice for Gender Equality in Education. Oxfam Publications.

Ajzen, I. (1988). Attitudes, personality and behavior, Chicago, Illinois: Dorsey Press.

Ajzen, I. (1991) The theory of planned behaviour. Reactions and reflections. $\begin{array}{lllll}\text { Psychology } \quad \text { \& } & \text { Health, }\end{array}$ https://doi.org/10.1080/08870446.2011.613995

Ajzen, I. (2015) The theory of planned behaviour is alive and well, and not ready to retire: a commentary on Sniehotta, Presseau, and Araújo-Soares. Health $\begin{array}{lll}\text { Psychology } \quad \text { Review, } & \text { 9(2), }\end{array}$ https://doi.org/10.1080/17437199.2014.883474

Albarracin, D., Johnson, B. T., Fishbein, M., \& Muellerleile, P. A. (2001). Theories of reasoned action and planned behavior as models of condom use: a metanalysis. Psychological Bulletin, 127, 142-161. https://doi.org/10.1037/0033-2909.127.1.142

Al Iryani, B., Basaleem, K. A., Crutzen, R., Kok, G., \& van den Borne, B. (2011). Evaluation of a School-Based HIV prevention Intervention for Yemeni Adolescents. BMC Public Health, 11(279). https://doi.org/10.1186/14712458-11-279

Al Iryani, B., Basaleem, H., Al Sakkaf, K., Kok G., \& van den Borne, B. (2013). Process evaluation of school-based peer education for HIV prevention among Yemeni adolescents. SAHARA-J: Journal of Social Aspects of HIV/AIDS, 10(1), 55-64. https://doi.org/10.1080/17290376.2012.745294

Andrade H. H., Brito de Mello, M., Sousa, M. H., Makuch, M.Y., Bertoni, N., \& Faundes, A. (2009). Changes in sexual behavior following a sex education program in Brazilian public schools. Cad Saúde Pública, 25, 1168-1176. https://doi.org/10.1590/s0102-311x2009000500023

Aramburu, M., Estripeaut, D., Rowley, S., Smoot, S., Chamorro, F., et al. (2012). Educational impact of peer-intervention on the knowledge and attitudes about 


\section{References}

HIV/AIDS in adolescents in Panama. International Journal Adolescent Medicine and Health, 24, 135-41. https://doi.org/10.1515/ijamh.2012.020

Araúz Ledezma, A. B., Massar, K., \& Kok, G. (2020a). Behavioural and environmental influences on adolescent decision making in personal relationships: a qualitative multi-stakeholder exploration in Panama. Health Education Research, 35(1), 1-14. https://doi.org/10.1093/her/cyz033

Araúz Ledezma, A. B., Massar, K., \& Kok, G. (2020b). Me and My New World: Effects of a school-based social-emotional learning program for adolescents in Panama. Education Science, 10(9). https/doi.org/10.3390/educsci10090251

Ballet, J., Biggeri, M., \& Comim, F. (2011). 'Children's agency and the capability approach: A conceptual framework'. In M. Biggeri, J. Ballet and F. Comim (Eds), Children and the Capability Approach (22-45), Palgrave Macmillan.

Bandura, A. (1986) Social Foundations of thought and action: A Social Cognitive Theory. Englewood Cliffs, NJ: Prentice Hall.

Bandura, A. (1997). Self-Efficacy: The exercise of control. W. H. Freeman.

Banerjee, R., Weare, K., \& Farr, W. (2014). Working with "social and emotional aspects of learning" (SEAL): associations with school ethos, pupil social experiences, attendance, and attainment. British Educational Research Journal, 40(4), 718-742. http://dx.doi.org/10.1002/berj.3114

Baraldi, C. (2008). Promoting Self-Expression in Classroom Interactions. Childhood, 15(2), $239-257$.

https://doi.org/10.1177/0907568207088425

Bartholomew Eldredge, L. K., Markham, C. M., Ruiter, R. A. C., Fernández, M. E., Kok, G. \& Parcel, G. (2016). Planning Health promotion programs: An Intervention Mapping approach, 4th edition, Jossey-Bass.

Basu, K., \& Foster, J. (1998). 'On measuring literacy'. The Economic Journal, 108(451), 1733-1746. https://doi.org/10.1111/1468-0297.00369

Baumann, A. A., Mejia, A., Lachman, J. M., Parra Cardona, R., Lopez Zeron, G., et al. (2019). Parenting Programs for Underserved Populations in Low- and Middle-Income Countries: Issues of Scientific Integrity and Social 


\section{References}

Justice. Global Social Welfare, 6, 199-207. https://doi.org/10.1007/s40609$\underline{018-0121-0}$

Bearinger, L., Sieving, R., Ferguson, J., \& Sharma, V. (2007). Global perspectives on the sexual and reproductive health of adolescents: patterns, prevention, and potential. Lancet, 369, 1220-1231. https://doi.org/10.1016/S0140$\underline{6736(07) 60367-5}$

Bessems, K. M., van Assema P., de Vries, N. K., \& Paulussen, T. W. G. M. (2014). Exploring determinants of completeness of implementation and continuation of a Dutch school-based healthy diet promotion program. International Journal of Health Promotion \& Education, 52, 315-327. https://doi.org/10.1080/14635240.2014.912445

Bierman, K. L., Coie, J. D., Dodge, K. A., Greenberg, M. T., Lochman, J. E., et al. (2010). The effects of a multiyear universal social-emotional learning program: The role of student and school characteristics. Journal of Consulting and Clinical Psychology, 78, 156-168. https://doi.org/10.1037/a0018607

Biggeri, M., Libanora, R., Mariani, S. \& Menchini, L. (2006). Children conceptualizing their capabilities: Results of the survey during the First Children's World Congress on Child Labour. Journal of Human Development, 7(1), 59-83. https://doi.org/10.1080/14649880500501179

Biggeri, M. (2007). Children's valued capabilities. In M. Walker and E. Unterhalter (Eds) Amartya Sen's Capability Approach and Social Justice in Education (197-214). Palgrave Mcmillan.

Biggeri, M., Ballet, J., \& Comim, F. (2011). Children and the Capability Approach. Palgrave Macmillan.

Biggeri, M., \& Santi, M. (2012). The Missing Dimensions of Children's Well-being and Well-becoming in Education Systems: Capabilities and Philosophy for Children. Journal of Human Development and Capabilities, 13, 373-395. https://doi.org/10.1080/19452829.2012.694858 


\section{References}

Biggs, B. K., Vernberg, E. M., Twemlow, S. W., Fonagy, P., \& Dill, E. J. (2008). Teacher Adherence and Its Relation to Teacher Attitudes and Student Outcomes in an Elementary School-Based Violence Prevention Program. School Psychology Review, 37(4), 533-549.

Binstock G., \& Näslund-Hadley, E. (2010). Iniciación sexual, asistencia escolar y embarazo adolescente sectores populares de Asunción y Lima: una aproximación cualitativa. Debates en Sociología, 35, 45-67.

Bird, J., \& Markle, R. (2012). Subjective Well-Being in School Environments: Promoting Positive Youth Development Through Evidence-Based Assessment and Intervention. American Journal of Orthopsychiatry, 82(1), 61-66. https://doi.org/10.1111/j.1939-0025.2011.01127.x

Bonvin, J. M., \& Galster, D. (2010). Making them employable or capable; Social integration policy at the crossroads. In H. U. Otto and H. Ziegler (Eds), Education, Welfare and the Capabilities Approach. Barbara Budrich Publishers.

Brackett, M. A., Patti, J., Stern, R., Rivers, S. E., Elbertson, N. A., et al. (2009). A sustainable, skill-based approach to building emotionally literate schools. In Hughes, M., Thompson, H. L., Terrell, J. B. (Eds.), Handbook for developing emotional and social intelligence: Best practices, case studies, and strategies. Pfeiffer/John Wiley.

Brackett, M. A., Reyes, M. R., Rivers, S. E., Elberston, N. A., \& Salovey, P. (2012). Assessing teachers' beliefs about social and emotional learning. Journal of Psychoeducational Assessment, 30, 219-236. https://doi.org/10.1177/0734282911424879

Bronfenbrenner, U., \& Morris, P. (1998). The ecology of developmental processes. In R. M. Lerner (Ed.), Handbook of Child Psychology. Wiley, Hoboken.

Buston, K., Wight, D., Hart, G., \& Scott, S. (2002). Implementation of a teacherdelivered sex education programme: Obstacles and facilitating factors. Health Education Research, 17(1), 59-72. https://doi.org/10.1093/her/17.1.59 


\section{References}

Butterfly Works, The Netherlands, One World, UK, Action Health Incorporated, \& FLHE Program and NERDC, Nigeria. (2009). Learning about Living (LAL) program. Authors.

Caffe, S., Plesons, M., Camacho, A.V., Brumana, L., Abdool, S. N., et al. (2017). Looking back and moving forward: can we accelerate progress on adolescent pregnancy in the Americas? Reproductive Health, 14, 83. https://doi.org/10.1186/s12978-017-0345-y

Caemmerer, J. M., \& Keith, T. Z. (2015). Longitudinal, reciprocal effects of social skills and achievement from kindergarten to eighth grade. Journal of School Psychology, 53, 265-281. https://doi.org/10.1016/j.jsp.2015.05.001

Campero, L. D., Walker, D., Atienzo, E. E., Gutierrez, J. P. (2011). A Quasiexperimental Evaluation of Parents as Sexual Health Educators Resulting in Delayed Sexual Initiation and Increased Access to Condoms. Journal of Adolescence, 34, 215-223. https://doi.org/10.1016/j.adolescence.2010.05.010

CASEL - Collaborative for Academic, Social, and Emotional Learning. (2003). Safe and sound: An educational leader's guide to evidence-based social and emotional learning (SEL) programs. Author.

CASEL - Collaborative for Academic, Social, and Emotional Learning. (2005). Safe and Sound: An Educational Leader's Guide to Evidence-Based Social and Emotional Learning (SEL) Programs-Illinois Edition. Author.

CASEL - Collaborative for Academic, Social, and Emotional Learning. (2012). 2013 CASEL guide: Effective social and emotional learning programs (Preschool and elementary school edition). Author.

CASEL - Collaborative for Academic, Social, and Emotional Learning. (2014).

Social and emotional learning core competencies. Author.

CASEL - Collaborative for Academic, Social, and Emotional Learning. (2015). Effective Social and Emotional Learning Programs. Middle and High School Edition. Author. 


\section{References}

Cerise, S., \& Francavilla, F. (2012). Tackling the root causes of gender inequalities in the post-2015 development agenda. Addressing Inequalities: The Heart of the Post-2015 Development Agenda and the Future We Want for All. Global Thematic Consultation. Paris.

Chandra Mouli, V., Plesons, M., Adebayo, E., Amin, A., Avni, M., et al. (2017). Implications of the Global Early Adolescent Study's Formative Research Findings for Action and for Research. Journal of Adolescent Health, 61, S5S9. https://doi.org/10.1016/j.jadohealth.2017.07.012

Chung, S., \& Moore McBride, A. (2015). Social and emotional learning in middle school curricula: A service learning model based on positive youth development. Children and Youth Services Review, 53, 192-200. https://doi.org/10.1016/j.childyouth.2015.04.008

Clark, D. A. (2006). Capability Approach. In D. A. Clark (ed.), The Elgar Companion to Development Studies. Edward Elgar Publishing. https://doi.org/10.4337/9781847202864

Coelho, V., Marchante, M., \& Sousa V. (2015). Positive Attitude: A multilevel analysis of the effectiveness of a social and emotional learning program for Portuguese middle school students. Journal of Adolescence, 43, 29-38. https://doi.org/10.1016/j.adolescence.2015.05.009

Coelho, V. A., \& Sousa, V. (2016). Comparing Two Low Middle School Social and Emotional Learning Program Formats: A Multilevel Effectiveness Study. Journal of Youth and Adolescence, 46, 656-667. https://doi.org/10.1007/s10964-016-0472-8

Cohen, J. (1999). Educating Minds and Hearts. Social Emotional Learning and the passage into adolescence. Teachers College Press.

Collie, R. J., Shapka, J. D., \& Perry N. E. (2012). School climate and socialemotional learning: predicting teacher stress, job satisfaction, and teaching efficacy. Journal of Educational Psychology, 104, 1189-1204. https://doi.org/10.1037/a0029356 


\section{References}

Collie, R. J., Shapka, J. D., Perry, N. E., \& Martin, A. (2015a). Teachers' beliefs about social-emotional learning: Identifying teacher profiles and their relations with job stress and satisfaction. Learning and Instruction Journal, 39,148-157. https://doi.org/10.1016/j.learninstruc.2015.06.002

Collie, R. J., Shapka, J. D., Perry, N. E., and Martin, A. J. (2015b). Teacher wellbeing: exploring its components and a practice-oriented scale. Journal of Psychoeducational Assessment, 33, 744-756. $\quad$ http://dx.doi.org/10. $1177 / 0734282915587990$

Comim, F., Qizilvash, M., \& Alkire, S. (2008). The Capability Approach: Concepts, Measures and Applications. Cambridge University Press.

Comim, F., Ballet J., Biggeri, M., \& Iervese, V. (2011). Introduction and Theoretical Perspectives on Children and the CA. In M. Biggeri, J. Ballet, F. Comim (Eds.), Children and the Capability Approach. Palgrave Macmillan.

Conner, M., \& Norman, P. (2005). Predicting Health Behaviour: A Social Cognition Approach. Second Edition. Open University Press. McGraw- Hill Education.

Cornwall, A. \& Rivas, A. M. (2015). From gender equality and 'women's empowerment to global justice: Reclaiming a transformative agenda for gender and development. Third World Quarterly, 36, 396-415. https://doi.org/10.1080/01436597.2015.1013341

Dane, A.V., \& Schneider, B. H. (1998). Program Integrity in Primary and Early secondary prevention: Are implementation effects out of control? Clinical Psychology Review, 18(1), 23-45. https://doi.org/10.1016/S02727358(97)00043-3

De Castro, F, Rojas-Martinez, R., Villalobos-Hernandez, A., et al. (2018). Sexual and reproductive health outcomes are positively associated with comprehensive sexual education exposure in Mexican high-school students. PLoS One, 13. https://doi.org/10.1371/journal.pone.0193780

DeJaeghere, J., \& Lee, S. K. (2011). What matters for marginalized Girls and Boys in Bangladesh: a capabilities approach for understanding educational well- 
being and empowerment. Research in Comparative and International Education, 6 (1), 27-41. https://doi.org/10.2304/rcie.2011.6.1.27

DeJaeghere, J. (2012). Public debate and dialogue from a capabilities approach: Can it foster gender justice in education? Journal of Human Development and Capabilities, 13, 353-371. https://doi.org/10.1080/19452829.2012.679650

DeJaeghere, J., \& Pellowski Wiger, N. (2013). Gender discourses in an NGO education project: Openings for transformation toward gender equality in Bangladesh. International Journal of Educational Development, 33, 557-565. https://doi.org/10.1016/j.ijedudev.2013.02.002

DePalma, R., \& Francis, D. A. (2014). The gendered nature of South African teachers' discourse on sex education. Health Education Research; 29, 625632. https://doi.org/10.1093/her/cyt117

Dholakia, J., Buchanan, R., \& Nash, W. (2012). Multifaceted adolescent reproductive health education strategies in Panama. J Global Health, 2 (2), 21-26. https://www.ghjournal.org/adolescent-reproductive-health-educationstrategies-in-panama/

Dür, M., \& Keller, L. (2018). Education for Sustainable Development through International Collaboration. A Case Study on Concepts and Conceptual Change of Students from India and Austria on Gender Equality and $\begin{array}{llll}\text { Sustainable Growth. Educational Science, } & 8, \quad 187 .\end{array}$ https://doi.org/10.3390/educsci8040187

Durlak, J., \& DuPre, E. (2008). Implementation Matters: A Review of Research on the Influence of Implementation on Program Outcomes and the Factors Affecting Implementation. American Journal of Community Psychology, 41, 327-350. https://doi.org/10.1007/s10464-008-9165-0

Durlak, J. A., Weissberg, R. P., Dymnicki, A. B., Taylor, R. D., \& Schellinger, K. B. (2011). The impact of enhancing students' social and emotional learning: A meta-analysis of school-based universal interventions. Child Development, 82, 405-432. https://doi.org/10.1111/j.1467-8624.2010.01564.x 


\section{References}

Durlak, J. A. (2015). Studying Program Implementation Is Not Easy but It Is $\begin{array}{llll}\text { Essential. Prevention } & \text { Science, }\end{array}$ https://doi.org/10.1007/s11121-015-0606-3

Durlak, J. A. (2016). Programme implementation in social and emotional learning: basic issues and research findings. Cambridge Journal of Education, 46, 333345. https://doi.org/10.1080/0305764X.2016.1142504

Durrani, N. (2008). Schooling the other: the representation of gender and national identities in Pakistani curriculum texts. Compare: A Journal of Comparative and International Education, 38, 595-610. https://doi.org/10.1080/03057920802351374

Elias, M. J., \& Arnold, H. A. (Eds.). (2006). The educator's guide to emotional intelligence and academic achievement: Social-emotional learning in the classroom. Thousand Oaks.

Elias, M. J., Leverett, L., Duffell, J. C., Humphrey, N., Stepney, C., et al. (2015). Integrating SEL with related prevention and youth development approaches. In J. A. Durlak, C. E. Domitrovich, R. P. Weissberg, \& T. P. Gullotta (Eds.), Handbook for social and emotional learning: Research and practice (33-49). Guilford.

Estrada, F., Suarez-Lopez, L., Hubert, C., Allen-Leigh, B., Campero, L., et al. (2018). Factors associated with pregnancy desire among adolescent women in five Latin American countries: A multilevel analysis. BJOG, 125, 1330-1336. https://doi.org/10.1111/1471-0528.15313

EIGE. (2020). Glossary of terms. European Institute for Gender Equality. Available online: $\quad$ https://eige.europa.eu/gender-mainstreaming/concepts-anddefinitions (accessed on 18 July 2020).

Faisal Cury, A., Tabb, K. M., Niciunovas, G., Cunningham, C., Menezes, P. R. et al. (2017). Lower education among low-income Brazilian adolescent females is associated with planned pregnancies. International Journal Women's Health, 9, 43-48. https://doi.org/10.2147/IJWH.S118911 


\section{References}

Fajardo Heyward, P. (2016). Comprehensive Sexual Education in Latin America. In M. F., Astiz \& M., Akiba (eds), The Global and the Local. The World Council of Comparative Education Societies. Sense Publishers.

Feeny, T., \& Boyden, J. (2004). Acting in adversity-Rethinking the causes, experiences and effects of child poverty in contemporary literature. Working Paper Series, WP 116, Queen Elizabeth House. University of Oxford.

Fernández, M. E., ten Hoor, G. A., van Lieshout, S., Rodríguez, S. A., Beidas, R. S., et al. (2019). Implementation Mapping: using Intervention Mapping to develop implementation strategies. Frontiers in Public Health, 7, 158. https://doi.org/10.3389/fpubh.2019.00158

Fleming, P. J., Andes, K. L., \& DiClemente, R. J. (2013). But I'm not like that: young men's navigation of normative masculinities in a marginalised urban community in Paraguay. Culture, Health \& Sexuality, 15(6), 652-666. https://doi.org/10.1080/13691058.2013.779027

Fishbein, M., \& Ajzen, I. (2010). Predicting and changing Behavior. The Reasoned Action Approach. Psychology Press, Taylor and Francis Group.

Foster Fishman, P. G., Nowell, B. \& Yang, H. (2007). Putting the system back into systems change: a framework for understanding and changing organizational and community systems. Am J Community Psychology, 39, 197-215. https://doi-org.ezproxy.ub.unimaas.nl/10.1007/s10464-007-9109-0

Fullman. N., Barber, R. M., Abajobir, A. A., Hassen Abate, K., Abbafati, C., et al. (2017). Measuring progress and projecting attainment on the basis of past trends of the health-related Sustainable Development Goals in 188 countries: an analysis from the Global Burden of Disease Study 2016. The Lancet, 390, 1423-1459. https://doi.org/10.1016/S0140-6736(17)32336-X

Gianella, C., Rodríguez, M., \& Peñas Defago, A. (2017). What causes Latin America's high incidence of adolescent pregnancy? CMI Chr. Michelsen Institute Brief, 16(9). https://doi.org/10.13140/RG.2.2.19789.95206

Glanz, K., Rimer, B. K., \& Viswanath, K. (Eds.). (2008). Health behavior and health education: Theory, research, and practice (4th ed.). Jossey-Bass. 


\section{References}

Graetz, B., Littlefield, L., Trinder, M., Dobia, B., Souter, M., et al. (2008). Kidsmatter: A population health model to support student mental health and well-being in primary schools. The International Journal of Mental Health Promotion, 10, 13-20. https://doi.org/10.1080/14623730.2008.9721772

Greenberg, M. T., Weissberg, R. P., O’Brien, M. U., Zins, J. E., Fredericks, L., et al. (2003). Enhancing school-based prevention and youth development through coordinated social, emotional, and academic learning. American Psychologist, 58, 466 - 474. https://doi.org/10.1037/0003-066X.58.6-7.466

Hahn, R., Fuqua Whitley, D., Wethington, H., Lowy, J., Crosby, A., et al. (2007). Effectiveness of universal school-based programs to prevent violent and aggressive behavior: A systematic review. American Journal of Preventive Medicine, 33, S114-S129. https://doi.org/10.1016/j.amepre.2007.04.012

Harlacher, J. E., \& Merrell, K. W. (2010). Social and Emotional Learning as a universal level of student support: Evaluating the follow-up effect of strong Kids on social and emotional outcomes. Journal of Applied School Psychology, 26, 212-229. https://doi.org/10.1080/15377903.2010.495903

Hart, C. S., \& Brando, N. (2018). A capability approach to children's well-being, agency and participatory rights in education. European Journal of Education, 53, 293-309. https://doi.org/10.1111/ejed.12284

Heilborn, M. A., Brandão, E. R., \& Da Silva Cabral, C. (2007). Teenage pregnancy and moral panic in Brazil. Culture, Health \& Sexuality, 9, 403-414. https://doi.org/10.1080/13691050701369441

Hirsch, J. A. (2003). Courtship after Marriage: Sexuality and Love in Mexican Transnational Families. University of California Press.

Hoffman, A. M. (2006). The Capability Approach and educational policies and strategies: effective life skills education for sustainable development. Agence Française du évelopement (AFD), Paris.

Holzberger, D., Philipp, A., \& Kunter, M. (2014). Predicting teachers' instructional behaviors: the nterplay between self-efficacy and intrinsic needs. 


\section{References}

Contemporary Educational Psychology, 39, 100-111. http://dx.doi.org/10.1016/j.cedpsych.2014.02.001

Holsen, I., Smith, B. H., \& Frey, K. S. (2008). Outcomes of the social competence program second step in Norwegian elementary schools. School Psychology International, 29, 71-88. https://doi.org/10.1177/0143034307088504

Hsieh, H. F., \& Shannon, S. E. (2005). Three approaches to qualitative content analysis. Qualitative Health Research, 9, 1277-1288. https://doi.org/10.1177/1049732305276687

Ibarraran, P., Ripani, L., Taboada, B., Villa, J. M., \& Garcia, B. (2012). Life Skills, Employability and Training for Disadvantaged Youth: Evidence from a Randomized Evaluation Design. Working paper serie -IDB Inter-American Development Bank, 342.

James, S., Reddy, P., Ruiter, A. M., \& van den Borne, B. (2006). The impact of an HIV and AIDS life skills program on secondary school students in KwazuluNatal, South Africa. AIDS Education and Prevention, 18, 281-294. https://doi.org/10.1521/aeap.2006.18.4.281

Janz, N., \& Becker, M. (1984). The Health Belief Model: A decade later. Health Education Quarterly, 11, 1-47. https://doi.org/10.1177/109019818401100101

Jennings, P. A., \& Greenberg, M. T. (2009). The prosocial classroom: teacher social and emotional competence in relation to student and classroom outcomes. Review of Educational Research, 79, 491-525. https://doi.org/10.3102/0034654308325693

Jones, S. M., Brown, J. L., Hoglund, W. L. G., \& Aber, J. L. (2010). A schoolrandomized clinical trial of an integrated social-emotional learning and literacy intervention: Impacts after 1 school year. Journal of Consulting and Clinical Psychology, 78, 829-842. https://doi.org/10.1037/a0021383

Jones, S., \& Bouffard, S. (2012). Social and emotional learning in schools from programs to strategies. Social Policy Report, Society for Research in Child Development, 26, 4 . 


\section{References}

Jütting, J., Morrison, C., Dayton-Johnson, J., \& Drechsler, D. (2008). Measuring gender (In)Equality: The OECD gender, institutions and development data base. Journal of Human Development, 9, 65-86. https://doi.org/10.1080/14649880701811401

Kalafat, J., Illback, R. J., \& Sanders, D. (2007). The relationship between implementation fidelity and educational outcomes in a school-based family support program: Development of a model for evaluating multidimensional full-service programs. Evaluation and Program Planning, 30, 136-148. https://doi.org/10.1016/j.evalprogplan.2007.01.004

Kelder, S. H., Hoelscher, D. \& Perry, C. L. (2015). How individuals, environments, and health behaviors interact: Social Cognitive Theory. In Glanz, K. Rimer, B. \& Viswanath, K. (Eds.), Health behavior; theory, research and practice ( $5^{\text {th }}$ ed., 159-181). Jossey-Bass.

Kelly, B., \& Perkins, D. F. (2012). Handbook of Implementation Science for Psychology in Education. Cambridge University Press.

Kimber, B., Sandell, R., \& Bremberg, S. (2008). Social and emotional training in Swedish classrooms for the promotion of mental health: Results from an effectiveness study in Sweden. Health Promotion International, 23, 134-143. https://doi.org/10.1093/heapro/dam046

Kimber, B. (2011). Primary prevention of mental health problems among children and adolescents through social and emotional training in school. Karolinska Institute, Stockholm, Sweden.

King, N., \& Horrocks, C. (2010). Interviews in Qualitative Research. ( $1^{\text {st }}$ ed.). Sage Publications.

Klassen, R. M., \& Chiu, M. M. (2010). Effects on teachers' self-efficacy and job satisfaction: Teacher gender, years of experience, and job stress. Journal of Educational Psychology, 102, 741-756. https://doi.org/10.1037/a0019237 


\section{References}

Knapp, M., McDaid, D., \& Parsonage, M. (2011). Mental health promotion and mental illness prevention: the economic case. Department of Health, London, UK.

Kok, G., Gottlieb, N. H., Panne, R., Smerecnik, C. (2012). Methods for environmental change; an exploratory study. BMC Public Health, 12, 1037. https://doi.org/10.1186/1471-2458-12-1037

Kok, G., Gottlieb, N. H., Peters, G. J. Y., Mullen, P. D., Parcel, G. S., et al. (2016). A taxonomy of behaviour change methods: An Intervention Mapping approach. Health Psychology Review, 10, 297-312. https://doi.org/10.1080/17437199.2015.1077155

Kok, G., Peters, L., \& Ruiter, R. (2017). Planning theory- and evidence-based behavior change interventions: a conceptual review of the intervention mapping protocol. Psicologia: Reflexão e Crític, 30 (19). https://doi.org/10.1186/s41155-017-0072-x

Kruger, D., \& Berthelon, M. (2014). The Impact of Adolescent Motherhood on Education in Chile. ForschungsinstitutzurZukunft der Arbeit/ Institute for the Study of Labor, IZA DP, 807.

Krugu, J. K., Mevissen, F. E. F., Prinsen, A., \& Ruiter, R. A. C. (2016). Who's that girls? A qualitative analysis of adolescents girls' views on factor associated with teenage pregnancies in Bolgatanga, Ghana. Reproductive Health, 13(39). https://doi.org/10.1186/s12978-016-0161-9

Lansdown, G. (2005). The evolving capacities of the child. Innocenti Insight Save the Children-UNICEF Innocenti Research Centre, Florence, 1-82 .

Lee, Y. M., Dancy, B., Florez, E., \& Holm, K. (2013). Factors related to sexual practices and successful sexually transmitted infection/HIV intervention programs for Latino adolescents. Public Health Nursing, 30, 390-401. https://doi.org/10.1111/phn.12039

Leerlooijer, J. N., Kok, G., Weyusya, J., Bos, A. E. R., Ruiter, R. A. C., Rijsdijk, L.E., Nshakira, N., \& Bartholomew, L. K. (2014). Applying Intervention Mapping to develop a community-based intervention aimed at improved 


\section{References}

psychological and social well-being of unmarried teenage mothers in Uganda. Health Education Research, 29(4), 598610. https://doi.org/10.1093/her/cyu020

Lendrum, A., Humphrey, N., \& Wigelsworth, M. (2013). Social and emotional aspects of learning (SEAL) for secondary schools: Implementation difficulties and their implications for school-based mental health promotion. Child and Adolescent Mental Health, 18, 158-164. https://doi.org/10.1111/camh.12006

Loots, S. \& Walker, M. (2015). Shaping a gender equality policy in higher education: which human capabilities matter? Gender and Education, 27, 361-375. https://doi.org/10.1080/09540253.2015.1045458

Malhotra, A., Sidney S., \& Boender C. (2002). Measuring women's empowerment as a variable in international development. Paper commissioned by the World Bank Gender and Development Group and World Bank Social Development Group.

Manandhar, M., Hawkes, S., Buse, K., Nosratid, E., Magar, V. (2018). Gender, Health and the 2030 Agenda for Sustainable Development. Bulletin of the World Health Organization, 96, 644-653, doi:10.2471/BLT.18.211607

Matthews, H. (2003). Children and regeneration: Setting and agenda for community participation and integration. Children and Society, 17, 264-276. https://doi.org/10.1002/CHI.745

Mayring, P. (2010). Qualitative content analysis. Basics and techniques. [Qualitative Inhaltsanalyse. Grundlagen und Techniken.]12th edition.Weinheim Basel: BeltzVerlag.

Mejia, A., Calam, R., \& Sanders, M.R. (2015). Examining Delivery Preferences and Cultural Relevance of an Evidence-Based Parenting Program in a LowResource Setting of Central America: Approaching Parents as Consumers. Journal of Child and Family Studies, 24, 1004-1015. https://doi.org/10.1007/s10826-014-9911-X 
Meyers, D. C., Durlak, J. A., \& Wandersman, A. (2012). The quality implementation framework: A synthesis of critical steps in the implementation process. American Journal of Community Psychology, 50, 462-480. https://doi.org/10.1007/s10464-012-9522-x

McKown, C., Gumbiner, L. M., Russo, N. M., \& Lipton, M. (2009). SocialEmotional Learning Skill, Self-Regulation, and Social Competence in Typically Developing and Clinic-Referred Children. Journal of Clinical Child \& Adolescent Psychology, 38, 6, 858871. https://doi.org/10.1080/15374410903258934

MEF - Ministry of Economy and Finances (Ministerio de Economía y Finanzas). (2015). Poverty and Inequality in Panama. Panama.

MEF - Ministry of Economy and Finances (Ministerio de Economía y Finanzas), Ministry of Social Development, \& National Institute of Statistics and Census. (2018). Índice de Pobreza Multidimensional de Niños, Niñas y Adolescentes de Panamá: Año 2018. [Index of Multidimensional Poverty of boys, girls and adolescents of Panama: 2018].

MINSA - Ministry of Health of Panama (Ministerio de Salud de Panamá). (2017).

Proporción de Adolescentes embarazadas, Enero a Noviembre 2017. [Proportion of pregnant teenagers, January to November, 2017].

MINSA - Ministry of Health of Panama (Ministerio de Salud de Panamá). (2018) Proporción de Adolescentes embarazadas, Enero a Noviembre 2018. [Proportion of pregnant teenagers, January to November, 2018].

Meyers, D. C., Durlak, J. A. \& Wandersman, A. (2012). The Quality Implementation Framework: A Synthesis of Critical Steps in the Implementation Process. American Journal of Community Psychology, 50,462-480. https://doi-org.ezproxy.ub.unimaas.nl/10.1007/s10464-012-9522-x

Muñoz Boudet, A. M., Petesch, P., Turk, C., \& Thumala, A. (2013). On Norms and Agency: Conversations About Gender Equality with Women and Men in 20 Countries. The World Bank. 


\section{References}

Murphy-Graham, E. (2012). Opening Minds, Improving Lives: Education and Women's Empowerment in Honduras. Vanderbilt University Press.

Murray, C., \& Hallett, C. (2000). Young People's Participation in Decisions Affecting Their Welfare. Childhood, 7(1), 11-25. https://doi.org/10.1177/0907568200007001003

North, D. (1990). Institutions. Journal of Economic Perspectives, 5, 97-112. https://doi.org/10.1257/jep.5.1.97

Nugent R. (2006). Youth in a global world. (pp. 1-8). BRIDGE, Population Reference Bureau.

Nussbaum, M. (2011). Creating Capabilities: The Human Development Approach. (pp. 256). Harvard University Press. Cambridge, MA, USA.

Oberle, E., Domitrovich, C. E., Meyers, D. C. \& Weissberg, R. P. (2016). Establishing systemic social and emotional learning approaches in schools: a framework for schoolwide implementation. Cambridge Journal of Education, 46, 277-297. https://doi.org/10.1080/0305764X.2015.1125450

Patton, M. Q. (2008). Utilization-focused evaluation ( $4^{\text {th }}$ ed.). Thousand Oaks, Sage. PAHO. (2010). Adolescent and Youth Regional Strategy and Plan of Action 2010 2018. Pan American Health Organization.

PAHO. (2015). Violence Against Women. Strategy and plan of action on strengthening the health system to address violence against women. Pan American Health

Organization. https://iris.paho.org/bitstream/handle/10665.2/18386/CD549Rev2 eng.pdf?s equence $=7 \&$ isAllowed $=\mathrm{y}$

PAHO, UNFPA, \& UNICEF. (2017). Accelerating progress toward the reduction of adolescent pregnancy in Latin America and the Caribbean. Report of a technical consultation. https://iris.paho.org/handle/10665.2/34493

Paulussen, T. G., Kok, G., \& Schaalma, H. P. (1994). Antecedents to adoption of classroom based AIDS education in secondary schools. Health Education Research, 9(4), 227-243. https://doi.org/10.1093/her/9.4.485 


\section{References}

Payton, J. W., Wardlaw, D. M., Graczyk, P. A., Bloodworth, M. R., Tompsett, C. J., et al. (2000). Social and emotional learning: A framework for promoting mental health and reducing risk behavior in children and youth. Journal of

School Health, 70(5), 179-185. https://doi.org/10.1111/j.17461561.2000.tb06468.x

Radja, K., Hoffmann, A. M., \& Bakhshi, P. (2008). Education and Capabilities Approach: Life Skills Education as A Bridge to Human Capabilities. Paper presented at the $3^{\text {rd }}$ Conference on the Capability Approach, Pavia.

Ransford, C. R., Greenberg, M. T., Domitrovich, C. E., Small, M., \& Jacobson, L. (2009). The role of teachers' psychological experiences and perceptions of curriculum supports on the implementation of a social and emotional learning curriculum. School Psychology Review, 38, 510-532.

Ricardo, C., Nascimento, M., Fonseca, V., \& Segundo, M. (2010). Program H and Program M: Engaging young men and empowering young women to promote gender equality and health. Promundo and PAHO, USA.

Rico, M., \& Trucco, D. (2014). Adolescents: Right to education and future wellbeing [Adolescentes: Derecho a la educación y al bienestar futuro]. CEPALUNICEF/Chile. Serie Políticas Sociales, 190.

Ridgeway, C. (2011). Framed by Gender: How Gender Inequality Persists in the Modern World. Oxford Univesity Press.

Rijsdijk, L. E., Bos, A. E. R., Ruiter, R. A. C., Leerlooijer, J. N., de Haas, B., et al. (2011). The World Starts With Me: A multilevel evaluation of a comprehensive sex education programme targeting adolescents in Uganda. BMC Public Health, 11, 334. http://www.biomedcentral.com/1471$\underline{2458 / 11 / 334}$

Rijsdijk, L. E. (2013). The World Starts with Me. Promoting sexual and reproductive health and rights of adolescents in Uganda. Universitaire Pers Maastricht.

Robeyns, I. (2006). Three models of education: rights, capabilities and human capital. Theory and Research in Education, 4(1), 69-84. https://doi.org/10.1177/1477878506060683 


\section{References}

Rossi, P. H., Lipsey, M. W., \& Freeman, H. E. (2004). Evaluation: A systematic approach $\left(7^{\text {th }}\right.$ ed.). Thousand Oaks, Sage.

Rogers, E. M. (2003). Diffusion of innovations (5th ed.). Free Press.

Ruiz Canela, M., López del Burgo, C., Carlos, S., \& Calatrava, M. (2012). Family, friends, and other sources of information associated with the beginning of sexual relations in adolescents in El Salvador. [Familia, amigos y otras fuentes de información asociadas al inicio de las relaciones sexuales en adolescentes de El Salvador.] Revista Panamericana de Salud Pública, 31, 54-61.

Rutgers. (2013). The World Start with me (WSWM) program. The Netherlands.

Salazar, X., Caceres, C., Rosasco, A., Kegeles, S., Maiorana, A., et al. (2005). Vulnerability and sexual risks: Vagos and vaguitas in a low income town in Peru. Culture, Health \& Sexuality, 7(4), 375-387. https://doi.org/10.1080/13691050500100849

Santamaría, A., Gerald, C., Chamorro, F., Herrera, V., et al. (2019). Social determinants of violence against women in Panama: results from populationbased cross-sectional studies and a femicide registry. International Health. https://doi.org/10.1093/inthealth/ihz116

Seabrook, R. C., Ward, L. M., Cortina, L. M., Giaccardi, S., \& Lippman, J. R. (2017). Girl power or powerless girl? Television, sexual scripts, and sexual agency in sexually active young women. Psychology of Women Quarterly, 41(2), 240 253. https://doi.org/10.1177/0361684316677028

Schonert-Reichl, K. A., \& Hymel, S. (2007). Educating the Heart as well as the Mind: Social Emotional Learning for School and life successes. Canadian Education Association. University of British Columbia.

Schutte, L., Mevissen, F. E. F., \& Kok, G. (2014). Ondersteuning vanuit de GGD byij implementation van seksuele voorlichting op school: faciliterende factoren en barrieres in een tijd van bezuinigingen [Support from the Municipal Health Services (MHS) in implementing school-based sex- 
education: enabling and inhibiting factors in times of economic cutbacks.] Tijdschrift voor Gezondheidswetenschappen, 92, 274-281.

Schutte, L., van den Borne, M., Kok, G., Meijer, S., \& Mevissen, D. E. F. (2016). Innovatively supporting teachers implementation of school-based sex education: Developing a Web-based coaching intervention from problem to solution. Journal of Medical Internet Research, 18,7. https://doi.org/10.2196/jmir.5058

Sen, A. K. (1999). Development as Freedom, Oxford University Press, Oxford.

Shepherd, J., Harden, A., Barnett-Page, E., Kavanagh, J., Picot, J., et al. (2014). Using process data to understand outcomes in sexual health promotion: an example from a review of school-based programmes to prevent sexually transmitted infections. Health Education Research, 29(4), 566582. https://doi.org/10.1093/her/cyt155

Singleton, R., Schroffel, H., Findlay, T., \& Winskell, K. (2016). Cultural scripts surrounding young people's sexual and romantic relationships in the Western Highlands of Guatemala. Culture, Health \& Sexuality,18, 1039-1053. https://doi.org/10.1080/13691058.2016.1142611

Skinner, C. S., Tiro, J. \& Champion, V. L. (2015). The Health Belief Model. In: Glanz, K. Rimer, B. \& Viswanath, K. (Eds.), Health behavior; theory, research and practice ( $5^{\text {th }}$ ed., pp. 75-94). Jossey-Bass.

Stambach, A. (2000). Lessons from Kilamanjaro: Schooling, Community and Gender in East Africa. Routledge.

Stromquist, N. (2006). Gender, Education and the possibility of Transformative Knowledge. Compare: A Journal of Comparative and International Education, 36(2), 145-161. https://doi.org/10.1080/03057920600741131

Stromquist, N. P., \& Fischman, G. E. (2009). Introduction - from denouncing gender inequities to undoing gender in education: practices and programmes toward change in the social relations of gender. International Review of Education/Internationale Zeitschrift fu“ $r$ Erziehungswissenschaft/Revue 


\section{References}

international 1'e'ducation, 55(5), 463-482. https://doi.org/10.1007/s11159$\underline{009-9146-\mathrm{Z}}$

Stromquist, N. P. (2013). Education Policies for Gender Equality: Probing into the States Responses. Education Policy Analysis Archives, 21(65), 1-28. https://doi.org/10.14507/epaa.v21n65.2013

Sullivan, O. (2004). Changing gender practices within the household: a theoretical perspective. Gender and Society, 182, 207-222. https://doi.org/10.1177/0891243203261571

Sullivan, O., Gershuny, J., \& Robinson, J. (2015). The Continuing "Gender Revolution" in Housework and Care: Evidence from Long-term Time-use Trends. A briefing paper prepared for the Council on Contemporary Families Online Symposium on Housework, Gender, and Parenthood. https://contemporaryfamilies.org/continuing-gender-revolution-briefreport/

Taylor, R. D., Oberle, E., Durlak, J. A.,\& Weissberg, R. P. (2017). Promoting Positive Youth Development Through School-Based Social and Emotional Learning Interventions: A Meta-Analysis of Follow-Up Effects. Child Development, 88, (4), 1156-1171. https://doi.org/10.1111/cdev.12864

Thomas, D. R. (2006). A general inductive approach for analyzing qualitative evaluation data. American Journal of Evaluation, 27(2), 237-246. https://doi.org/10.1177/1098214005283748

Tobler, N., Roona, M., Ochshorn, P., Marshall, D., Streke, A., et al. (2000). Schoolbased adolescent drug prevention programs: 1998 meta-analysis. Journal of Primary Prevention, 30, 275-336. https://doi.org/10.1186/1747-597X-9-48

Trani, J. F., Bakhshi, P. \& Biggeri, M. (2011). Re-thinking children's disabilities through the capability lens: a framework for analysis and policy implications. In M. Biggeri, J. Ballet \& F. Comim (Eds), Children and the Capability Approach, Palgrave Macmillan.

UN. (2015). The Millennium Development Goals Report 2015. United Nations. 
UNAIDS. (2016). Prevention Gap Report 2016. Joint United Nations Programme on HIV/AIDS.

UNAIDS. (2017). Ending AIDS: progress towards the 90-90-90 targets. Global Aids Update, 2017. Joint United Nations Programme on HIV and AIDS.

UNECLAC. (2018). Social Panorama of Latin America 2018. United Nations publication. ISBN: 978-92-1-122009-4.

UNESCO. (2018). International technical guidance on sexuality education. An evidence-informed approach. United Nations Educational, Scientific and Cultural Organization.

UNFPA. (2013). Adolescent Pregnancy: A Review of the Evidence.

UNFPA. (2015). Girlhood Not Motherhood. Preventing Adolescent Pregnancy.

UNFPA. (2016). Universal Access to Reproductive Health: Progress and Challenges. United Nations Population Fund.

UNFPA. (2017). State of world population 2017.

UNICEF. (2017). A Familiar Face: Violence in the Lives of Children and Adolescents. United Nations Children's Fund.

UNICEF \& PLAN. (2014). Experiences and accounts of Pregnancy among adolescents. An approximation towards the cultural, social and emotional factors influencing teenage pregnancy, through a study in six countries in the region.

Unterhalter, E. (2007). Gender Equality, Education and the Capability Approach. In M. Walker and E. Unterhalter (Eds), Sen's Capability Approach and Social Justice in Education (87-107). Palgrave.

Unterhalter, E. (2008). Cosmopolitanism, global social justice and gender equality in education. Compare: A Journal of Comparative and International Education, 38(5), 539-553. https://doi.org/10.1080/03057920802351291

Unterhalter, E. (2014). Thinking about gender in comparative education. Comparative Education, 50(1), 112-126. https://doi.org/10.1080/03050068.2013.872321 


\section{References}

UN Women. (2015). Progress of the world's women: Transforming economies, realizing rights 2015-2016. United Nations Entity for Gender Equality and the Empowerment of Women.

Van Der Veen, Y. J. J., Van Empelen, P., \& Richardus, J. H. (2012). Development of a culturally tailored Internet intervention promoting hepatitis B screening in the Turkish community in the Netherlands. Health Promotion International, 27, 342-355. https://doi.org/10.1093/heapro/dar044

Van Lieshout, A., Mevissen, F., de Waal, E., \& Kok, G. (2017). Long Live Love+: evaluation of the implementation of an online school-based sexuality education program in the Netherlands, Health Education Research, 32(3), 244-257. https://doi.org/10.1093/her/cyx041

Vanwesenbeeck, I., Westeneng, J., de Boer, T., Reinders, J., \& van Zorge, R. (2016). Lessons learned from a decade implementing Comprehensive Sexuality Education in resource poor settings: The World Starts With Me. Sex Education, 16:5, 471-486. https://doi.org/10.1080/14681811.2015.1111203

Vaughan, R. P. (2016). Gender equality and education in the Sustainable Development Goals. Background paper prepared for the 2016 Global Education Monitoring Report. UNESCO, Paris, France. file:///C:/Users/abara/Downloads/245574eng.pdf

Vasilenko, S. A., Espinosa-Hernández, G., \& Halgunseth, L. C. (2016). Positive and negative perceived consequences of first intercourse among middle and high school students in Puebla, Mexico. Culture, Health \& Sexuality, 18, 582-596. https://doi.org/10.1080/13691058.2015.1101164

Walker, M. (2012). Egalitarian policy formulation in lifelong learning: two models of lifelong education and social justice for young people in Europe. In D. N. Aspin, J. Chapman, K. Evans and R. Bagnall (Eds), Second International Handbook of Lifelong Learning. Handbooks of Education series, Springer International, 26, 181-193. 


\section{References}

Walker, M. (2015). Imagining STEM higher education futures: advancing human well-being. Higher Education,

$70,417-425$. http://dx.doi.org/10.1007/s10734-016-9983-1

Weissberg, R. P., \& O'Brien, M. U. (2004). What Works in School-Based Social and Emotional Learning Programs for Positive Youth Development. The Annals of the American Academy of Political and Social Science, 591, 86-97. https://doi.org/10.1177/0002716203260093

Weissberg, R. P., Durlak, J. A., Domitrovich, C. E., \& Gullotta, T. P. (2015). Social and emotional learning: Past, present, and future. In J. A. Durlak, C. E. Domitrovich, R. P.Weissberg, \& T. P. Gullotta (Eds.), Handbook for social and emotional learning: Research and practice (3-19). Guilford.

WHO. (2017). Violence Against Women. Strategy and plan of action on strengthening the health system to address violence against women. World Health Organization.

Wigelsworth, M. A., Lendrum, A., Oldfield, J., Scott, A., ten Bokkel, I., et al. (2016). The impact of trial stage, developer involvement and international transferability on universal social and emotional learning programme outcomes: A meta analysis. Cambridge Journal of Education, 46, 347-376. https://doi.org/10.1080/0305764X.2016.1195791

Wight, D., \& Abraham, C. (2000). From psycho-social theory to sustainable classroom practice: developing a research -based teacher delivered sex education programme. Health Education Research, 15(1), 25-38. https://doi.org/10.1093/her/15.1.25

Wolpert, M., Humphrey, N., Belsky, J., \& Deighton, J. (2013). Embedding mental health support in schools: Learning from the Targeted Mental Health in Schools (TaMHS) national evaluation. Emotional and Behavioural Difficulties, 18(3), 270-283. https://doi.org/10.1080/13632752.2013.819253

Wood, W., \& Eagly, A. H. (2015). Two Traditions of Research on Gender Identity. Sex Roles, 73, 461-473. https://doi.org/10.1007/s11199-015-0480-2 


\section{References}

Wood, P., \& Brownhill, S. (2018) 'Absent fathers', and children's social and emotional learning: an exploration of the perceptions of 'positive male role models' in the primary school sector. Gender and Education, 30(2), 172-186. https://doi.org/10.1080/09540253.2016.1187264

World Bank Country Database (2018). Available online https://datahelpdesk.worldbank.org/knowledgebase/articles/906519-worldbank-country-and-lending-groups

Yankah, E., \& Aggleton, P. (2008). Effects and effectiveness of life skills education for HIV prevention in young people. AIDS Education and Prevention, 20(6), 465-485. https://doi.org/10.1521/aeap.2008.20.6.465

Yoder, N. (2014). Teaching the whole child: Instructional practices that support SEL in three teacher evaluation frameworks (Revised edition, pp. 1-37). Center on great teachers and leaders at American Institutes for Research.

Zins, J. E., Weissberg, R. P., Wang, M. C., \& Walberg, H. J. (2004). Building academic success on social and emotional learning: What does the research say? Teachers College Press.

Zins, J. E., Bloodworth, M. R., Weissberg, R. P., \& Walberg, H. J. (2007a). The scientific base linking social and emotional learning to school success. Journal of Educational and Psychological Consultation, 17, 191-210. https://doi.org/10.1080/10474410701413145

Zins, J. E., \& Elias, M. J. (2007b). Social and emotional learning: Promoting the development of all students. Journal of Educational and Psychological Consultation, 17, 233-255. https://doi.org/10.1080/10474410701413152

Zinsser, K. M., Shewark, E. A., Denham, S. A., \& Curby, T. W. (2014). A mixedmethod examination of preschool teacher beliefs about social-emotional learning and relations to observed emotional support. Infant and Child Development, 23(5), 47-493. https://doi.org/10.1002/icd.1843 




\section{SUMMARY}





\section{Summary}

Adolescents in Panama face multiple challenges to their sexual health, rights, and well-being such as high rates of teenage pregnancy, increased HIV infections, and family- and intimate partner violence. Around $30.5 \%$ of all pregnant women are girls between 10 and 19 years old (MINSA, 2018). In the absence of Comprehensive Sexuality Education (CSE) legislation, as well as an ongoing debate in Panamanian society about how to approach adolescents' health problems which is compounded by a lack of sufficient scientific evidence on these topics, this dissertation had two main aims: 1) To fill this gap by gathering evidence-based data related to the multiple behavioral and environmental factors affecting the decision making capacities of adolescents; 2) To examine the impact of Social Emotional Learning (SEL) as a potential educational strategy, which could forge behavioral changes towards the promotion of equal personal relationships among adolescents in Panama.

The studies reported in this dissertation were conducted in the district of Boquete, Republic of Panama. Boquete is located $481 \mathrm{~km}$ west of Panama City, the capital of the Republic of Panama. Tourism and agriculture are the main economic activities of the region. The country is situated in Central America. It borders both the Caribbean Sea and the Pacific Ocean, between Colombia and Costa Rica. Its latitude lies between latitudes $7^{\circ}$ and $10^{\circ} \mathrm{N}$, and longitudes $77^{\circ}$ and $83^{\circ} \mathrm{W}$ (a piece of the country area lies west of $83^{\circ}$ ). Panama's population is around 4.1 million (MEF et al., 2018), of which 1.3 million or $33 \%$ are children and adolescents (MEF et al., 2018). Around $32.8 \%$ of them are living in multidimensional poverty (MEF et al., 2018). In 2018, Panama became a high-income country (World Bank, 2018). Nevertheless, the country is listed within the top five countries in Latin 


\section{Summary}

America with most unequal distribution of income, with a Gini coefficient of 0.51(UNECLAC, 2018).

Chapter 2 presents the main discourses on gender roles and gender equality in Panama, from different actors' perspectives. The aim of this qualitative study was to explore the perceptions and attitudes of different societal actors, namely governmental employees, NGO employees, academics, members from religious groups, teachers and parents. We conducted in-depth interviews $(\mathrm{N}=34)$ which focused on the behavioral and environmental factors considered to influence adolescents' decision making with regard to love, friendships and family relations. Furthermore, we explored how these stake- holders viewed the role of the education system, and the potential of including social-emotional learning (SEL) in the curriculum to provide skills and capacities, which could encourage adolescents to make better decisions and improve their well-being, in general but also in the context of sexual behaviors. The findings showed five central themes, i.e. perceptions towards gender roles and equality, adolescents' love (sexual) relationships, capacity needs regarding prevention of risk behaviors and the role of education, comprehensive sexuality education in schools and the potentiality of SEL in the education system. The results of the study can enhance understanding on the views of stakeholders regarding the factors influencing adolescents' decision-making, as well as regarding the possibilities of introducing SEL in the Panamanian educational curriculum.

Chapter 3 describes the process of development and planning surrounding the development, implementation and evaluation of the SEL pilot program Me and My New World (MANW) in Panama, based on the Intervention Mapping (IM) Protocol. Equal relationships between women 


\section{Summary}

and men are likely to increase health benefits. In this study, we suggest that a school-based enhancement of Social and Emotional Learning core competencies - awareness of self and others, positive attitudes and values, responsible decision making, and social interaction skills - could foster positive changes in behaviors between boys and girls, specifically through a focus on equal roles, equal rights in relationships and nonviolent problem solving. Qualitative methods were used for data collection. The findings provide a framework to analyze the multiple factors influencing the development and implementation of Social Emotional Learning programs to the promotion of equal relationships among adolescents in a developing country, with a special consideration to culture, educational systems, and policies, from a capability development perspective. The program that resulted from this IM development process was carried out as a pilot project in a middle school in Panama. The outcomes of this intervention will indicate whether behaviors of youngsters were improved towards equal behaviors between women and men. If positive, it could be of great importance to reduce the increasing rate of early pregnancies and sexual violence in the country; and improve the decision-making capacities of young people towards more equal and meaningful personal relationships.

Chapter 4 reports the outcomes of the intervention SEL / MANW pilot program to the promotion of gender equality behaviors - equal roles, equal rights in relationships and the use of nonviolent problem solving - what changes are perceived on participants' determinants of behavior towards gender equality behaviors? It includes the dynamics perceived during the program, e.g. how students discuss the effects of the program in terms of transforming their views on equal roles, rights, and use of nonviolence. This article examines to what extent a newly developed social-emotional learning 


\section{Summary}

(SEL)/ MANW program, provides a context in which students can learn to recognize and manage emotions, to care about others and themselves, make responsible decisions, develop social awareness, and could facilitate behavioral changes of young people towards more gender equality behaviors. Specifically, we focused on equal gender roles, equal rights in relationships and nonviolent problem solving, and present the qualitative effect evaluation among adolescents in Panama. In-depth interviews were conducted for data collection. Participants, 55 students in total (26 girls and 29 boys) from group $7^{\text {th }}$ and $9^{\text {th }}$ of middle-high school, were selected by the school. The age was between 12-15 years. The findings suggest that SEL-based lessons might broaden views on how young people experience the process of exploring identity formation, how assumptions of inequalities can be recreated through the lessons, and that SEL can emphasize the significance of choice and decision making in interpersonal relationships. The perspectives, needs, and limitations highlighted by the adolescents living in a conservative context are highly valuable for improving future learning strategies towards healthier relationships, which could increase their well-being and quality of life.

Chapter 5 reports findings of the intervention process -explaining the program and its implementation. The study aimed to deeply explore the factors influencing the implementation of the pilot social-emotional learning program MANW, which emphasizes enhancing personal capacities toward equal personal relationships and behaviors of adolescents in Panama. Since the effect assessment of the program showed improved personal capacities of adolescents that might positively influence their personal relationships and wellbeing, a deeper understanding of the conditions and factors experienced during the implementation is necessary. Qualitative and quantitative methods 


\section{Summary}

were used for data collection: 6 in- depth interviews were carried out with teachers and parents, and 48 students participated in 12 focus group discussions. Completeness and fidelity were explored, as well as other possible enhancing and impeding factors during a future diffusion process. The results revealed that the MANW program was highly accepted by students, teachers, and parents. Enhancing factors of the implementation were the innovation aspect of the program and local needs, adaptability of lessons and acceptability of the program. Barriers influencing the implementation appeared to be the lack of time for lessons during regular curriculum, cultural transferability and organizational setting. The findings are relevant for improving development and implementation of social-emotional learning programs, especially oriented towards equal personal relationships and better decision making of adolescents, especially in conservative contexts.

Chapter 6 offers a broad general discussion of the results of all the qualitative studies presented in this dissertation. It describes the methods used during the current research, as well as the strengths and limitations of the investigation. Further, implications of the studies and its link with theory, as well as contribution to literature are explored, leading towards recommendations for future interventions and policy development. As final conclusion, the studies in this dissertation revealed that interpersonal capacity development of adolescents through Social Emotional Learning could be an effective strategy to prepare adolescents to gain self-worth, self-efficacy, and make better decisions in personal relationships, which in the long term could improve their (sexual) health and well -being. In a conservative setting such as Panama, a program like MANW that is enjoyable for teachers and pupils, and which provides both with the intra- and interpersonal capacities that social emotional learning encompasses, encourage a holistic human 


\section{Summary}

development of adolescents. Further, in this dissertation Intervention Mapping was an essential tool to facilitate the process of investigating the root of the problem, developing the intervention, and analyzing the effectiveness and evaluation of an innovative intervention.

Especially in the absence of CSE, the findings of this dissertation 1) offer scientific evidence on an innovative way to approach adolescents' health problems in a conservative context, especially to reduce teenage pregnancy; 2) identified factors enhancing and impeding this type of health promotion interventions. Specifically, we have highlighted the importance of a constructive participatory approach among main stakeholders, the capacity needs of all actors, including adolescents, parents, teachers, and government; and the potential of education as a remaining vehicle to allow adolescents to explore new ways of thinking, awareness, new attitudes and skills for adolescents, the new generation, the future! 




\section{SAMENVATTING}





\section{Samenvatting}

Tieners in Panama hebben te maken met vele problemen rondom hun sexuele gezondheid, hun rechten en hun persoonlijk welbevinden. Tienerzwangerschappen, HIV infecties en huiselijk geweld komen veelvuldig voor. Ongeveer 30,5\% van alle zwangerschappen betreft meisjes tussen 10 en 19 jaar oud (MINSA, 2018)

Wetgeving rond sexuele vorming ontbreekt in Panama, en er is geen coherent beleid ten aanzien van gezondheidsproblemen bij tieners. Deze belemmerende factoren worden nog versterkt door een gebrek aan wetenschappelijke kennis over dit soort onderwerpen.

Dit proefschrift heeft twee doelen: 1) het verzamelen van wetenschappelijke data over de diverse gedrags- en omgevingsfactoren die de beslisvaardigheid van tieners beïnvloeden, en 2) het onderzoeken of Sociaal Emotioneel Leren (SEL) als mogelijke onderwijsaanpak het gedrag van adolescenten in Panama zou kunnen veranderen naar gelijkwaardiger persoonlijke verhoudingen.

De onderzoeken in dit proefschrift werden uitgevoerd in de gemeente Boquete in de Republiek Panama. Boquete bevindt zich $481 \mathrm{~km}$ ten westen van Panama-Stad, de hoofdstad van Panama. Toerisme en landbouw zijn de belangrijkste economische activiteiten in deze regio. Het land ligt in MiddenAmerika, en grenst aan zowel de Caraïbische Zee als de Grote Oceaan, tussen Colombia en Costa Rica. Panama's coördinaten liggen tussen breedtegraad $7^{\circ}$ en $10^{\circ} \mathrm{N}$, en lengtegraad $77^{\circ}$ en $83^{\circ} \mathrm{W}$ (een klein deel van het land ligt ten westen van $83^{\circ}$ ).

Panama heeft ongeveer 4.1 miljoen inwoners (MEF et al., 2018), van wie 1.3 miljoen of 33\% kinderen en tieners zijn (MEF et al., 2018). Ongeveer $32.8 \%$ van hen leven in meervoudige armoede (MEF et al., 2018). In 2018 


\section{Samenvatting}

werd Panama een hoog inkomen land (World Bank, 2018). Niettemin staat het land in de top vijf van landen in Latijns Amerika met de grootste inkomensongelijkheid, met een Gini-coëfficiënt van 0.51(UNECLAC, 2018).

Hoofdstuk 2 presenteert de belangrijkste theorieën over genderrollen en gendergelijkheid in Panama, vanuit verschillende perspectieven. Het doel van dit kwalitatieve onderzoek was om de waarnemingen en gedragingen te verkennen van verschillende maatschappelijke actoren, namelijk ambtenaren, medewerkers van NGO's, academici, leden van religieuze groeperingen, leraren en ouders. We namen diepgaande interviews af $(\mathrm{N}=34)$, waarbij de focus lag op de gedrags- en omgevingsfactoren waarvan verondersteld wordt dat ze van invloed kunnen zijn op de besluitvorming van tieners met betrekking tot liefde, vriendschap en familierelaties. Verder onderzochten we de mening van deze maatschappelijke actoren over de rol van het bestaande onderwijssysteem en de mogelijkheid om SEL in het curriculum op te nemen. Hiermee zouden vaardigheden aan adolescenten aangeleerd kunnen worden, die hun kunnen helpen om betere beslissingen te nemen en hun welbevinden te verbeteren, in het algemeen maar ook waar het sexueel gedrag betreft.

De bevindingen toonden vijf centrale thema's aan: (1) houding tegenover genderrollen en gendergelijkheid, liefdes- en sexuele relaties, (2) de behoefte aan vaardigheden om risicovol gedrag te voorkomen en (3) de rol van onderwijs daarin, (4) uitgebreide sexuele vorming in scholen en (5) de mogelijkheid van SEL in het onderwijssysteem. De resultaten van dit onderzoek kunnen meer licht werpen op de zienswijzen van maatschappelijke actoren ten aanzien van factoren die de besluitvorming bij adolescenten beïnvloeden. Ook worden de verschillende zienswijzen van maatschappelijke 
Samenvatting

actoren duidelijker over de mogelijkheid om SEL in het Panamese onderwijssysteem te introduceren.

Hoofdstuk 3 beschrijft de ontwikkeling en planning rond de uitvoering en evaluatie van het SEL pilot programma Me and My New World (MANW) in Panama, dat gebaseerd is op het Intervention Mapping (IM) Protocol. Gelijke verhoudingen tussen vrouwen en mannen hebben waarschijnlijk positieve effecten op hun gezondheid. We onderzoeken de hypothese dat verbetering van de kernkwaliteiten binnen SELzelfbewustzijn en empathie, een positieve houding en waarden, verantwoordelijke besluitvorming, en sociale vaardigheden- het gedrag kan verbeteren tussen jongens en meisjes, met name door de nadruk te leggen op gelijke rollen, gelijkwaardigheid in relaties en geweldloze probleemoplossing. Voor het verzamelen van data werden kwalitatieve methoden gebruikt. De bevindingen tonen een overzicht van de vele factoren die de ontwikkeling en uitvoering beïnvloeden van SEL programma's in een ontwikkelingsland. Hierbij was de aandacht speciaal gericht op cultuur, onderwijssysteem en beleid vanuit het perspectief van vaardigheidstraining.

Het resulterende programma werd uitgevoerd als een pilot project op een middelbare school in Panama. De uitkomsten suggereren dat het gedrag van jongeren positief beïnvloedbaar is in de richting van gelijke behandeling van vrouwen en mannen. Als deze suggestie juist is, kunnen dergelijke programma's zeer goede hulpmiddelen zijn om tienerzwangerschappen en sexueel geweld in Panama te verminderen. Ook kunnen ze dan de vaardigheden verbeteren van jongeren om goede besluiten te nemen voor wat betreft gelijke en stabiele persoonlijke relaties. 


\section{Samenvatting}

Hoofdstuk 4 presenteert de resultaten van het MANW pilot programma gelijke rollen, rechten en het gebruik van geweldloze probleemoplossing: welke factoren blijken het meest bepalend bij de deelnemers om te bewegen in de richting van gelijke behandeling van vrouwen en mannen? Ook worden de groepsprocessen beschreven die tijdens het programma werden waargenomen, bijvoorbeeld hoe leerlingen de effecten van het programma bespreken in termen van verandering van hun eigen kijk op gelijke rollen, rechten en geweldloosheid. Dit hoofdstuk onderzoekt in welke mate een nieuw ontwikkeld SEL / MANW programma, handvatten kan bieden waarmee leerlingen hun emoties leren kennen en beheersen, leren om anderen en om zichzelf te geven, om verantwoorde beslissingen te nemen en om sociaal bewustzijn te ontwikkelen. Dit zou kunnen helpen het gedrag van jongeren te veranderen naar meer gelijkwaardigheid tussen vrouwen en mannen. We concentreerden ons op gelijke genderrollen, gelijke rechten in relaties en geweldloze probleemoplossing. Voor het verzamelen van data werden diepgaande interviews afgenomen. De school selecteerde de deelnemers, 55 leerlingen ( 26 meisjes en 29 jongens) uit groepen 7 en 9 van de middelbare school. De leeftijd van de leerlingen lag tussen 12 en 15 jaar. De resultaten indiceren dat op SEL gebaseerde lessen ons kunnen leren hoe jongeren het proces van identiteitsvorming ervaren, hoe ingebakken noties van ongelijkheid kunnen worden omgevormd, en dat SEL het belang kan benadrukken van het nemen van juiste beslissingen in interpersoonlijke relaties. Inzicht in de zienswijzen, behoeften en beperkingen van jongeren in een behoudende samenleving is zeer nuttig voor de ontwikkeling van nieuwe onderwijsstrategieën ten behoeve van gezondere relaties, beter welbevinden en betere kwaliteit van leven van jongeren. 


\section{Samenvatting}

Hoofdstuk 5 toont de opeenvolgende interventiestappen in het programma en geeft een toelichting op de implementatie ervan. Er wordt grondig onderzoek gedaan naar de factoren die de implementatie van het $M A N W$ programma beïnvloeden. Dit programma legt de nadruk op het vergroten van persoonlijke vaardigheden om meer gelijkwaardige relaties en gedrag te bewerkstelligen. Omdat de evaluatie van het programma een verbetering van de persoonlijke vaardigheden van adolescenten toonde, is het vervolgens zinvol om beter begrip te krijgen van de voorwaarden en factoren die tijdens de uitvoering van het programma door hen werden beleefd. Voor het verzamelen van de data werden zowel kwalitatieve als kwantitatieve methoden gebruikt: 6 diepgaande interviews werden afgenomen bij leraren en ouders, en 48 leerlingen namen deel in 12 groepsgesprekken. De factoren volledigheid en trouw werden onderzocht, evenals andere mogelijke bevorderende en belemmerende factoren. De resultaten toonden aan dat het MANW programma zeer gewaardeerd werd door leerlingen, leraren en ouders. Bevorderende factoren bleken het innovatieve aspect van het programma en de mogelijkheid om de lessen aan te passen aan de situatie ter plaatse. Belemmerende factoren bleken het gebrek aan tijd voor lessen tijdens het reguliere curriculum, culturele overdraagbaarheid en organisatorische setting. Deze resultaten zijn relevant om de ontwikkeling en implementatie van SELprogramma's te verbeteren, met name gericht op gelijke persoonlijke relaties en betere besluitvorming bij adolescenten in een conservatieve samenleving.

Hoofdstuk 6 toont een uitgebreide bespreking van de resultaten van de kwalitatieve studies in dit proefschrift. Het beschrijft de gebruikte methoden en ook de sterktes en zwaktes van het onderzoek. Verder worden ook implicaties van het onderzoek en het verband met de theorie en wetenschappelijke literatuur besproken. Dit mondt uit in aanbevelingen voor 


\section{Samenvatting}

toekomstig onderzoek en beleidsontwikkeling. De onderzoeken in dit proefschrift tonen aan dat de ontwikkeling van interpersoonlijke vaardigheden met gebruik van SEL een effectieve aanpak kan zijn om adolescenten toe te rusten hun eigenwaarde en zelfwerkzaamheid te vergroten en om betere beslissingen te nemen in persoonlijke relaties. Dit kan op de lange termijn hun (sexuele) gezondheid en welbevinden verbeteren. In een conservatieve samenleving als Panama kan een programma als MANW een holistische menselijke ontwikkeling van adolescenten aanmoedigen, mede omdat het een prettig programma is voor leraren en leerlingen, en zowel intraals interpersoonlijke vaardigheden bevordert,. Verder bleek Intervention Mapping een essentiële methode om zowel de kern van het probleem als de ontwikkeling van het programma en de de effectiviteit ervan te onderzoeken.

Met name in situaties waar wetgeving rond sexuele vorming ontbreekt, bieden de resultaten van dit proefschrift 1) wetenschappelijk bewijs met betrekking tot een innovatieve manier om gezondheidsproblemen bij adolescenten in een conservatieve context te benaderen, en in het bijzonder om tienerzwangerschappen te verminderen; 2) inzicht in factoren die dit soort gezondheidsprogramma's bevorderen, dan wel belemmeren. Specifiek hebben we het belang benadrukt van een constructieve deelname van de belangrijkste maatschappelijke actoren (ondermeer adolescenten, ouders, leraren, en de overheid) en hun behoefte aan kennis en vaardigheden. Tot slot onderstrepen wij het potentieel van onderwijs om adolescenten nieuwe manieren aan te bieden van denken, bewustzijn, gedrag en vaardigheden. Zij zijn de nieuwe generatie, de toekomst! 


VALORIZATION 

This valorization chapter will expand on the social and economic value of the findings presented in this dissertation. First, it will highlight the relevance of the findings for the target group, to emphasize the potentialities of the research intervention and its implications for enhancing adolescents' decision-making capacity in personal relationships. Second, our findings describe the extent to which the findings contribute to the promotion of equal relationships among women and men in a conservative context and which goes beyond the 'girl schooling' traditional agenda. Third, the chapter expands on the implications of Social Emotional Learning (SEL), as an innovative approach, towards not only empowerment and a holistic development of adolescents, but also as a tool that ultimate could help reduce teenage pregnancies - and its economic burden - and health risks of the adolescents, their families, and their communities. For all three of these issues it is recommended that considerations are guided by an evidence-based protocol such as Intervention Mapping (IM; Bartholomew Eldredge et al., 2016).

\section{The target group}

Adolescents in Panama were the main target group of this dissertation. The findings presented in this study are highly relevant for this group in particular: Alarming levels of teenage pregnancies, and an increase of HIV infections and (sexual) violence have become imminent barriers for adolescents' health, well-being, and achievement of their potential in life. Therefore, in the absence of comprehensive sexual education, to change the way boys and girls, women and men relate to each other requires a new set of inner capacities which could support them to make better decisions in their personal relationships, whether at home, with (girl-boy)friends, or in school. 


\section{Valorization}

Therefore, educational transformations are needed, to provide these young people with capacities such as self- concept, self-esteem, critical thinking, emotion management, communication, negotiation, and problem-solving skills. This has been established in research, but was also explicitly recognized by all stakeholder participants in this research project. The stakeholders considered such competences as crucial to adolescent empowerment and development.

Furthermore, the findings of this research project, and the evaluation of the intervention program in particular, highlighted the possibilities to create new spaces where students can explore new ways of thinking, their identities formation, factors influencing their behaviors as boys or girls. Most importantly, these capacities could allow a palette of new behavioral choices and positive decisions, which in turn could enhance their lives, instead of limiting their potential, education and ultimately their quality of life. Educational approaches focusing on the social emotional development of children and young people could bridge the gap between interventions merely focusing on the biological aspects of reproduction - the current situation in Panamanian secondary education - and a broader spectrum of activities to address barriers and facilitating factors that influence adolescents' behavior in their relationships. Specifically, we argue that the combination of Social Emotional Learning (SEL) and the promotion of gender equality behavior among boys and girls could thus represent an educational alternative. In this line, the findings also provide insights about the process of adolescents' agency development in a conservative and developing context like Panama. 


\section{The context}

Given the need to promote adolescents' healthier behaviors, the findings of this research project contribute to knowledge about achieving (equality) educational goals, in particular for conservative contexts like Panama. Gender equality educational strategies such as the MANW program offer a methodology that could encourage deeper transformation towards gender equal behavior, as it is based on scientific evidence of SEL and contextualized gender equality promotion strategies. Likewise, the findings provide a broader alternative to the 'girls schooling' approach, which for decades has promoted more girls accessing schools as a way to promote gender equity and equality, but has lacked extensive strategies to eradicate gender inequalities in schools and society at large. Importantly, our findings enhance understanding of the cultural transferability of SEL, in this case to a developing country, and as an educational alternative in the absence of Comprehensive Sexuality Education (CSE) in a conservative context.

Furthermore, the findings of this research highlight the importance of utilizing the capabilities approach perspective. This approach enhances our understanding of which capacities are required by adolescents and young people in assessing their levels of agency and self-efficacy towards making better decisions in personal relationships. At the same time, these influence their beings and doings (what they are able to do in their own circumstances and their values and priorities) to increase their perspectives of a holistic human development and well-being. 


\section{Valorization}

\section{The approach}

A wealth of scientific evidence has shown the multiple positive outcomes of Social Emotional Learning (SEL) interventions towards the promotion of healthy behaviors and subjective well-being among children and young people. The fact that most results of these interventions have been observed in developed countries, the findings presented in this dissertation are novel, since they highlight the importance of using educational alternatives as SEL to approach the multiple health risks and challenges faced by adolescents in developing countries. Especially when even the terms 'gender equality' or 'sexuality of adolescents' represent conflictive and taboo topics in conservative contexts, nuanced and innovative approaches are required. The combination of different disciplines during this research project, which included perspectives from behavioral sciences (SEL, socio-cognitive theoretical-based evidence), development studies (Gender and the Capability Approach / Evolving capabilities of children and young people), facilitated the development of the innovative intervention. These perspectives and evidence-based practices were guided through a systemic Intervention Mapping Approach (IM), and as such allowed us a wider innovative perspective to approach and encourage behavioral changes. 


\section{ACKNOWLEDGEMENTS}





\section{Acknowledgements}

This $\mathrm{PhD}$ research project was not brought to light without a very insightful and enlightening process. I am so grateful for the honor to have met a group of incredible human beings, who have guided and supported me in this journey to achieve this goal. Since my early years, living in the countryside of Panama, growing among two worlds, one which offered a view of the lives of people in poverty, facing cultural and socio-economic barriers, concerns, health problems, searching for better ways to improve their lives; and another world where I was provided ample opportunities to study, to get to know the world, the differences, to evolve as a human being, there, between these two paradigms, the search for equality, of all kinds, was born, not only in my heart but also in my life path.

Through my professional career, searching for innovative alternatives to provide new generations with personal capacities, which they could apply to transform Education into real improvements in their lives, I came across with Social Emotional Learning (I thought I will not mention it in this section, but it is necessary), and I decided that I will explore and test the possibilities of its use, but most important, to generate scientific evidence, in a context such as Panama. Since research science has as basic element, the search for evidence, the process of this $\mathrm{PhD}$ project is also a testimony of how a human being (myself) can reinforce resilience, determination, patience, and selfconfidence, with the support of great minds, whom I will attempt to thank through the following lines, despite the fact that there are no words enough to thank them. I will be eternal grateful for their insights, knowledge, advice and personal dedication, which has inspired me throughout this process.

First, my deepest thanks go to my promotor, Professor Gerjo Kok, who allowed me the great opportunity to be part of Maastricht University at the Faculty of Psychology and Neuroscience. Gerjo, your knowledge, 


\section{Acknowledgements}

enthusiasm, kindness and humbleness are very impressive and actually much needed in the academic sector. I feel honored to have had the opportunity to be your student. Your charisma, openness, human side, respect and constructive feedback during my $\mathrm{PhD}$ research years, encouraged and supported me at every step of the process. I am also impressed by your contribution to academic knowledge and practice, through the highly effective Intervention Mapping (IM) protocol. It is a great tool to develop programs and guide interventions' implementation, especially in limited contexts as Panama. Involving different disciplines and actors into the use of the IM could enhance the well-being and potential achievement of young people in the future. Gerjo, thank you for your legacy and hard efforts to instruct new generations of professionals (me included) and guide us through multidisciplinary processes using IM.

Second, also my deepest thank to my co-promotor Dr. Karlijn Massar. I feel so honored to have been guided and supported by you all these years. As I have told you before, there will be never enough words to thank you. I think you are one of the best teachers I ever had in my life. Your kindness, dedication and attention to details during this research process, have set high standards for quality $\mathrm{PhD}$ process supervision. Your genuine interest and positive approach to guide me during this $\mathrm{PhD}$ process, make you a remarkable leader, encouraging the best efforts of your students, and capable to undertake and succeed in any multilayer research project in the future. I wish many more students will have the honor to receive your guidance and advices.

Gerjo and Karlijn, I will miss you both, my great Professors! 


\section{Acknowledgements}

My special thanks go to all participants of the research project in Panama. Especially, Professor Dr. Dania Vergara, for your valuable and relentless support to implement the intervention of the pilot program, as well as for your strong determination to search for educational strategies which could improve the lives of new generations in Panama. Querida Profesora Dania, le estaré eternamente agradecida por su apoyo y determinación para realizar este proyecto en el colegio. Su tenacidad es admirable. Muchas gracias.

I would like to thank my dearest students' participants of the project, parents, teachers and school administration. Thank you for the opportunity to carry out this $\mathrm{PhD}$ research project together, and to explore new learning pedagogies. Your willingness and openness were crucial during the implementation of this process, and therefore I feel honored to have been able to work with you. A special thanks to Mariblanca Staff Wilson, for your valuable insights and vast experience, which enriched the views of different stakeholders in Panama. Igualmente, un gran agradecimiento a todos los colaboradores de la Defensoría del Pueblo en David, Chiriquí y Panamá.

Furthermore, I would like to thank the organization KASELD (Knowledge alliance for Social Emotional Learning and Development), in Panama and The Netherlands, for their support and cooperation during this $\mathrm{PhD}$ research project. Without their support, this project would have not been possible. Special thanks to my appreciated colleague and friend, Paul de Bruin, for his unconditional support always, especially for sharing and encouraging my views to explore Social Emotional Learning through research and practice in Panama and the Netherlands. 


\section{Acknowledgements}

I would like to thank my colleague Saartu Musa, for her insights about the topics of this research. Dear, your enthusiasm and commitment to help young people is admirable! Thank you for sharing it with me.

To my beloved family and friends, who supported and encouraged me at every step of this research process. Thank you! A mis padres, Bertha y Bonifacio, un millón de gracias por haberme dado la oportunidad de estudiar y enseñado que la educación puede ser un vehículo de transformación personal y global, al igual que puede contribuir a mejorar la calidad de vida de las personas. ¡Los amo! A mis hermanos, hermanas y amigos en Panamá, Holanda y Francia, todos, muchas gracias por el apoyo que me brindaron. Merci. Todo mi amor para ustedes. Un agradecimiento especial a Yadira Castillo, por tu apoyo y determinación para la realización de este proyecto en el colegio. Estaré siempre agradecida.

Speciale dank aan Opa Cor en Oma Maaike (mijn schoonouders), voor alle steun door de jaren heen, en het zorgen voor de kinderen tijdens de studie. Zonder jullie steun was het ook niet mogelijk! Bedankt voor jullie liefde.

To my chosen family, my sisters Georgie and Liz Schutte, ¡muchas gracias queridas! Thank you for your unconditional love and presence every time I need help in all areas of my life, and especially throughout this $\mathrm{PhD}$ process. I thank life every day that you both came in my path and are a joy and laughter every time we are together. Liz, basically you are an angel! When I needed help to find a university to carry out this PhD study, you were immediately helpful and assertive, and I was able to join Maastricht University. I will be eternally grateful. Your humbleness, kindness and 


\section{Acknowledgements}

academic accolades are a gift to the world. Georgie, I am so honored you are in my life. Every time I talk to you, I remember what it is to enjoy life, and how pure and genuine human beings can be. You are truly an example, always listening, good advices and a role model in multiple ways. I will never forget when you called me from Timbuktu, Mali, literally standing high to get a cellphone sign, just because I needed your support, and you were just there, encouraging me. Thank you sis, were are eternally bound!

Liz and Georgie, once again thank you for being my paranymphs, what a great emotional support! I would not have liked it different.

And finally, I would like to thank the most special gifts of my life, my children Lillyan and Karsten, and my partner for life: Jurgen van Buuren. You are all my inspiration and energy every day. Thank you for allowing me the time and concentration to carry out this research project. To Lilly and Karsten, I can finally answer your question: Mom, when are you going to finish this $\mathrm{PhD}$ ? Well, the moment is now! But I can ensure you, that I will continue working to promote social-emotional capacity development of young people, as my small contribution to leave a better world for you as human beings! You both inspired this project, and you are the reason.

This research project was not possible without the endless support of an incredible person, who I have the honor to have in my life, my husband Jurgen. I feel blessed to have your laughter, extreme positive attitude towards life, and enchanting energy almost every day of our lives together. Your wisdom, to explain complex issues, in just a few words, while I am searching for the academic explanation, is admirable! The culmination of this $\mathrm{PhD}$ is also to a great extent, the effect of your consistent encouragement, patience 


\section{Acknowledgements}

and persistence, which allowed me to carry on and finally finish the project. From serving coffee to teachers during the Training of Trainers, and during implementation of the program in Panama (under the scrutiny of observers, who perhaps were doubting if a man should carry this chores), to driving to the mountain at 5 o'clock in the morning, and always ensuring that our needs at home where fulfilled, your support definitely made the difference. I promised you 10 pages of acknowledgement, especially when this dissertation focus on equal relationships between women and men, and the support and positive involvement of men in the life of women is highly necessary, however, I will rather shortly attempt, but in a most profound way, to express you my gratitude, through the following lines:

\section{Ode to Jurgen}

In this life you never thought, that your name will be, on a PhD dissertation.

But your contribution is actually, named as one of the most important.

What you probably do not realize, is that your spirit, has encouraged revolutionary ways of thinking, and lifestyles, as the one you model,

I admire you for that!

The only logical reason you have expressed

is Love,

and love is all our reasons.

You are a truly testimony, of love and equality! 
Acknowledgements

This dissertation is dedicated to Lillyan, Karsten and Mia, the new generation, the future! 

CURRICULUM VITAE 

Ana Belinda Araúz Ledezma was born on 5th March 1975 in David, Chiriquí, Republic of Panama, where she grew up and attended primary and high school at the Colegio Nuestra Señora de los Angeles. In 2001, Ana obtained a bachelor's degree in Psychology, and in 2003, a Master's in Development Studies, with an emphasis on Women, Gender and Development, from the Institute of Social Studies, Erasmus University, the Netherlands. Ana has worked for different international organizations, such as IFOR, and Oxfam Novib, in the Netherlands. After working for years developing educational programs and as a psychologist, Ana decided to establish her own international organization. She is the founder of KASELD (Knowledge Alliance for Social Emotional Learning and Development). Currently Ana is the director of the organization and is involved in research, development, and implementation of social-emotional learning programs at primary schools in The Hague, The Netherlands. 

APPENDIX 

Appendix 1. Overall content of the MANW program lessons

\begin{tabular}{|c|c|c|}
\hline $\begin{array}{l}\text { Social-Emotional } \\
\text { Competencies/Lessons }\end{array}$ & $\begin{array}{l}\text { Social-Emotional } \\
\text { Competencies and gender } \\
\text { equality concepts }\end{array}$ & Topics \\
\hline $\begin{array}{l}\text { Module 1. Self - } \\
\text { Awareness } \\
\text { Session 1. But Who am } \\
\text { I? }\end{array}$ & $\begin{array}{l}\text { Introduction to the program, } \\
\text { self- awareness, interest, } \\
\text { values and strengths, critical } \\
\text { thinking. }\end{array}$ & $\begin{array}{l}\text { Students explore identity } \\
\text { development, gender and } \\
\text { roles allocation; discover } \\
\text { their self-concept and } \\
\text { increase critical thinking. }\end{array}$ \\
\hline $\begin{array}{l}\text { Session 2. My feelings } \\
\text { and me }\end{array}$ & $\begin{array}{l}\text { Identification of emotional } \\
\text { changes during adolescence, } \\
\text { self -esteem, decision- } \\
\text { making. }\end{array}$ & $\begin{array}{l}\text { Students discuss self- } \\
\text { esteem and its links with } \\
\text { gender, how it is } \\
\text { developed, connections } \\
\text { with emotional changes } \\
\text { during adolescence and the } \\
\text { significance of decision } \\
\text { making to manage better } \\
\text { decisions. }\end{array}$ \\
\hline $\begin{array}{l}\text { Session 3. Playing the } \\
\text { roles }\end{array}$ & $\begin{array}{l}\text { Gender, gender roles, } \\
\text { masculinities, femininities, } \\
\text { empathy. }\end{array}$ & $\begin{array}{l}\text { Discuss boys and men's } \\
\text { socialization, gender } \\
\text { norms and stereotypes; } \\
\text { take the perspective of } \\
\text { others; reflect on different } \\
\text { gender roles, rights. } \\
\text { Also refer to: Guidelines } \\
\text { for Integrating Gender- } \\
\text { Based Violence } \\
\text { Interventions in } \\
\text { Humanitarian Action: } \\
\text { https://gbvguidelines.org/wp/ } \\
\text { wp- } \\
\text { content/uploads/2015/09/201 }\end{array}$ \\
\hline
\end{tabular}




\section{Appendix}

\begin{tabular}{|c|c|c|}
\hline & & $\begin{array}{l}\text { 5-IASC-Gender-based- } \\
\text { Violence-Guidelines_lo- } \\
\text { res.pdf }\end{array}$ \\
\hline $\begin{array}{l}\text { Session 4. My body, my } \\
\text { say }\end{array}$ & $\begin{array}{l}\text { Problem solving skills, self- } \\
\text { efficacy and self-esteem. } \\
\text { Own strength and limitations } \\
\text { (physical) }\end{array}$ & $\begin{array}{l}\text { Body image and } \\
\text { adolescence, its influence } \\
\text { on the way they feel and } \\
\text { act; learn strategies to } \\
\text { analyze and search for } \\
\text { solutions. }\end{array}$ \\
\hline $\begin{array}{l}\text { Module 2. Self- } \\
\text { Management } \\
\text { Session 5. Power } \\
\text { relations and ME }\end{array}$ & $\begin{array}{l}\text { Gender violence, power } \\
\text { relations, assertiveness. }\end{array}$ & $\begin{array}{l}\text { Discuss the theory of } \\
\text { power, power relations and } \\
\text { its intersections with } \\
\text { gender violence and abuse } \\
\text { of rights; follow steps to } \\
\text { make assertive decisions } \\
\text { and learn to say NO. }\end{array}$ \\
\hline $\begin{array}{l}\text { Session } 6 . \text { Are these my } \\
\text { rights? }\end{array}$ & Goal setting and monitoring. & $\begin{array}{l}\text { Become aware of their } \\
\text { diversity on needs, rights } \\
\text { and the capacities they } \\
\text { require to achieve goals } \\
\text { and overcome obstacles. } \\
\text { Set goals and monitoring } \\
\text { strategies. }\end{array}$ \\
\hline Session 7. I am in control & $\begin{array}{l}\text { Recognizing and analyzing } \\
\text { emotions through a gender } \\
\text { perspective. }\end{array}$ & $\begin{array}{l}\text { Recognize own emotions } \\
\text { and they ways they have } \\
\text { learnt to express it due to } \\
\text { their genders; } \\
\text { communication; } \\
\text { connections with violence } \\
\text { and abuses. }\end{array}$ \\
\hline
\end{tabular}


Appendix

\begin{tabular}{|c|c|c|}
\hline $\begin{array}{l}\text { Session 8. Gender Based } \\
\text { Violence }\end{array}$ & $\begin{array}{l}\text { Emotions regulations, } \\
\text { impulses, coping with stress. }\end{array}$ & $\begin{array}{l}\text { Learn strategies how to } \\
\text { manage negative emotions } \\
\text { in a positive way, and } \\
\text { steps to handle stressful } \\
\text { situations. } \\
\text { Refer to: Guidelines for } \\
\text { Integrating Gender-Based } \\
\text { Violence Interventions in } \\
\text { Humanitarian Action: } \\
\text { https://gbvguidelines.org/wp/ } \\
\text { wp- } \\
\underline{\text { content/uploads/2015/09/201 }} \\
\underline{\text { 5-IASC-Gender-based- }} \\
\underline{\text { Violence-Guidelines_lo- }} \\
\underline{\text { res.pdf }}\end{array}$ \\
\hline $\begin{array}{l}\text { Module 3. Social } \\
\text { Awareness } \\
\text { Session 9. What about } \\
\text { my life? }\end{array}$ & $\begin{array}{l}\text { Pregnancy } 4 \text { boys and girls. } \\
\text { Respect for themselves and } \\
\text { for others. }\end{array}$ & $\begin{array}{l}\text { Students reflect on the } \\
\text { pressures related to } \\
\text { unwanted teenage } \\
\text { pregnancies and } \\
\text { responsibilities of both } \\
\text { boys and girls; connection } \\
\text { between decision making, } \\
\text { self-esteem and self- } \\
\text { concept. }\end{array}$ \\
\hline $\begin{array}{l}\text { Session 10. Friendship } \\
\text { and relationship }\end{array}$ & $\begin{array}{l}\text { People in your life, empathy, } \\
\text { managing peer pressure. }\end{array}$ & $\begin{array}{l}\text { Explore how gender } \\
\text { norms, beliefs and values } \\
\text { influence friendships and } \\
\text { personal relationships; } \\
\text { defend their rights and } \\
\text { limits; learn how to resist }\end{array}$ \\
\hline
\end{tabular}




\section{Appendix}

\begin{tabular}{|c|c|c|}
\hline & & $\begin{array}{l}\text { individual or group } \\
\text { pressure. }\end{array}$ \\
\hline $\begin{array}{l}\text { Session } 11 . \text { I negotiate } \\
\text { my way }\end{array}$ & $\begin{array}{l}\text { Negotiation skills, critical } \\
\text { thinking. }\end{array}$ & $\begin{array}{l}\text { Learn different techniques } \\
\text { to negotiate difficult } \\
\text { situations in daily life } \\
\text { (with friends, school, } \\
\text { home). }\end{array}$ \\
\hline $\begin{array}{l}\text { Module 4. Relationship } \\
\text { skills } \\
\text { Session 12. Did you get } \\
\text { what I mean? }\end{array}$ & Effective communication. & $\begin{array}{l}\text { Discuss effective ways on } \\
\text { how to express their } \\
\text { opinion, ideas, needs, } \\
\text { preferences; active } \\
\text { listening. }\end{array}$ \\
\hline $\begin{array}{l}\text { Session } 13 \text { Girls and } \\
\text { boys act for change }\end{array}$ & Problem solving. & $\begin{array}{l}\text { Learn strategies to be an } \\
\text { active bystander and know } \\
\text { who and where to go in } \\
\text { need of support. Provide } \\
\text { help when needed. }\end{array}$ \\
\hline $\begin{array}{l}\text { Module 5. Responsible } \\
\text { decision-making } \\
\text { Session } 14 \text {. Your } \\
\text { dreams, your future }\end{array}$ & $\begin{array}{l}\text { Life plan development with } \\
\text { gender equality perspective, } \\
\text { responsible decision making, } \\
\text { creative thinking. }\end{array}$ & $\begin{array}{l}\text { Use creativity to set a plan } \\
\text { focusing on using the } \\
\text { capacities learnt during the } \\
\text { program, as to achieve } \\
\text { their goals (e.g. finishing } \\
\text { school and have respectful } \\
\text { and healthy relationships). }\end{array}$ \\
\hline
\end{tabular}



